Portland State University

PDXScholar

Winter 3-7-2013

\title{
Neighborhood Identity and Sustainability: A Comparison Study of Two Neighborhoods in Portland, Oregon
}

Zachary Lawrence Hathaway

Portland State University

Follow this and additional works at: https://pdxscholar.library.pdx.edu/open_access_etds

Part of the Civic and Community Engagement Commons, and the Urban Studies and Planning Commons

Let us know how access to this document benefits you.

\section{Recommended Citation}

Hathaway, Zachary Lawrence, "Neighborhood Identity and Sustainability: A Comparison Study of Two Neighborhoods in Portland, Oregon" (2013). Dissertations and Theses. Paper 683.

https://doi.org/10.15760/etd.683

This Thesis is brought to you for free and open access. It has been accepted for inclusion in Dissertations and Theses by an authorized administrator of PDXScholar. Please contact us if we can make this document more accessible: pdxscholar@pdx.edu. 
Neighborhood Identity and Sustainability: A Comparison Study of Two Neighborhoods in Portland, Oregon

\author{
by \\ Zachary Lawrence Hathaway
}

A thesis submitted in partial fulfillment of the requirements for the degree of

\author{
Master \\ of \\ Urban Studies
}

Thesis Committee:

Loren Lutzenhiser, Chair

Vivek Shandas

Daniel Sullivan

Portland State University

2013 


\begin{abstract}
Anthropogenic impact on the environment, mainly resource depletion and pollution, is limiting the potential for future generations to have the same resources that previous generations have enjoyed. Perhaps one of the greatest challenges of our time will be curtailing our own personal impacts on the environment. To do this, we must adopt more sustainable lifestyles at home. This research sought to understand how neighborhood identity affects sustainability at the household level. In the summer of 2012, residents of two neighborhoods in Portland, Oregon completed 314 self-report, web-based surveys. The neighborhoods selected for this research were demographically similar, but one projected a sustainable neighborhood identity and the other did not. Survey questions were designed to determine respondents: level of engagement in their neighborhood, attitudes towards the environment, and adherence to sustainable behaviors. Findings suggest that neighborhood engagement can influence household sustainability levels in Portland. This research also suggests that the city or region may have more effect on perceived household sustainability than the neighborhood does.
\end{abstract}




\section{Acknowledgements}

I want to first thank my committee chair, Loren Lutzenhiser, for his ongoing advice and supervision. Loren has been played a pivotal role in the development of my academic interests and professional career. I am also grateful for the support and advice of Vivek Shandas. Last but certainly not least, I thank Daniel Sullivan for his guidance and support throughout the years. His teaching and guidance inspired me to continue my education at the graduate level. I am also grateful for the direction and assistance provided by Reuben Deumling, the President of the Sunnyside Neighborhood Association. To my former colleagues at the PSU Survey Research Lab, especially Debi Elliott, thank you for your encouragement and support in my educational endeavors. Working at the SRL provided me invaluable knowledge and expertise that I applied directly to my academic studies and professional career. For my lifelong friends, Kyle, Anton, Jake, Danielle, and Oliver, thank you for being an open ear and providing much needed good times.

Lastly, I thank my family for their love and encouragement. Thank you for instilling in me confidence and a drive to pursue my goals and dreams. I especially thank my mom for her emotional support; I would not have made it this far without you. Most of all, I thank my loving, understanding, reassuring, and patient partner Tiffany whose support and assistance over the years is so appreciated. I could not have done this without you. Thank you. 


\section{Table of Contents}

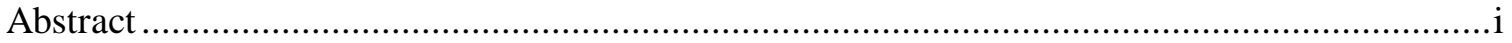

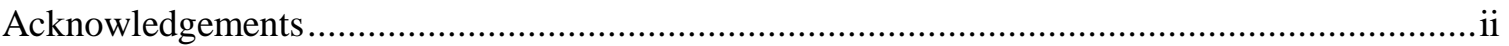

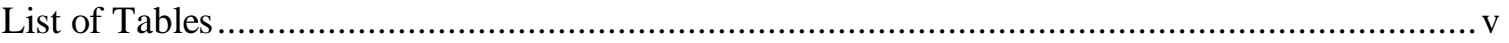

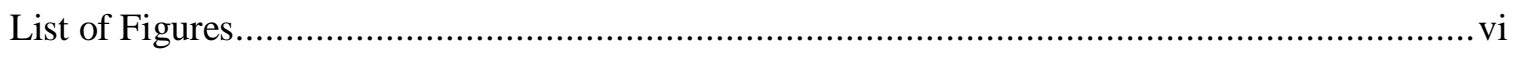

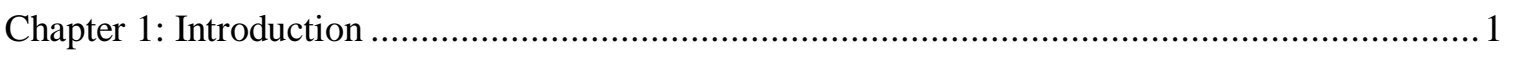

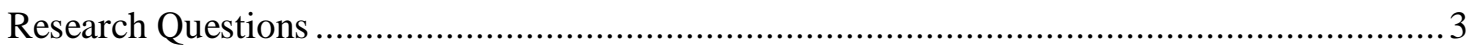

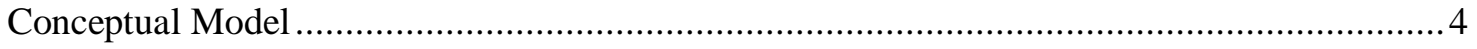

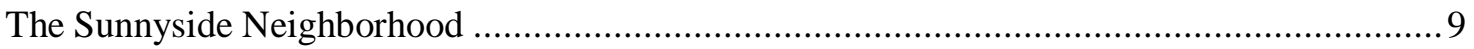

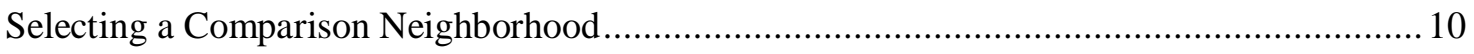

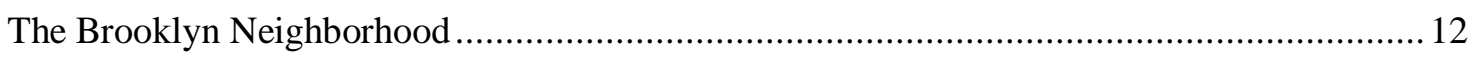

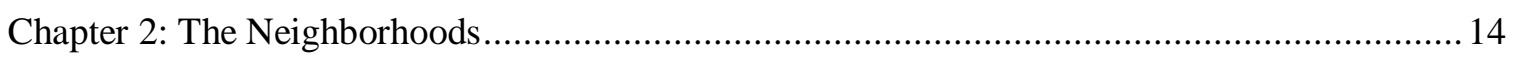

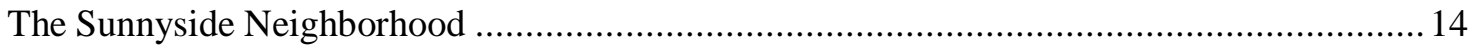

History of the Sunnyside Neighborhood .......................................................................... 14

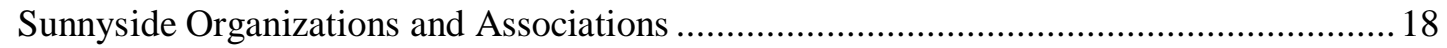

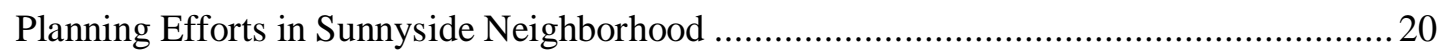

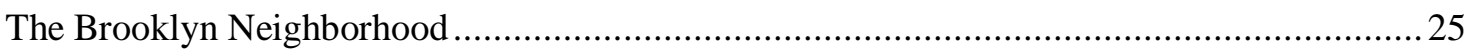

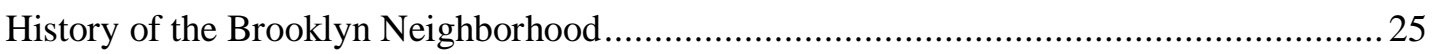

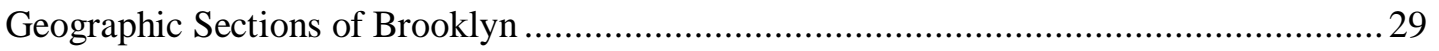

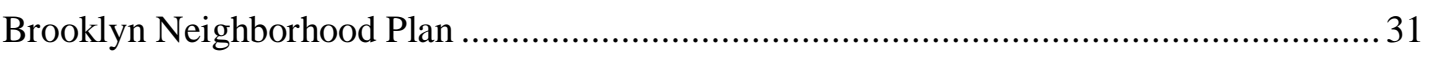

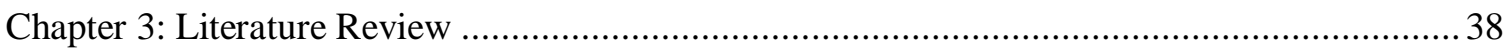

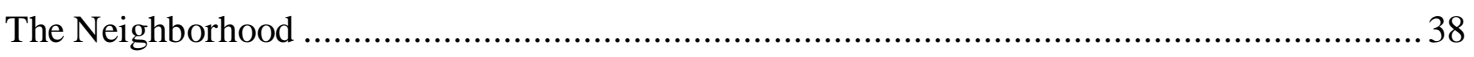

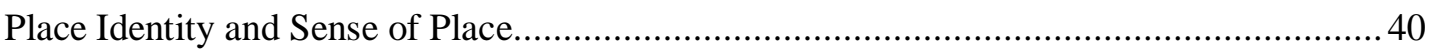

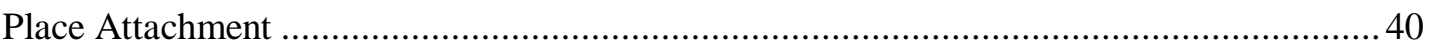

Neighborhood Identity and Sustainable Behavior ........................................................ 42

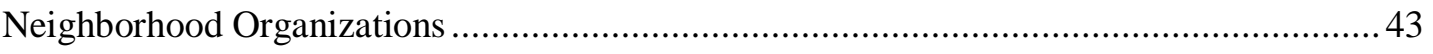

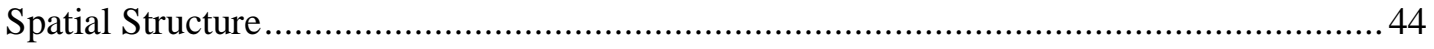

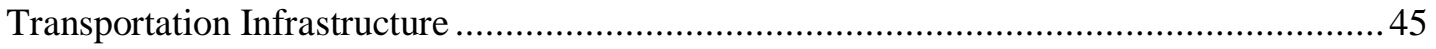

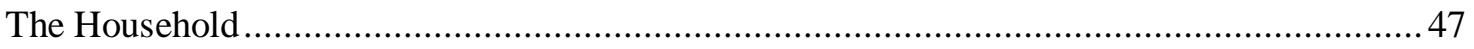

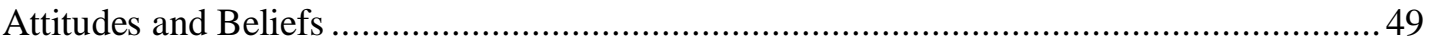

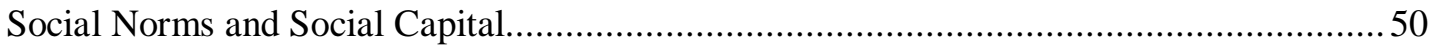

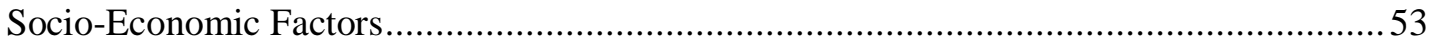

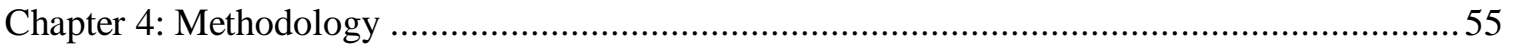




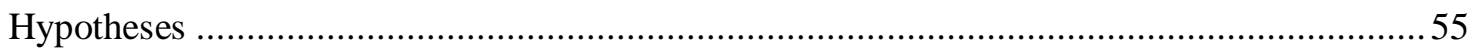

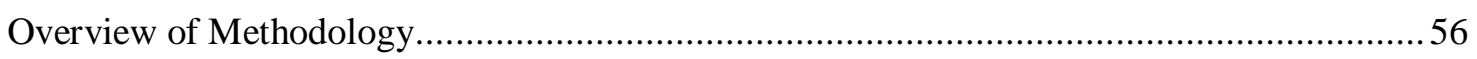

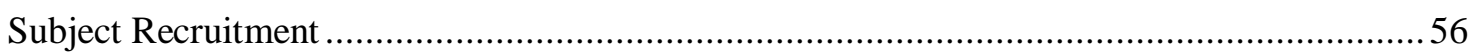

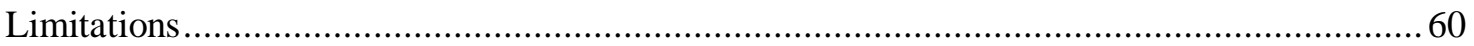

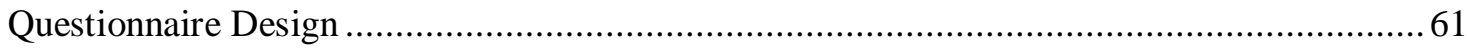

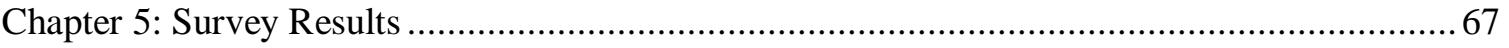

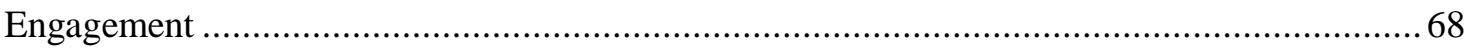

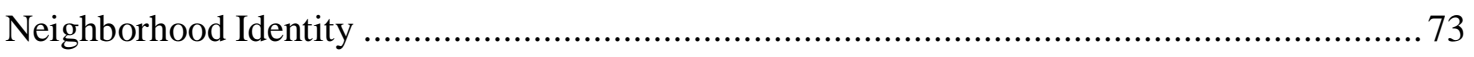

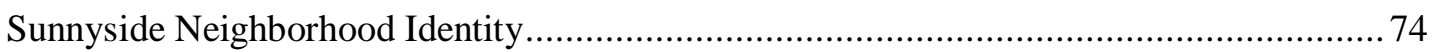

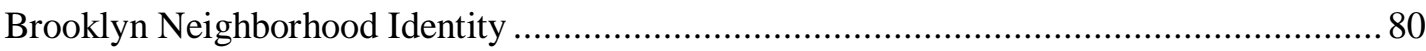

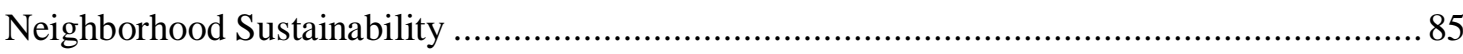

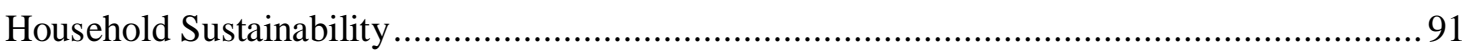

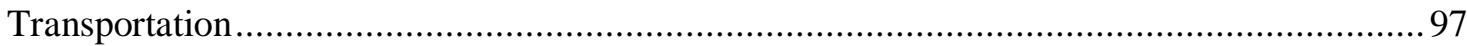

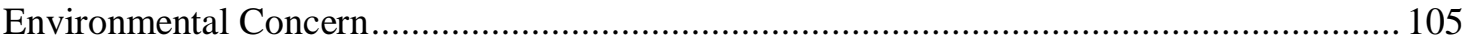

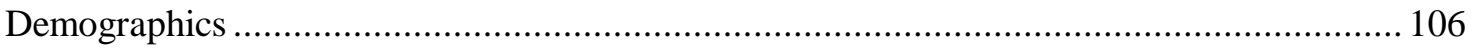

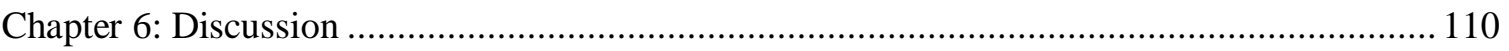

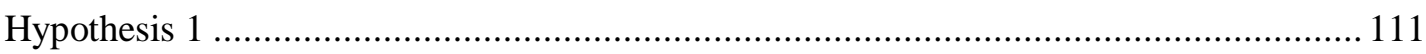

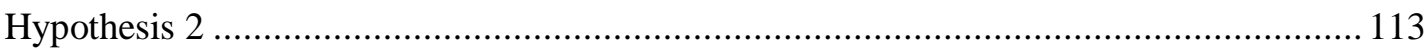

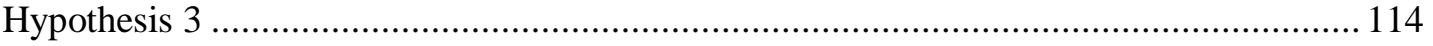

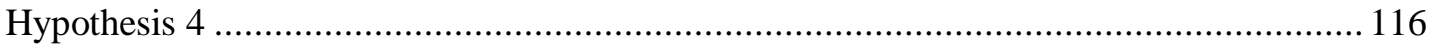

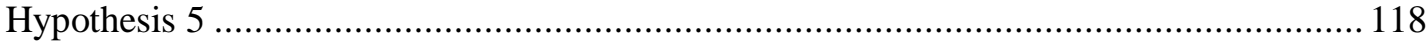

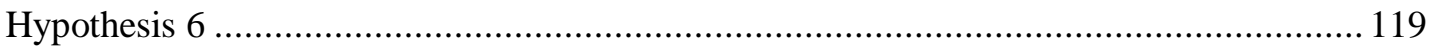

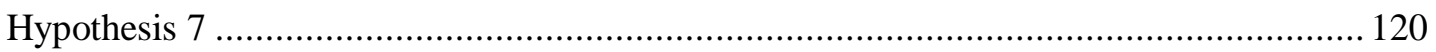

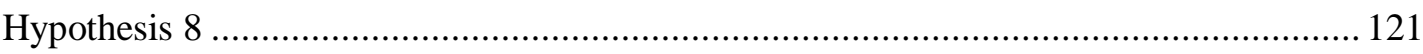

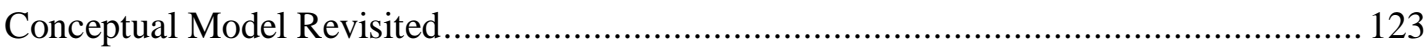

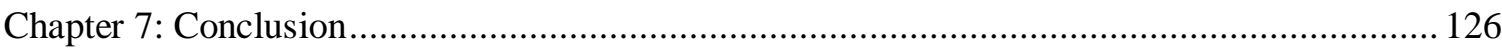

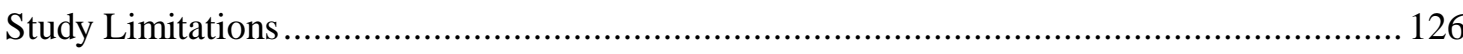

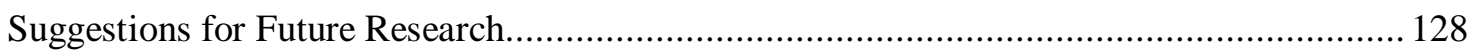

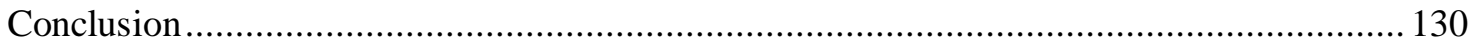

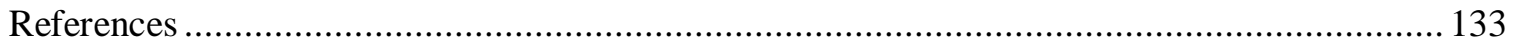

Appendix A - Survey Flyer and Newsletter Announcement ................................................. 142

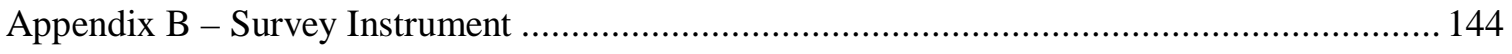




\section{List of Tables}

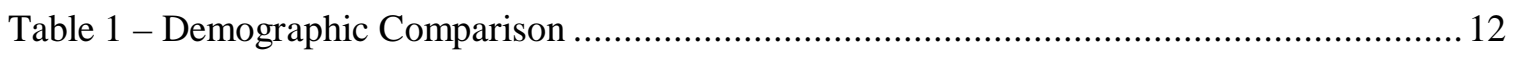

Table 2 - Participation in Neighborhood Organizations, Events, and Activities ........................ 68

Table 3 - Reasons for Moving to the Neighborhood (Multiple Responses Allowed) ................... 87

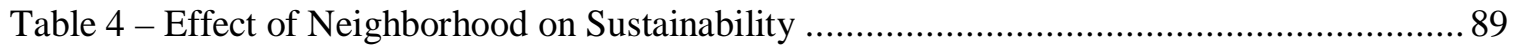

Table 5 - Causes of Increased Sustainable Behaviors …........................................................... 90

Table 6 - Energy Efficiency Upgrades Performed (Multiple Responses Allowed) ..................... 95

Table 7 - Average Temperature and Cost of Energy ................................................................ 96

Table 8 - Number of Miles Driven Each Week ....................................................................... 101

Table 9 - Aspects that Encourage Alternative Transportation Use ......................................... 104

Table 10 - Aspects that Discourage Alternative Transportation Use ........................................ 105

Table 11 - Mean Ratings of Environmental Concern .............................................................. 106

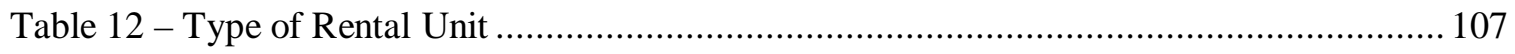

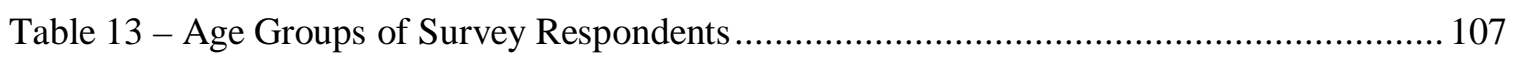

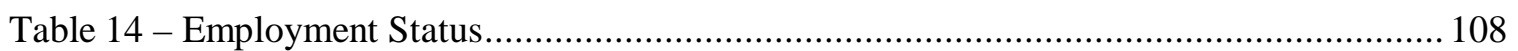

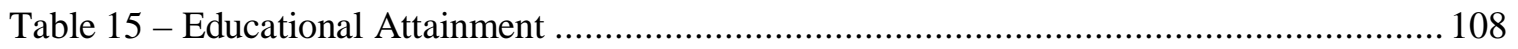

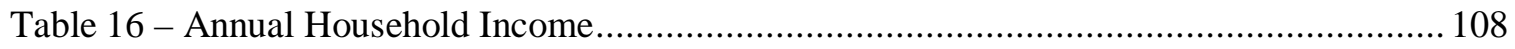

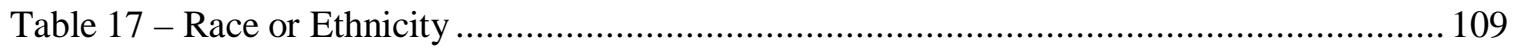




\section{List of Figures}

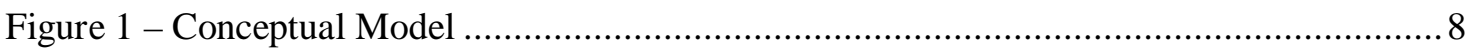

Figure 2 - Map of the Two Study Neighborhoods............................................................ 13

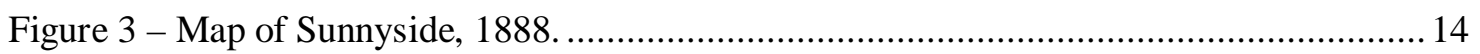

Figure 4 - Brooklyn Neighborhood Plan Map ..................................................................... 37

Figure 5 - Map of Brooklyn Flyer Coverage..................................................................... 58

Figure 6 - Map of Sunnyside Flyer Coverage ................................................................... 59

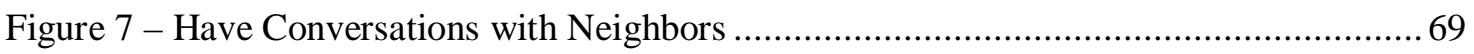

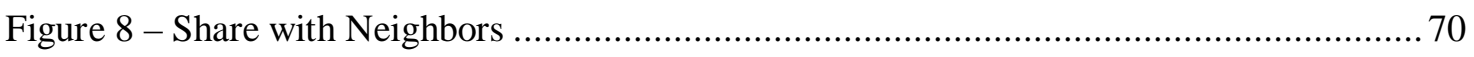

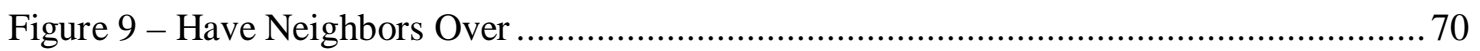

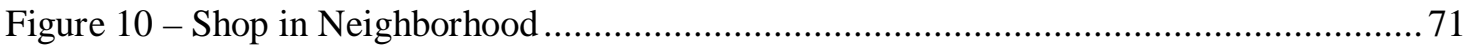

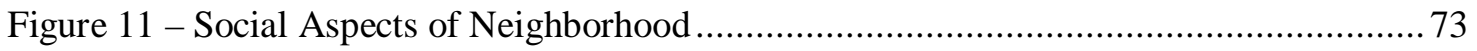

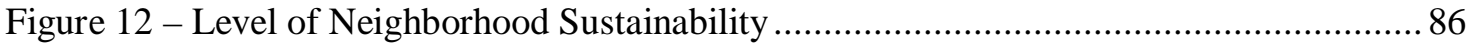

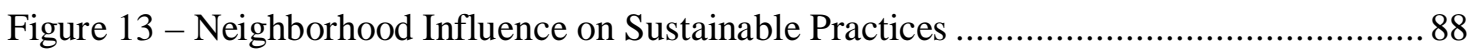

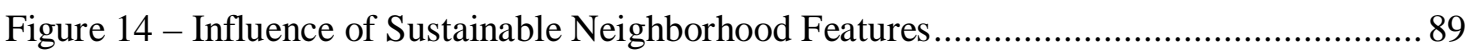

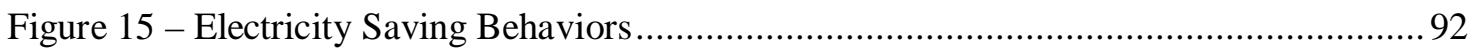

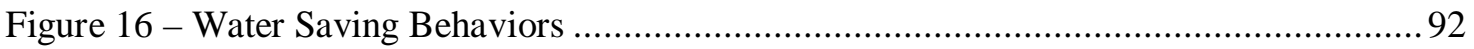

Figure 17 - Heating or Cooling Adjustments to Save Energy............................................. 92

Figure 18 - Recycling Paper, Metals, Plastics, and Glass ................................................... 93

Figure 19 - Taking Hard to Recycle Materials to Drop-off Locations ................................. 93

Figure 20 - Purchasing Energy Efficient Products ............................................................. 93

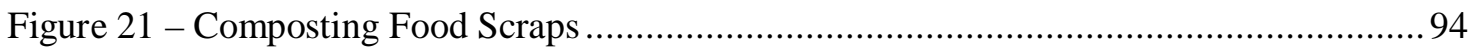

Figure 22 - Alternative Transportation Infrastructure in the Brooklyn Neighborhood ............99

Figure 23 - Alternative Transportation Infrastructure in the Sunnyside Neighborhood......... 100

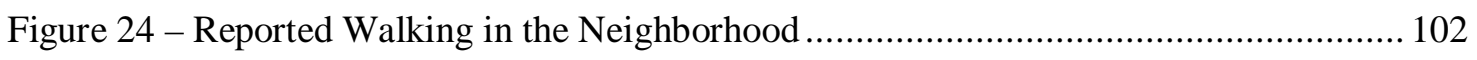

Figure 25 - Reported Public Transportation Use............................................................... 102

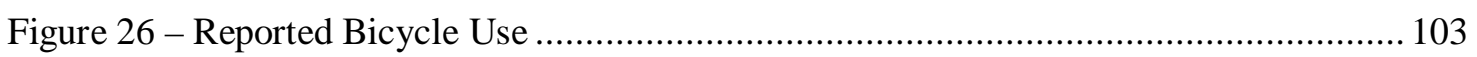

Figure 27 - Conceptual Model Revisited ........................................................................ 125 


\section{Chapter 1: Introduction}

The human race is facing unprecedented challenges as we move further into the $21^{\text {st }}$ century. To address these challenges, increases in environmentally sustainable behavior are necessary. To be sustainable is to meet the needs of the present without compromising the ability of future generations to meet their needs (WCED 1987, 43). To do this, we must continuously work to limit our impact on the environment and to conserve natural resources as much as possible. Current consumption patterns are outstripping the planet's finite natural capital. Additionally, the amount of anthropogenic carbon dioxide $\left(\mathrm{CO}_{2}\right)$ and other greenhouse gasses (GHG) released by burning fossil fuels has a tremendous impact on public health and the environment. An ongoing debate in the United States argues the extent to which humans are causing climate change, and more specifically, how much burning fossil fuels impacts the Earth’s biosphere. Even if one does not fully accept warnings regarding global climate change, ignoring the risks and perpetuating environmentally-destructive lifestyles is irresponsible and potentially disastrous. Since energy is the 'lifeblood' of all economic and social activity, continued inattention to its limits should be a source of serious concern (Rosa et. al. 1988, 151).

Future energy use patterns in the United States and abroad will need to drastically change in order to sustain future generations. Consumption in the United States surpasses that of all other westernized countries (Top World Energy Consumers, 2009). This behavior is a result of abundant and cheap energy supplies, specifically fossil fuels. The 
persistent push of consumer society has resulted in many environmental and social implications that are rarely fully considered. This preoccupation with material goods has enormous implications on our ability to sustain the human species into the future. It is important to note that even small shifts in individual behavior can equate to meaningful decreases in energy consumption that can go a long way towards helping United States become a more sustainable society. ${ }^{1}$

The household and personal transportation make up a large proportion of energy consumption United States. Both are also major contributors to greenhouse gas emissions, and thus important sectors to focus on in order to improve sustainability efforts. ${ }^{2}$ With household and transportation activities having such an impact on environmental outcomes, sustainability measures and polices are needed to mitigate these harmful environmental effects. Since the household is a key socialization unit, it is an important aspect to consider when fostering more sustainable lifestyles.

Urban neighborhoods are also in a unique position to influence household energy usage and transportation choices. Dense urban neighborhoods have a number of

\footnotetext{
${ }^{1}$ According to the 2008 International Energy Agency (IEA) Key World Energy Statistics, $\mathrm{CO}_{2}$ emission in the U.S. was at 18.38 tons per capita (IEA 2010, 57). This figure is striking when compared to worldwide average $\mathrm{CO}_{2}$ emissions (4.39 t CO 2 /capita) (ibid, 49). According to the U.S. Department of Energy, in 2008 the U.S. consumed 99.5 quadrillion BTUs (British thermal units), or roughly 20 percent of worldwide energy usage (DOE, 2011). The U.S., however, only contains $4.5 \%$ of the world's population (ibid). This inequality can be largely explained by the excessive consumption patterns. In 2000, the average American individual's share of total emissions was more than 14,000 pounds of $\mathrm{CO}_{2}$, and totaled at 4.1 trillion pounds for all Americans (Vandenbergh 2007, 1675). The 4.1 trillion pounds attributable to American individuals consist of 32 percent of total U.S. annual emissions, 8 percent of the world total (ibid).

${ }^{2}$ Residential energy use in the U.S. made up 23\% of all energy used in 2010, mainly in the form of electricity (derived from coal-fired power plants) and natural gas (Energy Consumption Estimates by Sector Overview, 2010). In 2009, American cars and light trucks used 16.4 quadrillion BTUs of energy, which represented approximately $17 \%$ of the total U.S. energy consumption (U.S. Department of Energy, 2011).
} 
advantages to their suburban counterparts. Density allows for more interaction with others in the neighborhood. This close proximity to people promotes social interactions that can be useful in disseminating social norms and values. Additionally, visual cues of low-energy and sustainable activities (e.g., solar panel arrays, rainwater catchment, home gardening, etc.) may also have a direct influence on what other neighborhood residents do. Dense urban areas are also generally more walkable and have alternative transportation available for residents to use instead of personal automobiles.

\section{Research Questions}

There is an abundance of existing research on sustainability, specifically regarding energy consumption in society. The intersection between the built environment, social institutions (such as neighborhood associations), and household sustainability is the primary focus of this research. This study aims to better understand whether or not neighborhood identity directly affects household sustainability. Thus, the research question is: How does neighborhood identity affect household-level sustainable behaviors? To answer this question, this research will gather data on 1) household-level sustainable behaviors 2) household transportation choices 3) level of community involvement, and 4) general perceptions of the neighborhood.

This research uses a comparative case-study approach to analyze two neighborhoods in Portland, Oregon. The Sunnyside and Brooklyn neighborhoods both are located within inner-southeast Portland. These neighborhoods were chosen because they are demographically similar in terms of education attainment, age, race and ethnicity, and 
housing tenure. However, the neighborhoods have their own unique identities. Sunnyside prides itself on fostering a bohemian atmosphere, a forward-looking sustainable character, and a focus on families and small local businesses. Brooklyn's identity has grown out of its past; a history of strong working class immigrants, railroads, and lumber industry. Brooklyn also is a neighborhood marked by a century of division wrought on by roads, bridges, and rail yards that have segmented the neighborhood into distinctive pockets. To determine the effects that neighborhood identity has on household sustainability, the Sunnyside and Brooklyn neighborhoods were systematically surveyed in the summer of 2012. A web-based survey was fielded in both neighborhoods to gather data that was used to better understand the identity of the neighborhoods and to determine the level of residential sustainability.

\section{Conceptual Model}

To begin conceptualizing this research into a simple and comprehensive visual model, various aspects from other popular models were incorporated together to create a multifaceted and robust model for this research. The Consumer Lifestyle Approach (CLA), designed by Shui Bin and Hadi Dowlatabadi (2005), provided a general framework of consumer decision-making associated with energy use. In this model the 'consumer,' or the neighborhood resident, is the central actor in decision-making who purchases and uses products and services for the purpose of individual or household consumption (Bin and Dowlatabadi 2005, 198). In the CLA model, 'lifestyle' is loosely defined as, "a way of living that influences and is reflected by ones consumption 
behavior” (Bin and Dowlatabadi 2005, 198). CLA is unique because it incorporates a number of aspects that influence consumer choices, including social-psychological aspects.

There are five major areas covered by the CLA model. The first three areas directly influence consumer choices: the external environment, individual determinants, and household characteristics. The external environment consists of a number of external variables that influence consumers. These variables include: culture, economics, technology, and social class. These factors form the external context of a consumer's decision-making process (Bin and Dowlatabadi 2005, 198). Individual determinants account for the social-psychological influences of consumer decision-making. Variables within this area include: attitudes, affects, motives, perceptions, and preferences. The third factor is household characteristics, which include: income, location, household size (number of people within the household), and home size. These variables form a ‘household context' for individual consumer decision-making (Bin and Dowlatabadi 2005, 198). The three areas of direct influence, lead the consumer (the fourth aspect) to make consumption decisions. These decisions are then fed into the fifth aspect, the consequences. Consequences, such as resource use and related environmental impacts, are the end results of consumer choices (Bin and Dowlatabadi 2005, 198). The environmental consequences of consumption feedback into the CLA model creating a repeating and self-reinforcing cycle.

A significant body of research has analyzed the various social-psychological aspects of household sustainability, especially in terms of energy use. In order to increase 
the breadth of the Individual determinants area of the CLA model, aspects from the Theory of Planned Behavior (TPB) proposed by Ajzen (1991) were incorporated into the CLA model for this research. The TBP model suggests that an individual's behavior is influenced by behavioral intentions, where behavioral intentions are a function of an individual's attitude towards a given behavior, the subjective norms surrounding the performance of the behavior, and the individual's perceived behavioral control. This research uses a number of variables to determine how an individual's intensions, attitudes, subjective norms, and perceived behavioral control interact with each other to influence sustainable behaviors.

The conceptual model for this research centers on both the neighborhood and the household, and how the interaction between each entity can foster more sustainable lifestyles. ${ }^{3}$ The household is the focal point of this research model, rather than the consumer. A number of models have attempted to better understand energy usage and sustainability. However, many have paid little attention to, or have completely ignored the consumer in this process. For example, a techno-rational framework is often used when discussing energy, specifically in terms of energy efficiency. This framework primarily focuses on 'end use' technologies such as furnaces, air conditioners, refrigerators, and automobiles (Lutzenhiser and Gossard 2000, 208). Often times the users of these devices are largely excluded from the model. The techno-rational model views the users of these devices as ‘consumers' who all use energy in similar ways,

\footnotetext{
3 'Lifestyle' is often a difficult concept to define. The definition of lifestyle used for this research is: "Distinctive modes of existence that are accomplished by persons and groups through social sanctioned and culturally intelligible patterns of action” (Lutzenhiser and Gossard 2000, 215).
} 
which is often not the case. It also assumes that these users make rational economizing choices about their energy use (Lutzenhiser and Gossard 2000, 208).

Models that focus only on individual decision-making are lacking in complexity. Multidimensional aspects of consumption need to be accounted for. Attitude-behavior processes are embedded in larger systems of beliefs, events, institutions, and influential 'background’ factors (Lutzenhiser 1993, 258). The conceptual model used for this research attempts to provide a multidisciplinary approach to understanding household sustainable behaviors by focusing on how the household is both influenced by its residents and the surrounding neighborhood. 


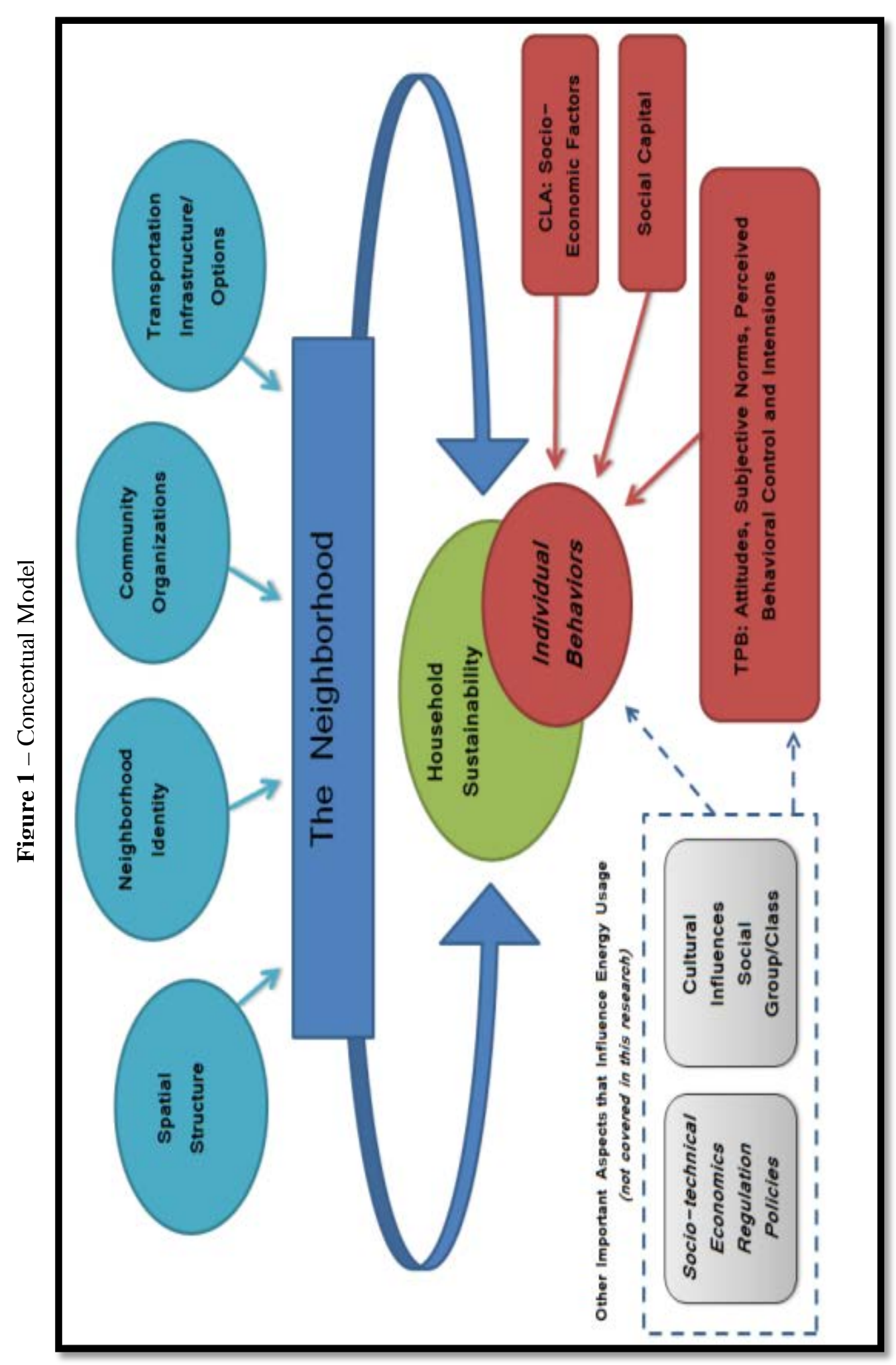




\section{The Sunnyside Neighborhood}

Portland, Oregon has been heralded for its sustainability efforts. ${ }^{4}$ Although many neighborhoods in Portland strive to increase their level of sustainability, the Sunnyside neighborhood is arguably one of the more eco-conscious communities within the City of Portland. The Sunnyside neighborhood was selected after reviewing neighborhood documentation (e.g., neighborhood association newsletters, neighborhood association website, and the 1999 neighborhood plan) as well as talking with neighborhood insiders. Following this investigation, it was determined that the Sunnyside neighborhood does have a specific agenda that encourages residents to care for the environment. Further, Sunnyside is one of few neighborhoods in Portland that have established a sustainability committee. Sunnyside’s sustainability committee is part of the Sunnyside Neighborhood Association (SNA) and has a goal to help its Sunnyside residents reduce their carbon footprint.

In terms of location, Sunnyside within Southeast Portland bordered to the south by Hawthorne Boulevard, to the north by Stark Street, to the west by $28^{\text {th }}$ Avenue and to the east by $49^{\text {th }}$ Avenue. Located in the middle of Sunnyside is Belmont Street, which contains the neighborhood's central business district, running from SE $33^{\text {rd }}$ Avenue to SE $35^{\text {th }}$ Avenue. The neighborhood encompasses 382 acres of land (2010 Portland Neighborhood Demographic Data). As of 2010, there were 7,354 people residing in the

\footnotetext{
${ }^{4}$ Portland, Oregon is routinely rated as one of the most sustainable cities in the country by leading sustainability ratings organizations such as Sustainlane.com. Portland also has a Bureau of Planning and Sustainability which has established a number of incentives to further sustainability efforts such as the 2009 Climate Action Plan which provides a path to achieve a 40 percent reduction in carbon emissions by 2030 and an 80 percent reduction by 2050.
} 
neighborhood, in a total of 3,685 occupied household units (2010 Portland Neighborhood Demographic Data). There were 963 more renters residing in the neighborhood than owners (1,361 vs. 2,324) (2010 Portland Neighborhood Demographic Data).

\section{Selecting a Comparison Neighborhood}

A number of variables were taken into consideration when selecting an appropriate comparison neighborhood. A comparison neighborhood was needed in this research because if only one neighborhood was researched (i.e., Sunnyside), it would be difficult to know if, and how, neighborhood identity actually affects adherence to sustainable behaviors. Furthermore, there would be no way to tell if observed sustainable behaviors were just an anomaly or if they were actually being influenced by the neighborhood's collective identity.

To begin the comparison neighborhood selection process, aggregated census data were reviewed. ${ }^{5}$ Four variables were used to select the comparison neighborhood: race and ethnicity, age, household tenure, and strength of neighborhood identity. Energy consumption and sustainable behavior varies based the demographic character, and thus it was important to find a neighborhood that matches Sunnyside's demographics. The number of demographic variables that closely matched Sunnyside was tallied for each neighborhood. Neighborhoods that were most similar to Sunnyside (identified by high a high number of matching variables) were selected for further analysis. Out of 101 neighborhoods in the City of Portland, seven neighborhoods were found to closely match

\footnotetext{
${ }^{5}$ Neighborhood level data were compiled by the Population Research Center at Portland State University.
} 
Sunnyside in terms of the four variables mentioned above: Boise, Brooklyn, HosfordAbernethy, Eliot, North Tabor, Reed, and South Portland.

Since Portland is a rather sustainably-minded city, in general, many neighborhoods would be expected to exhibit a somewhat sustainable identity. When selecting a comparison neighborhood for this study, it was important to identify a neighborhood that had a less distinct identity than Sunnyside. In order to isolate the effect of neighborhood identity, and rule out any other variables that may be affecting sustainability levels (income, race or ethnicity, housing tenure, etc.), the comparison neighborhood needed to be demographically similar to Sunnyside, except in the focus of this research: neighborhood identity with a focus on sustainability.

Neighborhood identity is a difficult concept to objectively measure, but it is critical to this study. To ascertain the presence and strength of the identity, a review of neighborhood association documentation, as well as tours of the neighborhoods were conducted. Additionally, individuals who were familiar with Sunnyside and the other seven neighborhoods in consideration (residents and neighborhood association members) were consulted to help determine what neighborhood would make for the best comparison to Sunnyside. 


\section{The Brooklyn Neighborhood}

The Brooklyn neighborhood was selected as being most similar to Sunnyside. Table 1illustrates the similarities between the two neighborhoods as compared to the City of Portland. On each item, Sunnyside and Brooklyn are within only a few percentage points of each other, suggesting that they are demographically similar.

Table 1 - Demographic Comparison

\begin{tabular}{|c|c|c|c|}
\hline & Brooklyn & Sunnyside & Portland \\
\hline \multicolumn{4}{|c|}{ Race/Ethnicity } \\
\hline White & $83 \%$ & $86 \%$ & $76 \%$ \\
\hline Black & $2 \%$ & $1 \%$ & $6 \%$ \\
\hline Asian & $3 \%$ & $4 \%$ & $7 \%$ \\
\hline Hispanic & $6 \%$ & $5 \%$ & $9 \%$ \\
\hline \multicolumn{4}{|c|}{ Age } \\
\hline Under 18 & $13 \%$ & $11 \%$ & $22 \%$ \\
\hline $18-24$ & $11 \%$ & $8 \%$ & $10 \%$ \\
\hline $25-44$ & $49 \%$ & $54 \%$ & $30 \%$ \\
\hline $45-64$ & $20 \%$ & $18 \%$ & $26 \%$ \\
\hline $65+$ & $7 \%$ & $8 \%$ & $12 \%$ \\
\hline \multicolumn{4}{|c|}{ Housing Tenure } \\
\hline Renter & $61 \%$ & $60 \%$ & $41 \%$ \\
\hline Owner & $33 \%$ & $35 \%$ & $55 \%$ \\
\hline
\end{tabular}

Brooklyn is also located in Inner Southeast Portland, is roughly the same size as the Sunnyside Neighborhood, and is also part of the Southeast Uplift Neighborhood Coalition. ${ }^{6}$ The northern boundary of the neighborhood is SE Powel Boulevard, the eastern boundary is made up of SE $26^{\text {th }}$ Avenue and the Union Pacific rail yard, the southern boundary is McLoughlin Boulevard, and the western boundary is the Willamette

\footnotetext{
${ }^{6}$ The Southeast Uplift Neighborhood Coalition is a nonprofit organization that provides support and small grants to neighborhood associations located in Southeast Portland.
} 
River. The most difficult part of making this decision was determining the strength of identity. To do this, neighborhood documentation (i.e., neighborhood newsletters, neighborhood association meeting minutes, etc.) and key individuals who are familiar with both the neighborhoods were consulted. Following this investigation, I felt that it was a fairly supported assumption that the Brooklyn neighborhood generally lacks the strong eco-conscious neighborhood identity that Sunnyside exhibits. Specifically, Brooklyn did not have a neighborhood sustainability committee, had a limited amount of visible sustainable features (e.g., rain barrels, community gardens, or farmers markets), and had few references to sustainability in its neighborhood newsletters.

Figure 2 - Map of the Two Study Neighborhoods

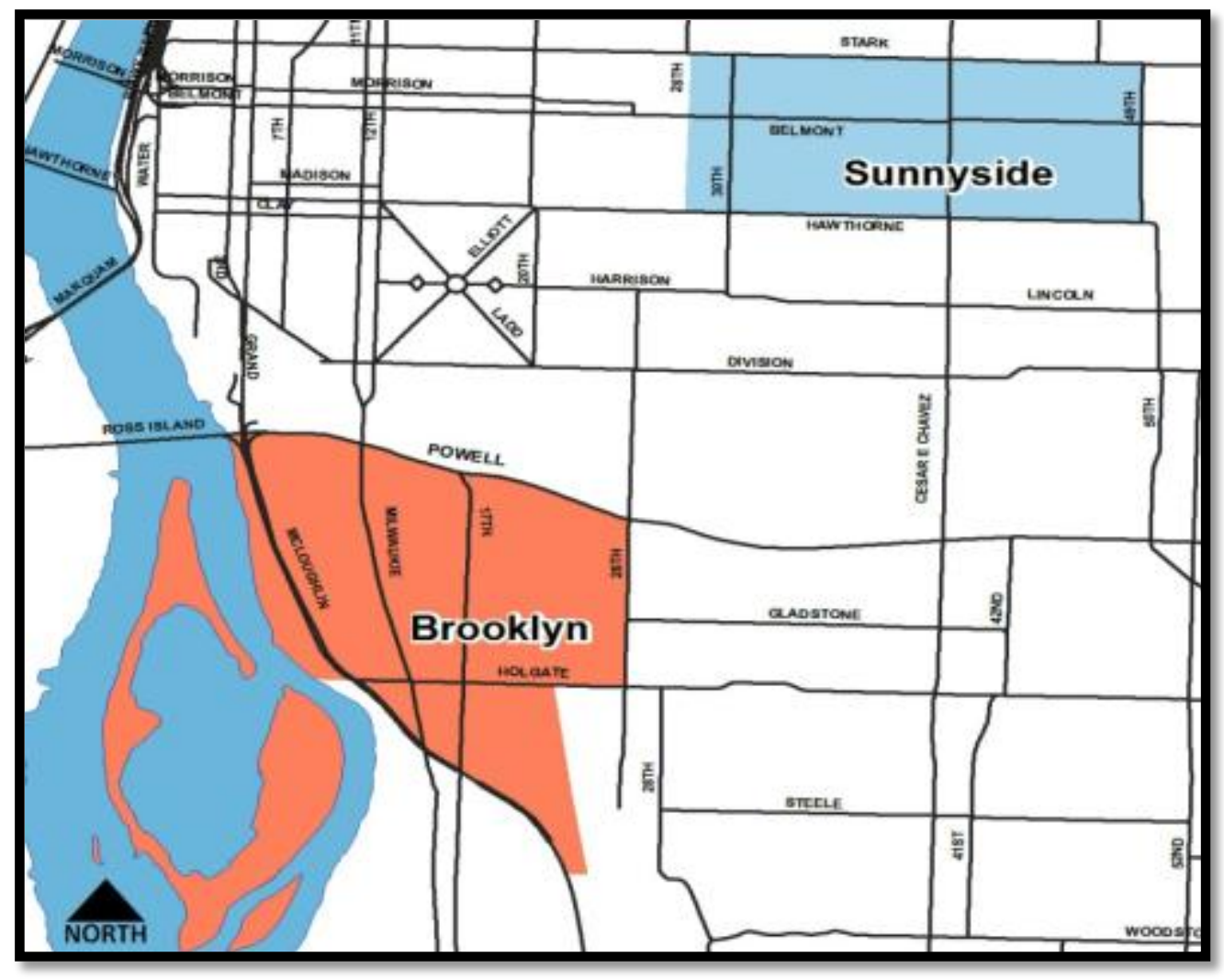




\section{Chapter 2: The Neighborhoods}

\section{The Sunnyside Neighborhood}

\section{History of the Sunnyside Neighborhood}

The slogan "Proud Past, Bright Future" adorns many of the neighborhood signs located within the Sunnyside neighborhood, and is something the residents of Sunnyside tend to take to heart. The area the neighborhood encompasses today was settled in 1851 on a portion of the Seldon Murrary donation land claim (Burns, Acres, Ryker \& Baribeau, 1999, p. 6). The Sunnyside Land Improvement Company was formed shortly thereafter and began developing the area for residential use. It is often cited that land

developers during this time played

on the "Sunnyside" name to advertise the neighborhood as being "the sunny side of the city, outside the shadows of the west hills and downtown Portland” (Burns, Acres, Ryker \& Baribeau, 1999, p. 6). The Sunnyside Land Improvement Company not only developed the land in the neighborhood, but was also responsible for developing the physical form of the neighborhood
Figure 3 - Map of Sunnyside, 1888. Courtesy of Oregon Historical Society, OrHi 39739

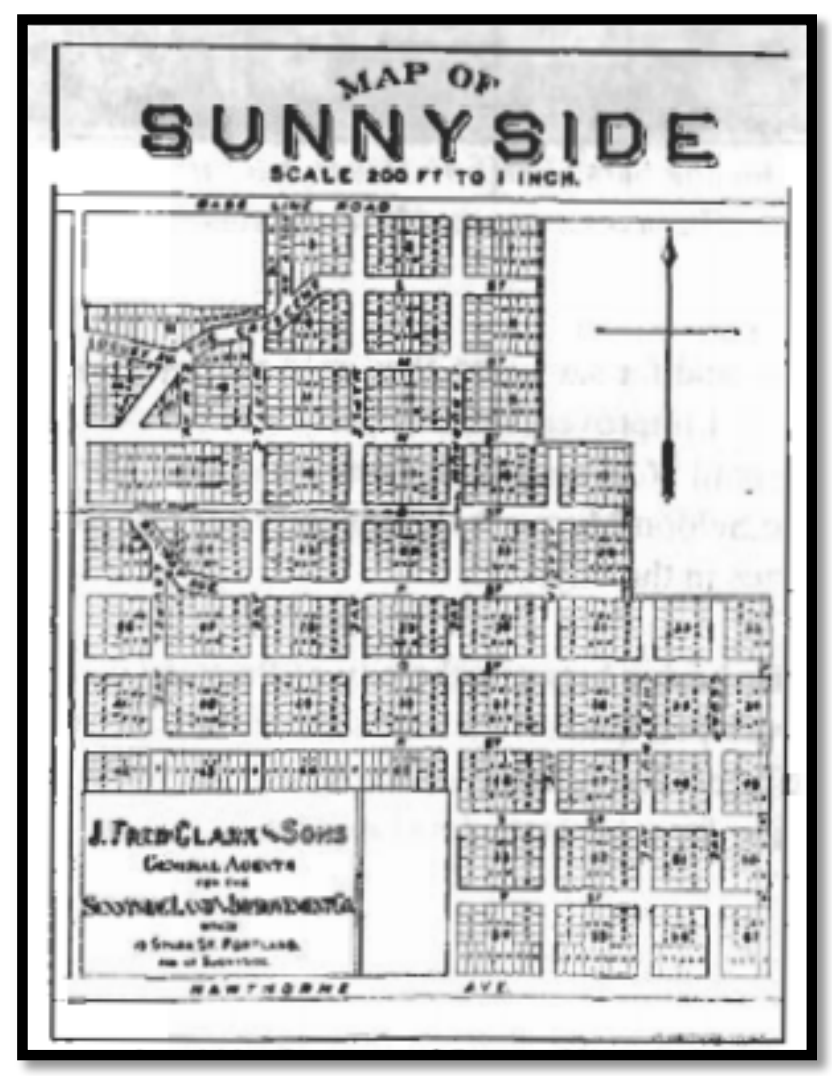


(streets, blocks, lot sizes, etc.). It was common practice for a builder to purchase a number of parcels to build on (Burns, Acres, Ryker \& Baribeau, 1999, p. 9). This resulted in many of the houses in the neighborhood to be similar in scale and form, creating interconnected streetscapes (Burns, Acres, Ryker \& Baribeau, 1999, p. 9).

With the opening of the Morrison Bridge in 1887, the east side of Portland was now easily accessible to residents wanting to move out of the downtown core. Shortly after the Morrison Bridge opened, the first steam dummy commuter rail line in Portland (the Mt. Tabor Line) began service to the Sunnyside neighborhood ("Streetcar line histories," 2010). ${ }^{7}$ The rail route ran from downtown Portland, up Morrison Street, down what is now $26^{\text {th }}$ Avenue, and over to Belmont Street into the heart of the Sunnyside neighborhood. Eventually, the line continued up Belmont Street to Mt. Tabor (Burns, Acres, Ryker \& Baribeau, 1999, p. 10). This new streetcar line brought with it city dwellers who were interesting in getting out of crowed and polluted downtown Portland and building homes in up-and-coming subdivisions like Sunnyside. With the rail line and the influx of new residences, a small commercial strip began to develop along Belmont Street between what is now Southeast $33^{\text {rd }}$ Avenue and Southeast $35^{\text {th }}$ avenue. This commercial strip continues to be Sunnyside's main shopping district, and still retains many of the historic buildings of the late $19^{\text {th }}$ century.

During the late 1920's, Sunnyside began to develop its residential character as a "staunch working class neighborhood with solid ties centered upon the Sunnyside School and several neighborhood churches” (Burns, Acres, Ryker \& Baribeau, 1999, p. 11).

\footnotetext{
${ }^{7}$ The steam dummy, a precursor to the electric street car, was a steam engine that was enclosed in a somewhat ornate wooden box, designed to resemble a typical railroad passenger coach (Steam Dummy).
} 
Around the same time, the automobile was quickly captivating the American populous. This led to changes in the fabric of the Sunnyside neighborhood. During the 1930s and 1940s, many of the historic buildings located near Belmont Street were demolished to make way for parking lots catering to clientele visiting from outside the neighborhood (MacColl, 45). By the 1950s, the Sunnyside neighborhood had changed dramatically from its quaint working class roots (Burns, Acres, Ryker \& Baribeau, 1999, p. 12). Large, single-family houses began to be split up to create multifamily apartment units ushering in a new population mostly consisting of younger, single adults (Burns, Acres, Ryker \& Baribeau, 1999, p. 12).

During the 1970s through the early 1990s, the Sunnyside neighborhood experienced many of the problems associated with urban blight that were plaguing most inner-city communities across the United States during this time. Social alienation, disorder, vandalism, crime, drug abuse, and automobile traffic all led to a period where Sunnyside lost much of its identity that was established during its 100 year history.

This downturn began to change in the mid-1990s when neighborhood began revitalizing itself through the process of gentrification. Today, the Sunnyside neighborhood has transformed once again. Many local small businesses have established a presence in the neighborhood, mainly along Southeast Belmont Street. A number of infill developments (mainly small apartment and condominium buildings) have also sprouted in the neighborhood. The Sunnyside Environmental School is generally considered to be the center of community gatherings in the neighborhood. The elementary school offers a "thematic environmental curriculum” that emphases "personal 
and social responsibility for all living systems” (Sunnyside Environmental School, 2011). All around the school, gardens have been planted by students in attempt to connect them to the food they eat. In 2008, Sunnyside laid out a plan to create a neighborhood thermal energy utility using renewable, carbon-neutral sources. The SunNE Project plan was supposed to power the Sunnyside Environmental School and provide space heat and domestic hot water to serve a 54 square block neighborhood which would include a mix of residential and commercial customers and owners (Sunnyside Neighborhood Energy, 2008). ${ }^{8}$

The Sunnyside Piazza is another notable landmark in the Sunnyside neighborhood. In 2001, Sunnyside began to discuss ways to improve the livability and vitality of the community (Semenza, 2003, p. 1439). The intersection at Southeast $33^{\text {rd }}$ Avenue and SE Yamhill Street was chosen to be the location of the Piazza project. With the help of City Repair ${ }^{9}$ a sunflower, the neighborhood symbol, was painted in the intersection by community members to serve to enhance social cohesion in the community (Semenza, 2003, p. 1439). Also included in the project were a number of artistic features including a neighborhood message kiosk, fountains, cob structures, and landscaping. This project was intended to reverse the urban decay in the neighborhood and restore a sense of place in the community (Semenza, 2003, p. 1439). Residents come

\footnotetext{
${ }^{8}$ Because of the economic problems of 2008, this project has been put on hold. There is not current information about when and if the project will continue at the time of this writing.

${ }^{9}$ City Repair is a local organization with a vision that aims to facilitate artistic and ecologically-oriented placemaking through projects that honor the interconnection of human communities and the natural world” (City Repair, 2010).
} 
together annually; close the intersection to traffic, and spend a weekend re-painting, talking, picnicking, and playing in the street. ${ }^{10}$

\section{Sunnyside Organizations and Associations}

A number of different associations began in Sunnyside in the late 1980s and early 1990s. In 1986, the Belmont Area Business Association (BABA) was formed. Its mission is "to promote the collective, individual, and civic interests and rights of all persons, firms and corporations within its boundaries” ("The BABA," 2012). BABA, in conjunction with the Sunnyside Neighborhood Association (SNA), also hosts an annual street fair on Belmont which brings in residents from across the city to enjoy local food, crafts, and entertainment. In 1982, the Hawthorne Boulevard Business Association (HBBA) began. The purpose of this association was similar to BABA; to help create a district that is conducive to creating a place to work, shop, and live (Burns, Acres, Ryker \& Baribeau, 1999, p. 28). HABA, along with the SNA, Richmond Neighborhood Association, and the Hosford-Abernathy Neighborhood association, hosts the popular Hawthorne Street Fair.

The Sunnyside Neighborhood Association is arguably the most important actor in neighborhood affairs. The SNA is a non-profit corporation which is organized under the direction of the City of Portland's Office of Neighborhood Involvement. The SNA was established over 30 years ago and flourishes today as an arena for Sunnyside residents to

\footnotetext{
${ }^{10}$ In 2003, Portland State University professor Jan Semenza conducted a pedestrian observations at the piazza and found that a $32 \%$ of pedestrians observed interacted with the intersection (compared to $7 \%$ at an unimproved intersection elsewhere in the neighborhood) (Semenza, 2003, p. 1440). Using data from a survey conducted within two blocks of the intersection, Semenza found that the project fostered social capital and increased social cohesion (Semenza, 2003, p. 1440).
} 
gather and participate in neighborhood activities. The mission of the SNA is to "provide advocacy review and community building while preserving and expanding livability for people who live, work, and own property (Burns, Acres, Ryker \& Baribeau, 1999, p. 29). Some notable accomplishments of the SNA include developing the Sunnyside School Park (located in the center of the neighborhood), helped repair deteriorating housing, address issues of homelessness in the neighborhood, and resolves issues regarding transportation and parking (Burns, Acres, Ryker \& Baribeau, 1999, p. 30). Additionally, the SNA has been involved in a number of social and political issues including: becoming Portland's first Nuclear Free Zone in $1983,{ }^{11}$ the failed attempt to turn the neighborhood into a "Hemp Free Zone” in 1993, ${ }^{12}$ and becoming the first neighborhood level “Transition Group” in the United States in 2009 (Waldron, 2011). ${ }^{13}$ Finally, the SNA is one of only a handful of neighborhoods in Portland to establish a sustainability committee. This committee’s mission is to help residents reduce their fossil fuel consumption (Sunnyside Sustainability Committee, 2008).

Another major actor in the Sunnyside neighborhood, along with the Brooklyn neighborhood, is the Southeast Uplift Neighborhood Coalition (SEUL). SEUL was formed in 1968 and is a 501(c)3 nonprofit organization. This organization has provided staff and support to neighborhoods in inner Southeast Portland. SEUL’s mission

${ }^{11}$ A Nuclear-Free Zone is an area where nuclear weapons and nuclear power are banned. Generally speaking, this label is symbolic in nature since such decisions are determined and regulated by higher levels of government ("Nuclear-free zone," 2012).

12 This initiative was proposed by local resident Floyd Landrath also known as “Mr. Hemp,” and would have designated the neighborhood as an area where law enforcement agencies would give lowest priority to marijuana-related offenses. This initiative resulted in the largest public attendance for a SNA meeting, but lost by a margin of two-to-one (Richmond, 1996).

${ }^{13}$ A transition neighborhood is one which "seeks to build community resilience in the face of such challenges as peak oil, climate change and the economic crisis” (Transition US, 2011). 
statement stipulates that the organization "assist the citizens and neighborhood

associations of Southeast Portland to create communities that are livable, socially diverse, safe and vital” ("Southeast uplift's mission"). SEUL also provides a number of different programs to neighborhoods within its jurisdiction. These programs include Solarize Southeast, ${ }^{14}$ Neighborhood Small Grants, graffiti abatement, community grants, and other programs that provide support to neighborhood associations.

\section{Planning Efforts in Sunnyside Neighborhood}

A number of planning efforts have taken place over the years. One of the first plans created was the Belmont Action Plan, in 1993. The plan focused on community development in the area immediately surrounding the main Belmont business district (between Southeast $23^{\text {rd }}$ Avenue and Southeast $39^{\text {th }}$ Avenue). The six goals of the plan included: 1) strengthening the Belmont business district, 2) improved housing while guarding against gentrification, 3) increased safety of the community, 4) increased safety for bicycle and pedestrian traffic, 5) improved neighborhood appearance, and 6) improved neighborhood livability (Burns, Acres, Ryker \& Baribeau, 1999, p. 31). A follow up to the Belmont Action Plan was the Belmont District Plan, in 1995. This plan was developed by the REACH Community Development Corporation and had many of the same goals as the Belmont Action Plan, but focused establishing partnerships between local businesses, residents, funders, and technical assistance partners (Burns, Acres, Ryker \& Baribeau, 1999, p. 32).

\footnotetext{
14 Solarize Southeast began in 2009 to provide outreach to people within Southeast Portland who are interested in home solarization projects. In 2010, participants in the program installed two megawatts of solar power ("Solarize southeast," 2010).
} 
The Sunnyside Neighborhood Plan

The most recent plan created in 1999, is the Sunnyside Neighborhood Plan. This plan was part of the Portland Comprehensive Plan, a planning document that guides planning and land use in the City of Portland. The Vision statement for the Sunnyside Neighborhood Plan stipulates:

“Foster Sunnyside’s vision as a place where the lifestyles of its residents and the activities of its businesses enhance the natural and human made environment, where culture and economic diversity thrives, where historic structures and features are preserved, and where businesses are an inherent part of neighborhood life” (Burns, Acres, Ryker \& Baribeau, 1999, p. 35).

The Sunnyside Neighborhood Plan establishes eight different policies to guide current and future activities in the neighborhoods. The following provides a brief description of the eight policies.

Policy 1 - Community Services: The main objectives for maintaining and increasing diversity in the neighborhood include working with organizations, institutions, and groups in Sunnyside to enhance community development, increasing access to affordable housing, and promote diversity as a community value (Burns, Acres, Ryker \& Baribeau, 1999, p. 43). To achieve these goals it was suggested that Sunnyside: conduct an annual neighborhood survey to identify community needs and desires, support programs that promote living history interactions between elders and youth, co-sponsor programs that promote rights 
and responsibilities of tenants and landlords, and welcome and introduce newcomers to the community (Burns, Acres, Ryker \& Baribeau, 1999, p. 46). Policy 2 - Economic Development: The main objective to increase economic development is to ensure relationships with businesses and the neighborhood are maintained and expanded, negative impacts are minimized between businesses and residents, ensuring business and commercial developments are compatible with the surrounding neighborhood, and enhancing business corridors as pedestrian oriented public spaces (Burns, Acres, Ryker \& Baribeau, 1999, p. 48). Actionable goals include, maintaining communication and helping to promote “district identities” with local business associations (Belmont Area Business Association and Hawthorne Boulevard Business Association), encouraging business to promote bike or pedestrian travel for their employees as well as providing bike parking where possible, and encouraging businesses to provide streetscape amenities for pedestrians (Burns, Acres, Ryker \& Baribeau, 1999, p. 50).

Policy 3 - Environment: The main objectives for this policy include increasing awareness of environmental issues, creating learning opportunities regarding the values, principals, and practices of sustainable and low-impact living, developing resources and tools for residents to better understand the state of the natural environment in the community, and promoting citizen involvement sustainable activities (Burns, Acres, Ryker \& Baribeau, 1999, p. 52). 
Policy 4 - Land Use: The main objectives for land use in the neighborhood include preservation of the character of the neighborhood, encouraging an eclectic mix of housing types, supporting mixed use development, and discouraging drivethrough developments, garages in front of housing units, and commercial intrusions into the residential area of Sunnyside (Burns, Acres, Ryker \& Baribeau, 1999, p. 56). Actionable goals include working with historical preservation advocates to preserve, upgrade, and maintain the historic character of Sunnyside, advocating for redevelopment of auto-oriented buildings, promoting development which support the pedestrian nature of the streetscape, and developing and adopting a set of voluntary design guidelines for the neighborhood (Burns, Acres, Ryker \& Baribeau, 1999, p. 59).

Policy 5 - Livability: The main objectives for increasing the livability of the Sunnyside neighborhood are developing and supporting social and cultural activities and public art projects to enhance neighborhood interactions and maintain the streets, yards, public pace, and building exteriors in the neighborhood (Burns, Acres, Ryker \& Baribeau, 1999, p. 62). A number of actionable goals were identified, including holding an annual street fair, creating a farmers market, developing a "Meet-Your-Neighbor” program to promote neighborhood interactions, and advocate for community space.

Policy 6 - Neighborhood History: The main objectives for this policy include celebrating the social and culture history of the neighborhood (Burns, Acres, Ryker \& Baribeau, 1999, p. 66). Many of the goals surrounding this policy 
advocate for continuing research on the historical background of the neighborhood, its buildings, and the people that have and continue to live in the neighborhood. A secondary goal is to make this information accessible to residents of the neighborhood and the City of Portland (Burns, Acres, Ryker \& Baribeau, 1999, p. 66).

Policy 7 - Public Safety: Objectives within this policy include promoting safety of the neighborhood through community building, encouraging crime prevention techniques, elimination of graffiti and vandalism ${ }^{15}$, maintaining a close relationship with the Portland emergency services, and reducing prejudice through education (Burns, Acres, Ryker \& Baribeau, 1999, p. 69). Goal include holding a National Night Out event as well as assisting with neighborhood block parties, form neighborhood and apartment watches each year, and continue monthly police bureau participation at SNA meetings.

Policy 8 - Transportation: Objectives regarding transportation in the Sunnyside neighborhood include encouragement of bicycle use, promotion of pedestrian travel, promote increased public transit use, and reduce the impact on neighborhood livability from motorized vehicle use (Burns, Acres, Ryker \& Baribeau, 1999, p. 74). Actionable goals for transportation include establishing and completing the bike system to facilitate travel by bike, provide bicycles to low-income residents, improve enforcement of pedestrian right-of-way, increase

${ }^{15}$ A 2012 survey of public opinions regarding graffiti in Sunnyside (and other Portland neighborhoods) found that residents do not fully support the removal of all graffiti, favoring a more selective approach to removal based on artistic merit and offensiveness (Conklin, 2012). The Belmont business district tends to attach graffiti; many people cite this as one of the things they actually enjoy about the neighborhood. 
bus service to and from the neighborhood, hold periodic events that close off streets to vehicular traffic, advocate for streetcar service to the area, and advocate for various pedestrian improvements to the neighborhood (Burns, Acres, Ryker \& Baribeau, 1999, p. 80).

The Sunnyside Neighborhood Plan is fairly robust, and was the product of many months of community input. Today, many of the goals stipulated in the plan have either been completed, or are in the process of completion. For example, the Belmont and Hawthorne Street Fairs have been held for many years and are tremendously successful. Bike and pedestrian infrastructure continues to improve in the neighborhood, and community space has been developed to foster both social interactions with residents as well as create spaces that are pedestrian and bicycle friendly. The goals surrounding the environment and sustainability are fundamental to the topic of this research, and have become a defining factor in the overall neighborhood identity.

\section{The Brooklyn Neighborhood}

\section{History of the Brooklyn Neighborhood}

The history of the Brooklyn neighborhood is a cautionary tale of the problems associated of disenfranchised citizens bearing the brunt of development. Like most neighborhoods in Inner-Southeast Portland, Brooklyn began in the 1890s when early farmers and businessmen began real estate speculation in the area. The population, however, was quite different than other neighborhoods in Portland. Many of the early residents of Brooklyn were European immigrants, who labored in Portland's sawmills 
and rail yards (Harrison, McKinney, Feldman, Galantha \& Hamlin, 1991, p. 9). The neighborhood grew into a bustling working class immigrant enclave, with much of its identity focused on the rail industry and the Willamette River. Continuing development of the rail yards in the neighborhood, as well as the destruction of large tracks of the neighborhood for highway building has forever changed the neighborhood's built environment as well as its identity.

In the mid-1850sm Gideon Tibbett’s, an immigrant farmer turned land speculator was the first person to begin developing the area that now includes now Brooklyn. Tibbett's first successful sale of land was to the Oregon Central Railroad in 1868 (Harrison, McKinney, Feldman, Galantha \& Hamlin, 1991, p. 9). The railroad was a crucial catalyst to development in this area. By the late 1890s, the neighborhood consisted of two large employers, the Inman-Poulsen Lumber Mill and the Southern Pacific rail yards and shops (Harrison, McKinney, Feldman, Galantha \& Hamlin, 1991, p. 11). The mill (the largest sawmill in Oregon at the time) was Brooklyn's economic link to the Willamette River. Many of those employed by these two firms were German and Scandinavian immigrants. For convenience, they lived near their place of work.

The transportation of goods and people has always been a defining characteristic of the Brooklyn neighborhood. By 1892, the neighborhood was fully integrated into Portland's streetcar network. The first rail line went down Southeast Milwaukee Avenue (the main commercial corridor of the neighborhood today) down to what is now the Sellwood area. Eventually, Brooklyn became home to a large streetcar shop at Southeast 
Center Street and Southeast $17^{\text {th }}$ Avenue. ${ }^{16}$ Today, Brooklyn is still a hub for railroad shipping and transportation. Like the Sunnyside neighborhood, it too has lost the streetcars that once passed through the neighborhood. However, Brooklyn will soon have two major light rail stations coming to the neighborhood along Southeast $17^{\text {th }}$ Avenue beginning in 2015. This line will provide easy and quick access to Downtown Portland and the Milwaukee.

Public transit was not the only form of transportation that has defined the Brooklyn neighborhood. In the 1926, Multnomah County built the Ross Island Bridge. The bridge head was located in the heart of the Brooklyn neighborhood. This, and the expansion of Southeast Powell Boulevard that feeds onto the bridge, was devastating to Brooklyn and its residents (Harrison, McKinney, Feldman, Galantha \& Hamlin, 1991, p. 16). To make way for the bridge, many houses and commercial properties were demolished. The bridge and the expanded boulevard dissected the neighborhood into a northern and southern section. Once bordering Southeast Division Street, the northern part of Brooklyn began to deteriorate, and many houses were condemned to make way for industrial uses. Eventually this division led to the redistricting of the neighborhood, which resulted in its northern section being transferred into the neighboring HosfordAbernathy neighborhood (Harrison, McKinney, Feldman, Galantha \& Hamlin, 1991, p. 16).

${ }^{16}$ Interestingly, Brooklyn remains a center for public transportation. Where the old streetcar shop once was is now home to one of Southeast Portland's Tri-Met bus depots as well as housing Tri-Met's administrative offices. 
Brooklyn residents have historically been connected to the Willamette River, both physically and culturally. Ross Island, a large island located in the middle of the Willamette River, has had close ties to the neighborhood and is currently within in the neighborhood boundaries. In the 1910s, the island was a favorite gathering place for residents during the summer months. The island, originally a cow pasture for Mr. Sherry Ross's farm, had become an unofficial park and picnic area for boaters (Harrison, McKinney, Feldman, Galantha \& Hamlin, 1991, p. 16). At the turn of the $20^{\text {th }}$ century, Ross Island was home to Bundy's Pier, an enclosed swimming and picnic area were popular attractions (Harrison, McKinney, Feldman, Galantha \& Hamlin, 1991, p. 16). The Great Depression was a challenging time for the Brooklyn neighborhood, both for its residents and the built environment. In 1937, Highway 99E (also known as Mcloughlin Boulevard) was built, effectively ending access to the Willamette River to neighborhood residents (Harrison, McKinney, Feldman, Galantha \& Hamlin, 1991, p. 18).

During World War II, Brooklyn experienced a boom in population from the wartime era ship building in the Portland area. The older homes in the neighborhood were converted into multi-family units to accommodate the booming population (Harrison, McKinney, Feldman, Galantha \& Hamlin, 1991, p. 18). This population boom was short lived however. After the war, Brooklyn declined once again. During this time, the InmanPoulson sawmill also closed, leaving many living in the neighborhood without employment. Brooklyn's rail industry also saw a decline during this period, mainly due to the switching from steam to diesel powered locomotives (Harrison, McKinney, Feldman, Galantha \& Hamlin, 1991, p. 18). 
During the 1960s, owner-occupied homes continued to be turned into rental units, while at the same time many of the local businesses in the area began to shut their doors. In 1962, neighborhood citizens rallied together to form the Brooklyn Action Corps (BAC), a neighborhood organization that hoped to turn the neighborhood around (Harrison, McKinney, Feldman, Galantha \& Hamlin, 1991, p. 19). The BAC has accomplished many things within the neighborhood since its inception. In the late 1970s, the BAC focused its attention on retaining the Brooklyn School as a neighborhood institution (Harrison, McKinney, Feldman, Galantha \& Hamlin, 1991, p. 19). The Brooklyn school (now in a different location than its wooden predecessor) remains an anchor for the community.

\section{Geographic Sections of Brooklyn}

Unlike Sunnyside, Brooklyn has a number of fairly unique geographic areas that make up the neighborhood. This is mainly due to the splitting up of the neighborhood overtime by railroad infrastructure and highways. Each area has its own unique identity, making it difficult for the neighborhood to have own single collective identity. The first geographic area is surrounding McLoughlin Boulevard and Ross Island. As stated earlier, Mcloughlin Boulevard acts as a barrier, separating Brooklyn from the Willamette River. There is a small strip of land between the road and the river, which contains the undeveloped Haig Park. The park is frequented by cyclists and pedestrians during the summer months, but it is not connected to the neighborhood. Also, in this area is Ross Island. The island remains in the neighborhood boundaries, but other than traveling by boat, there is no access to the mainland neighborhood. Access to the river and the island 
remains a high priority for the BAC, and many proposals have surfaced over the years to improve access, however, there are no current plans calling for this.

Benedict Heights is another unique geographic area of the Brooklyn neighborhood. Sandwiched between McLoughlin and Powell Boulevards, the Benedict Heights area contains some of the oldest houses in the neighborhood (Harrison, McKinney, Feldman, Galantha \& Hamlin, 1991, p. 25). The Poulsen House, a magnificent Queen Anne home built in 1892 is Brooklyn’s most famous residence. It sits high above the junction of McLoughlin and Powell Boulevards. ${ }^{17}$ The Benedict Heights area also contains Brooklyn Park, a well utilized park in the heart of the neighborhood. The park was once the site of the original Brooklyn School and today is used for leisure and sporting activities.

Milwaukie Avenue is the main commercial street in Brooklyn, and separates the Benedict Heights area from “Old Brooklyn.” There are a number of different stores, restaurants, pubs, and offices lining this road. The popular music venue, the Aladdin Theater, located at the corner of Milwaukie Avenue and Powell Boulevard, is arguably the most popular attraction in the Brooklyn neighborhood. An area known as Old Brooklyn borders Milwaukie Avenue to the east. Old Brooklyn is almost entirely residential, and contains the oldest house in Brooklyn as well as the Brooklyn School and Brooklyn School Park (Harrison, McKinney, Feldman, Galantha \& Hamlin, 1991, p. 30).

17 The Poulsen House was built by Johan Poulsen, the co-owner of the Inman-Poulsen Sawmill and is now home to businesses offices. Across Powell Boulevard once stood an identical Queen Anne home owned by Poulsen's partner, Robert Inman. The Inman house was torn down in 1956 to make way for a parking lot, which stands to this day (Haneckow, 2007). 
The final two geographic areas of Brooklyn are the areas south of Southeast Center and East Brooklyn. The Southeast center area is dominated by multifamily properties and commercial buildings. Many of the commercial buildings in this area are unkempt and vacant. The New Milwaukie light rail line currently being constructed caused a number of buildings in the area to be demolished. Once the new rail line opens in 2015, this area will be vastly different. A light rail station will not only provide residents with easy access to the downtown area, but a number of different beatification projects are planned in conjunction with the opening of the transit line.

East Brooklyn is the most distinct compared to other areas of Brooklyn. Running through the center of this area are the rail yards. The rail yards effectively cut off this part of the neighborhood from the rest of Brooklyn, where access is limited to one pedestrian overpass. A number of large commercial buildings exist in this area including Tri-Met's administrative offices and bus depot, Fred Meyer offices, and Portland General Electric. Powell Park is also located in East Brooklyn. The park is well maintained, with many trees and sporting facilities, but, its location limits its access.

\section{Brooklyn Neighborhood Plan}

Planning in the Brooklyn neighborhood has not been as intensive as it has been in Sunnyside. Unlike Sunnyside, only one plan was located. In 1991, the Brooklyn neighborhood published its neighborhood plan. Similar to Sunnyside’s plan, the Brooklyn plan acts as a blueprint for the future of the neighborhood. Part of the vision statement for the Brooklyn Neighborhood Plan states: 
"The Brooklyn neighborhood epitomizes the concept of the word “community.” The Brooklyn neighborhood vision encompasses community action that benefits both residents and businesses" (Harrison, McKinney, Feldman, Galantha \& Hamlin, 1991, p. 35).

Within in the neighborhood plan are ten different policies highlighting important aspects the people of Brooklyn found to be important. This section will highlight important aspects of each of those ten policies.

Policy 1 - Neighborhood Identity: When it comes to neighborhood identity, the Brooklyn neighborhood plan stipulates that history, railroads, ethnicities, and community defined the neighborhood at the time of its publication. The goal of this first policy is to develop a strong neighborhood identity, focusing on creating a sense of place for those who reside and visit the neighborhood (Harrison, McKinney, Feldman, Galantha \& Hamlin, 1991, p. 43). In order to achieve this goal a number of strategies are proposed. These include: establishing gateway markers, signage throughout the neighborhood identifying historic features, murals, and provide access to the Willamette River and Ross Island (Harrison, McKinney, Feldman, Galantha \& Hamlin, 1991, p. 43).

Policy 2 - Neighborhood Livability and Safety: At the time of its publication, the neighborhood plan cited poor up-keep of multifamily housing, drug and traffic problems, and a general concern for safety amongst its residents (Harrison, McKinney, Feldman, Galantha \& Hamlin, 1991, p. 48-49). The goal of this policy was to "nurture and sustain a vibrant, safe, diverse, and stable community" 
(Harrison, McKinney, Feldman, Galantha \& Hamlin, 1991, p. 49). To achieve this goal, a number of objectives are outlined, including: attracting businesses to the neighborhood, revitalizing the Aladdin Theater, expanding safety measures, reporting homeless encampments, and working with landlords to clean up rental properties (Harrison, McKinney, Feldman, Galantha \& Hamlin, 1991, p. 49).

Policy 3 - Historic Preservation: The historic character of the Brooklyn neighborhood is something that its residents do seem to identify with. The goal of this policy was to identify and manage the neighborhood's historic landscape (Harrison, McKinney, Feldman, Galantha \& Hamlin, 1991, p. 49). A number of objectives are mentioned in order to accomplish this goal. These objectives include: thoroughly recording the neighborhoods history, creating a design review committee and neighborhood style guidelines, placing plaques and interpretive signage throughout the neighborhood, and promoting its rail history through various means (Harrison, McKinney, Feldman, Galantha \& Hamlin, 1991, p. 5657). The Brooklyn neighborhood basically hoped to "market” itself as historic.

Policy 4 - Housing: Stabilizing and improving Brooklyn's existing housing stock is cited as being vital to increasing the livability of the neighborhood (Harrison, McKinney, Feldman, Galantha \& Hamlin, 1991, p. 60). Objectives to improve Brooklyn's housing stock included: encouraging residents and property owners to maintain their properties (specifically rental units), encouraging preservation, and restoration of older housing stock, ensuring equal access to housing for all socio- 
demographic levels, and promoting residential development on vacant lots (Harrison, McKinney, Feldman, Galantha \& Hamlin, 1991, p. 62).

Policy 5 - Land Use: The Brooklyn neighborhood has many types of land uses (compared to Sunnyside). Large commercial and light industrial take up a large portion of the neighborhood. This development is surrounded by pockets of residential areas. Objectives for this policy included: encouraging buffers between residential and commercial / industrial development, increasing density, and encouraging nonconforming businesses to relocate.

> Policy 6 - Gathering Places: Gathering places are historically significant in the Brooklyn neighborhood, but are noticeably lacking today. At one time, a large gathering place existed at the intersection of Powell Boulevard and Milwaukie Avenue. Before the construction of the Ross Island Bridge, this was the heart of the neighborhood, complete with a fountain and a produce market (Harrison, McKinney, Feldman, Galantha \& Hamlin, 1991, p. 72). The goal was to restore some of the lost gathering places in the neighborhood. Objectives included: reestablish a link to the Willamette River and Ross Island, creating pedestrian and bicycle routes between parks and other open spaces, supporting the creation of "pocket parks" within the neighborhood, and advocating for a community center.

Policy 7 - Transportation: Brooklyn has had a challenging relationship with transportation infrastructure over the years. Before the being dissected by roads and bridges, Brooklyn was a walkable neighborhood, with easy access to downtown via streetcars. The Brooklyn plan hopes to reestablish Brooklyn as 
being a bike and pedestrian friendly place, with access to downtown via light rail. Some of the objectives of this policy include: discouraging freight traffic on residential streets, supporting a light rail alignment that includes a station in the neighborhood, increasing use of transit use by neighborhood residents, improving pedestrian and bicycle infrastructure in the neighborhood, and promoting improved pedestrian connections across Powell Boulevard (Harrison, McKinney, Feldman, Galantha \& Hamlin, 1991, p. p84-86).

Policy 8 - Business and Industry: The main goal for this policy is to improve the attractiveness of the neighborhood to business and industry while at the same time maintaining and improving neighborhood livability (Harrison, McKinney, Feldman, Galantha \& Hamlin, 1991, p. p89). Objectives for this policy included: insuring business and industrial uses do not impact livability, encouraging businesses to improve their appearances, and maintaining communication between businesses and the neighborhood residents (Harrison, McKinney, Feldman, Galantha \& Hamlin, 1991, p. p89).

> Policy 9 - Milwaukee Avenue: Milwaukee Avenue bisects the Brooklyn neighborhood and is its only commercial district. Focusing attention on this section of the neighborhood can have tremendous benefits to the overall livability and vitality of the neighborhood. This policy stipulates the recreation of Milwaukee Avenue into a lively, pedestrian-oriented area with a mix of commercial and residential uses (Harrison, McKinney, Feldman, Galantha \& Hamlin, 1991, p. 93). Policy objectives include: encouraging mixed use 
development in the area, promoting Milwaukie Avenue as a pedestrian shopping district, promoting a theme of 'international' cuisine in stores and restaurants, and lowering traffic speeds to be more conducive for pedestrian activity (Harrison, McKinney, Feldman, Galantha \& Hamlin, 1991, p. 94).

Policy 10 - East of Seventeenth Avenue: The area east of $17^{\text {th }}$ Avenue is mostly cut off from the rest of the neighborhood. Large office buildings and industrial warehouses dominate this area, and a small enclave of residential units is separated from Brooklyn by this development. The goal of this policy is to maintain the area as an industrial, manufacturing, and distribution center, while at the same time minimizing the impact to its residential areas (Harrison, McKinney, Feldman, Galantha \& Hamlin, 1991, p. 96). Objectives include: promoting communication between residents and industrial neighbors, encouraging landscaping in the neighborhood that provides a buffer between residences and businesses, and encouraging cooperation between businesses and the Brooklyn Business Association (Harrison, McKinney, Feldman, Galantha \& Hamlin, 1991, p. 97).

Figure 4 is a map of the Brooklyn neighborhood that was included in the Brooklyn Plan. This map highlights some of the features discussed above in the neighborhood policies. 


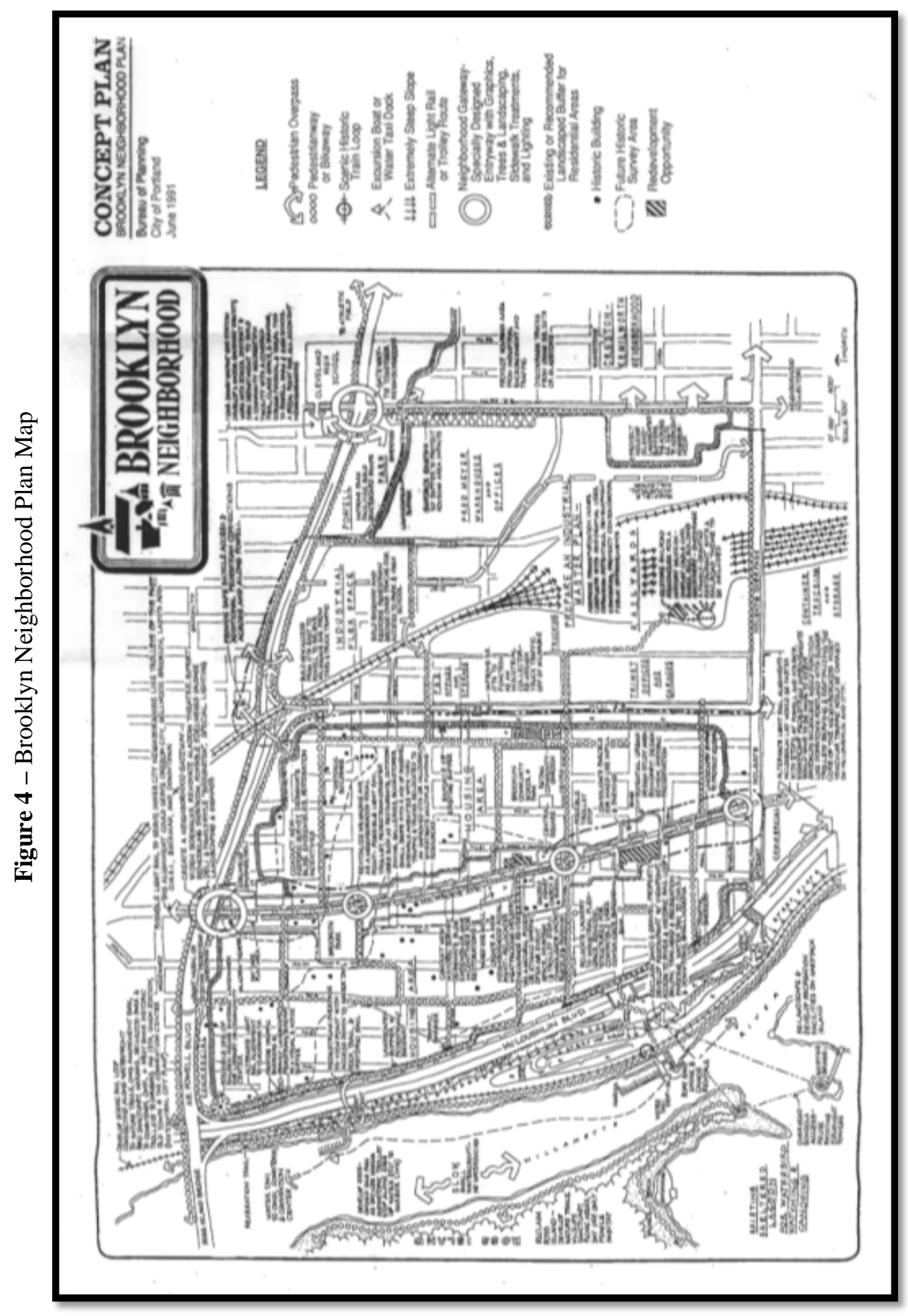




\section{Chapter 3: Literature Review}

This chapter provides an overview of the literature reviewed for this research.

Literature was selected based on the topic areas covered in the study's conceptual model. The literature review is divided into two main sections: 1) the neighborhood and 2) the household. Within each of these sections, I discuss the various aspects that can influence household sustainability, the unit of analysis for this study.

\section{The Neighborhood}

The neighborhood is an important factor to producing sustainable, low-energy lifestyles. First, it is important to ask: what is a neighborhood? Park and Burgess arguably established the foundation for urban sociology by defining local communities as "natural areas" that developed because of competition between population groups for affordable housing and businesses seeking land (Park et. al., 1925). According to this view, neighborhoods can be seen as subsets of a larger community, a collection of both people and institutions that occupy a spatially defined area influenced by ecological, cultural, and political forces (Park 1916, 147-154). Of course not all neighborhoods would be expected to have the same effects on their residents; neighborhood range in size, diversity, and identity. Some neighborhoods do have a unique advantage of fostering sustainable behaviors, however, because of their relatively small size, compared to a city or even a region. There have been very few research studies that specifically focus on how the neighborhood could influence household sustainability, specifically in terms of energy consumption. 
One way to understand energy consumption at a neighborhood level is to examine its metabolism or energy flows. Metabolism quantifies flow and stocks of water, energy, materials, and nutrients/biomass for urban systems (Codoban and Kennedy 2008, 21). Understanding the metabolism of a neighborhood in terms of energy flows is an important aspect of designing sustainable neighborhoods. Codoban and Kennedy (2008) discovered that on a per-capita basis apartment buildings were more energy efficient than houses in a study of neighborhoods in Toronto, Canada (Codoban and Kennedy 2008, 29). Older housing stock was also found to consume more energy than newer homes. Additionally, it was found that the further a neighborhood was away from the downtown center, the higher the transportation energy consumption (ibid).

Forest and Ade (2001) argue that the neighborhood, as an arena of socialization, is still important, despite many claims that the neighborhood is no longer a useful unit of analysis. They do acknowledge that 'neighborhoods' generally are no longer bounded by typical neighborhood boundaries, but now consist of many overlapping social networks, making them difficult to study. Generally within neighborhoods weak social ties dominate. For example, the connections made with neighbors by borrowing tools or through mundane, day-to-day street corner conversations. Borrowing from Jane Jacobs, Forest and Ade stress that these types of mundane interactions increase the social cohesion within neighborhoods, especially those which are spatially dense and contain mixed-use development. Additionally, since traditional social institutions have been declining, the neighborhood is now in a unique position to fill these societal gaps. Forest and Ade ask: "does the neighborhood become more important as an arena which 
citizenship is attained or experienced and in which personal and shared identities are created and maintained?” (Forest and Ade, (2001) 2128).

\section{Place Identity and Sense of Place}

This research seeks to better understand how neighborhood identity influences household energy consumption. Place identity is an important to consider in this research, because it can affect the presence and degree of neighborhood cohesion and social capital. Place identity can be thought of as the intersection between the built environment and a person's identity (Valera and Guardia, 2002). These 'feelings' we get about the spaces we inhabit can be referred to more broadly as our sense of place. Our sense of place is formed from a coalescence of our entire collective and individual experiences in that place, and the place's history, its design, what is present, and what is not. Some places stand out to us more than others. These places stand out to us because they influence us in some way. The uniqueness between places helps us to differentiate those places from each other. This process can be described as othering. For instance, although both on the American east coast, the feeling we get when being in New York City is very different than what we feel in Savannah, Georgia. In the broadest extent, this sense of belonging is also seen at the national level, with nationalistic pride and nationalism.

\section{Place Attachment}

Place attachment can be described as the affective link that people establish with specific environments, where they have a propensity to remain, and where they feel comfortable and safe (Hidalgo and Hernadez, 2001). Place attachment is a multidimensional construct that encompasses people, processes, and places (both social 
and physical characteristics). Familiar places, like homes, neighborhoods, or cities, may foster a particular 'sense of belonging' or 'attachment' in its inhabitants (Valera and Guardia 2002, 55). There is a number of different terms can be used when describing or understanding this phenomenon: topophilia (the love of a place), community sentiment (a community's beliefs), sense of community (how we experience community), and community identity (the collective traditions, values, and norms of the community). Hidalgo and Hernadez determined that scale plays a significant role in what type, and to what extent, place attachment exists. For example, they found that social attachment was stronger at the neighborhood level and physical characteristics of place were stronger at the city level (Hidalgo and Hernadez, 2001).

Rollero and Piccoli (2010) contend that place identity and place attachment are closely linked, but should be evaluated differently. They argue that place attachment is the emotional bound between places, whereas place identity is more cognitively based, and is determined by how strongly a person feels that they are a 'member' or part of that place (Rollero and Piccoli, 2010, pg. 199). To support this claim, Rollero and Piccoli found through a study of residents in Turin, Italy, that place identity and attachment were distinct constructs, however they were highly correlated. They also found that gender and education played a role in how attached individuals were to a place, with women and less-educated individuals being more likely to have higher place attachment than educated men. Another interesting finding Rollero and Piccoli made was that length of residence did not directly affect attachment, rather it indirectly influenced attachment 
through the number of relationships one has in the place (i.e., the longer one is in a place the more likely they are to have known people in that place, and vise-versa).

\section{Neighborhood Identity and Sustainable Behavior}

The connection between place attachment and environmental behavior has not been widely researched. However, there have been a few studies that indicate there may be some connection between the two. As stated, my research seeks to determine to what extent someone's neighborhood identity predicts their adherence (or not) to sustainable behaviors (such as recycling, using alternative modes of transportation, or decreasing household energy and water use).

The field of environmental psychology has produced some studies on understanding the connection between place identity and pro-environmental sustainable behavior. A 2001 study suggested that the presence and degree of place identity and place attachment can, in fact, predict environmental concern (Vorkinn and Riese 2001). Some research on 'actual' behavior (as opposed to behavioral intention) has found that a greater sense of place attachment results in more pro-environmental behavior (Vaske and Kobrin, 2001; Clayton, 2003; Scannell and Gifford 2010). Nevertheless, other studies have found that high levels of place attachment can have weak or even negative relationships to pro-environmental behavior (Uzzell et al., 2002). This contradictory evidence highlights the need for further investigation into the connection between place identity and sustainable behavior. 


\section{Neighborhood Organizations}

Neighborhood organizations allow for residents to come together collectively, learn from each other, voice concerns, and reinforce neighborhood identities. There has been a recent push by Southeast Uplift, a non-profit organization in Portland, to establish neighborhood 'sustainability committees.' A sustainability committee is a venue for "providing information to neighbors and creating a space where people can talk and share ideas” (SE Uplift 2011). As a result, many neighborhoods in Southeast Portland have formed sustainability committees, including the Sunnyside neighborhood. ${ }^{18}$

Looking at formal social structures within neighborhoods, like associations and committees, can help to form a better understanding of what the neighborhood residents' value. Warren and Clifton (1975) found that conservation and behavioral change were more common in 'integrated' neighborhoods. In other words, neighborhoods with strong social contacts, membership of organizations, and outside contacts, were more likely to create social structures that foster energy conservation. ${ }^{19}$ Research in West Auckland, New Zealand found that there was a connection between neighborhood sustainability programs and the sustainable behaviors of residents (Lietz et. al., 2008). It was found that active participation in neighborhoods through both public and private sectors produced more opportunities for greater sustainability.

\footnotetext{
18 Presently, the Brooklyn Neighborhood has not formed a sustainability committee.

19 This research was conducted during the United States energy crisis in the 1970s, and thus may be situation-specific.
} 


\section{Spatial Structure}

There are a number of aspects of the urban spatial structure that can encourage (or discourage) residents to live sustainable lifestyles. A neighborhood's compactness and density have both been shown to foster sustainable lifestyles (Jabareen, 2006). Compactness refers to the contiguity and connectivity of urban areas and the containment of sprawl (Jabareen 2006, 39). Compactness often minimizes the transport needed of energy, water, materials, products, and people and thus fosters more sustainable systems (Jabareen 2006, 39).

Density is the ratio of houses and people to land area (Jabareen 2006, 46). Once density reaches a certain threshold, the number of people within a given area becomes sufficient to generate the interactions necessary to establish urban functions or activities (such as neighborhood associations or other community outreach programs) that facilitate social cohesion (Jabareen 2006, 41). Suburban neighborhoods often have low social cohesion because their low density diminishes residents’ ability to interact with one another.

A neighborhoods diversity and design also contribute to sustainable urban lifestyles. Diversity and proximity are key components to social sustainability. Jane Jacobs popularized the diversity dimension of sustainability in the 1960s and 70s (Jabareen 2006, 42). Without density and diversity in neighborhoods, there is risk of polarization and decline because people do not come in contact with other people on a daily basis. Jacobs has said: 
"in dense, diversified city areas, people still walk, an activity that is impractical in the suburbs and in most grey areas. The more intensely various and close-grained the diversity in an area, the more walking. Even people who come into a lively, diverse area from outside, whether by car or public transportation, walk when they get there" (Jacobs, 230).

Thus, diversity of the built environment (i.e., mixed use development, multiple transportation options, and public spaces) is a key component to creating sustainable, low-energy neighborhoods because people are able to walk around the neighborhood and interact with similar and dissimilar people.

\section{Transportation Infrastructure}

A key feature of being able to lead a more sustainable lifestyle is having easy access to a transportation infrastructure that promotes alternatives to personal transportation (e.g., cycling, public transportation, and walking). The availability of transportation choices like bicycling, public transportation, and walking, can have a large impact on how sustainable a neighborhood is or is not. For instance, if a neighborhood has a concentration of daily conveniences (i.e. grocery stores, restaurants, post office, etc.) then residents (even those who are less able-bodied) are more likely to walk or ride a bike to their destination than they are to drive because at some point driving becomes more inconvenient than convenient. This easy access to daily amenities, combined with access to affordable and convenient public transportation, also increases the chance of households become completely car-free.

Transportation in the United States accounts for 27 percent of all energy used, of which, 61 percent is used by personal automobiles (Transportation Energy Data Book 2010, 19). The personal transportation sector in the U.S. not only consumes large 
amounts of fossil fuels (28.2 quadrillion Btu in 2009), but is also one of the largest contributors to $\mathrm{CO}_{2}$ emissions (Davis et. al., 2010). Furthermore, harmful automotive emissions make up between 50 to 90 percent of all air pollution in urban areas (HowStuffWorks, 2011). Additionally, over 30 thousand people die annually as a result of car related accidents (NHTSA National Statistics, 2011). Clearly, transportation is an area that more attention needs to be paid, not only because of the environmental and health impacts, but also because of the cost of human lives and the social and physical impact it has on the wellbeing of communities.

The American built environment has fostered a rather profound dependence on the automobile. Transportation mode-choice is a complex and often misunderstood process. Conventional strategies for solving problems involving personal automobile use are approaching the limits of their effectiveness (Reutter and Reutter 1996, 32). The various motivations, rationales, and functions that inform these behaviors must be more fully understood. There have been several theories and perspectives employed to better understand why automobiles are chosen over other modes of transportation. One example is discrete choice theory, which assumes that when individuals consider various travel modes they will choose the transport mode that provides them with the most utility or relative advantage (Uncles 1987). According to this theory, a neighborhood that has a large number of choices of transportation accessible to its residents would be expected to beneficial in getting people to use alternative forms of transportation. Of course, the choice of using a personal automobile over another mode such as public transportation or bicycling can be explained because it simply has more utility. 


\section{The Household}

Neighborhoods are made up of a collection of households; therefore, research on household energy use is important to review. The unit of analysis for this research is the household because of the amount of energy that is consumed at this level. Households constitute a key target group because households are major contributors to the emission of greenhouse gas (GHGs). Behaviors related to household energy conservation can be divided into two categories: efficiency and curtailment behaviors (Abrahamse et. al. 2010, 274). Households can vary drastically in their energy usage; however, it is important to understand what a typical household's energy usage is. On average, $45 \%$ of end-use energy in households is used for space heating; followed by water heating (18\%), space cooling (9\%), lighting (6\%), electronics (5\%), cooking/refrigeration (8\%), and other usage (9\%) (Residential Sector, 2010). Energy efficiency upgrades (such as replacing aging appliances, insulating/sealing the building shell, and replacing windows) can have a large impact on the amount energy a household uses.

A large part of energy consumption used directly by households is in maintaining a ‘comfortable’ indoor climate (Gram-Hanssen 2010, 175). By lowering heating temperatures by just $4^{\circ}$ Fahrenheit during the winter heating months can save an estimated $706 \mathrm{CO}_{2}$ pounds per year for a typical single-family home (Heede 2002). These changes are difficult to achieve because these behaviors are habitual and routine. Routines and habits are difficult barriers to overcome with any type of behavioral change (Lutzenhiser 2002, 349) because complex social and cultural structures are often established in early childhood and are thus unconsciously embedded into all our actions 
(Gram-Hanssen 2010, 176). To make sustainable behaviors routine and habitual to those who do not already practice them requires dramatic changes to their underlying attitudes and belief systems which could also be influenced by other variables (i.e., politics, cultural norms, social status, etc.).

Another key aspect of sustainability that is covered in this research is household water usage. In 2005, 410,000 million gallons of water per-day was used in the U.S. (Kenny et. al., 2009). Of that usage, $11 \%$ was for 'public-supply' and of that $58 \%$ was used for residential use (25.6 million gallons per day) (Kenny et. al., 2009). Relatively simple technologies and behavioral changes can limit residential water use. Installing faucet aerators, using rainwater catchment for gray water, and simply limiting the amount of time showering, can have large impacts on total water usage. As the climate changes due to increases in GHGs in the atmosphere, water usage will most likely continue to increase, especially in warmer, dryer, climates in the Southwest U.S.

A study was conducted in Portland, Oregon in 2012 to determine the effects of increased temperatures on residential water consumption. Researchers found that just a $2^{\circ}$ Celsius increase of overall temperature in the region would require an additional 1.8 million gallons of water per-day (Shandas, Rao \& McSharry-McGrath, 2012). Previous research has shown that social marketing can be used to decrease water usage at the household level. A study conducted in Toronto, Ontario in 1997 suggests that community-based social marketing can have a large impact on water usage. This study reviled a decrease of $54 \%$ in water-usage could be achieved by implementing simple community interventions (McKenzie-Mohr, 2000). The study also pointed out that 
information-based social-marketing was not as effective as personal face-to-face interventions (McKenzie-Mohr, 2000).

\section{Attitudes and Beliefs}

One key aspect that is expected to have a direct effect on how households use energy is resident's attitudes and beliefs in regards to energy conservation and ecoconsciousness. There has been some research done on how the connection between proenvironmental attitudes and concern about energy-related environmental issues. Brandon and Lewis (1999) found that there is disagreement among researchers in how attitudes and beliefs affect energy usage. Seligman and Kriss (1979) found that over half of the variance in energy use could be explained by attitudes towards energy conservation. Lutzenhiser (1993) found similar contention between researchers about whether or not pro-environmental and conservation attitudes and beliefs actually equate to meaningful reductions in energy usage. Individuals' notion of comfort (in terms of temperature, lighting, etc.) has been found to play a role in mitigating between attitudes and beliefs and energy use reduction (Lutzenhiser 1993, 252). Clearly, using attitudes and beliefs to explain energy consumption is a difficult and questioned area of energy research. Nevertheless, I believe that it is an important aspect to acknowledge in this research because of the potential ties to neighborhood identity and the attitudes and beliefs of residents.

There are a number of social-psychological models that exist to explain how attitudes and beliefs lead to behaviors. A widely used model in the field of behavioralenergy research is the Icek Ajzen's (1991) Theory of Planned Behavior (TPB) model. 
The TPB model stipulates that individual behavior is influenced by behavioral intentions where behavioral intentions are a function of an individual's attitude toward a given behavior, the subjective norms surrounding the performance of the behavior, and the individual's perceived behavioral control. Attitude toward a behavior is based upon the individual's positive or negative feelings about performing a behavior. It is determined through an assessment of one's beliefs regarding the consequences arising from a behavior and an evaluation of the desirability of these consequences. The subjective norm part of the model is the individual's perception of whether people important to the individual think the behavior should or should not be performed. The contribution of the opinion of any given referent is weighted by the motivation that an individual has to comply with the wishes of that referent. Perceived behavioral control is defined as one's perception of the difficulty of performing a behavior. The TPB model views the control that people have over their behavior as ranging from behaviors that are easily performed to those requiring considerable effort, resources, etc.

\section{Social Norms and Social Capital}

Social norms play an integral role in how much individuals and households consume energy. Allcott (2011) examined the effectiveness of non-cost based energy use reduction measures in Canada among 600,000 households. Traditionally, economist and policy makers have focused on relative prices as the primary force driving energy demand, and thus have focused on programs that pay close attention to price, such as time-of-day energy billing (Allcott 2011, 1). Programs based around social norms and other non-price energy conservations programs are increasingly gain traction in the 
energy field. Allcott's study, with the assistance of OPOWER, provided participant households feedback based on their energy consumption compared to 100 similar households in their neighborhood. The hypothesis, based on social norm theory, was that seeing similar household's energy consumption would cause people to reduce energy consumption. Allcott found that this was indeed the case. On average, households that participated in the program reduced their energy consumption by $2 \%$. This may seem to be a rather small percentage, but according to Allcott, is comparative to what is seen with price-based energy reduction incentives. This has implications on neighborhood energy consumption, because a socially cohesive neighborhood that is sustainably-minded would be expected to exhibit similar patterns of adhering to social norms.

It is generally accepted that technology and behavior are barriers to energy efficiency implementation in the domestic sector (POST 2005, Lutzenhiser 1993). Energy behavior, however, is fairly difficult to predict in real-world contexts. There can be fairly large discrepancies between what people say they do or will do, and what they actually do. Income is often viewed as an aspect that can predict the probability of adopting new technologies to upgrade the energy efficiency of households. Lutzenhiser (2003) found that households with similar incomes and types of housing often show considerable differences in energy use. This suggests that the linkages between income and efficiency are superficial at best. Wilhite et al. (2000) argue that energy consumers are actually less concerned with the actual cost of energy, but instead are more concerned with convince and comfort. 
Social capital may be an appropriate and useful tool to examine how social norms, social networks and the associate levels of trust and reciprocity, interact with variables that affect household energy use, with focus on influences that underlie social interactions between people, technology, and their environment (McMichael 2007, 1898). The term social capital is a somewhat contested topic, not necessarily in the idea, but in how to define it. The term was popularized in the 1980s and 1990s by a number of social scientists, such as Pierre Bourdieu and Robert Putnam. There are numerous definitions used to define social capital. Pierre Bourdieu is often credited with initial development of the theory of social capital. To Bourdieu, social capital is:

"the aggregate of the actual or potential resources which are linked to possession of a durable network of more or less institutionalized relationships of mutual acquaintance and recognition or in other words, to membership in a group which provides each of its members with the backing of the collectivity-owned capital, a credential which entitles them to credit, in the various senses of the word" $(1986,249)$.

Broadly put, social capital refers to the social resources available through networks, social norms, and associated levels of trust and reciprocity (McMichael 2007, 1889).

Research on the linkages between energy consumption (a proxy to sustainability) and social capital are fairly limited. One proxy measure for sustainability is degree of environmental concern. In 1996 the World Bank established the Social Capital Initiative to assess social capital's impact on environment concern (Grootaert and Van Bastelaer, 2002). A number of studies were conducted which concluded that there were three proxies for social capital: 1) membership in local associations and networks, 2) indicators of trust and adherence to norms, and 3) and an indicator of collective action (Grootaert and Van Bastelaer, 2002, 30). 
Megan McMichael (2007) conducted one of the only studies that have examined neighborhoods, social capital, and household energy-use. McMichael's research focused on whether or not social capital and household energy consumption are related, and if so, how this association may affect energy efficiency. McMichael references a 2004 World Bank Report that stressed the importance of social capital as an asset to environmental protection because it has the potential to ease the burden of disseminating information. McMichael argues that examining energy consumption from a social capital perspective could offer new insights into the social underpinnings that influence household energy consumption.

Kevin Leyden (2003) conducted a survey of 750 residents in Galway, Ireland to better understand how neighborhood design can enable or encourage social ties or community connections. Neighborhoods that are designed to foster greater interaction between residents (i.e., density, mixed use, pedestrian and bicycle infrastructure) will enhance social capital. Leyden's findings suggest, not surprisingly, that living in a more walkable neighborhood encourages social interaction, and as the walkability increase so too does the likeliness of residents knowing their neighbors. These mundane interactions build social capital and thus could be useful conduits for disseminating energy reduction information.

\section{Socio-Economic Factors}

The socio-economic factors of energy consumption are intricate and complex. Throughout modern history, growth in energy use has been seen as an indicator of social and economic progress (Lutzenhiser 2002, 347). Of course, this mind set has large 
implications for sustainability programs and should be addressed, but these issues are beyond the scope of this research. Instead, socio-economic factors that affect individual household consumption will be analyzed more closely. Kasulis et. al. (1981) found that lower income households are very likely to be using lower amounts of energy than their higher income counterparts and most likely would not have the ability to lower their consumption any further. Of course, higher income households tend to use more 'indirect energy' that is embodied in the various goods and services that are purchased by these households (Lutzenhiser 1993, 271).

Joerges and Muller (1983) found that many households may not have the ability to, or incentive to upgrade their homes. Therefore, rental units are of particular interest in this study since there will likely be a number of these types of households represented in the sample. Homeowners on the other hand will mostly likely be more willing to preform efficiency upgrades on their homes because of the value and potential payback that these upgrades provide. In additional the renters vs. owners dichotomy, analysis of household life-cycle, such as the composition and age of families, have been found to have an effect on heating, electricity use, energy efficiency, and types of appliances (Lutzenhiser 1993, 270). ${ }^{20}$

${ }^{20}$ Something that will not be covered in this research, but is still an important factor in energy consumption is cultural, ethnic, and social class differences in energy use. Lutzenhiser (1993 and 1992) suggests that differences between these three social aspects can offer a great deal of explanation of how individuals consume energy. 


\section{Chapter 4: Methodology}

\section{Hypotheses}

After reviewing the existing literature on residential sustainability and formulating a conceptual model, I developed eight hypotheses to be tested in this study:

1. Sunnyside residents have a more environmentally sustainable identity than Brooklyn residents.

2. Sunnyside households are more sustainable than Brooklyn households.

3. Sunnyside residents participate in neighborhood organizations and have more social contacts than Brooklyn residents.

4. Residents that 1) interact with their neighbors and 2) participate in neighborhood organizations have higher reported levels of household sustainability.

5. Sunnyside residents exhibit more environmental concern than Brooklyn residents.

6. The neighborhood that has more alternative transportation choices have more reported use of those transportation modes than the neighborhood with less alternative transportation choices.

7. Sunnyside residents are more likely to change their behaviors to be more sustainable after moving into the neighborhood than Brooklyn residents.

8. The presence of sustainable features in the neighborhood influence how sustainable its residents are. 


\section{Overview of Methodology}

This research compares two demographically similar neighborhoods in inner-SE Portland that (hypothetically) vary in their level of neighborhood identity, in order to determine how neighborhood identity affects sustainable behaviors at the household level. Data collection occurred in July and August of 2012 through a web-based survey instrument. A total of 314 surveys were completed by neighborhood residents; 169 in the Sunnyside Neighborhood and 145 in the Brooklyn Neighborhood. Questions pertained to household attitudes, beliefs, and behaviors regarding energy use, sustainability, transportation, and their perceptions of their neighborhood.

\section{Subject Recruitment}

All residents who were18 years of age or older, and lived in one of the two neighborhoods, were eligible to participate in the survey. Two subject recruitment methods were used: 1) a brief advertisement in the neighborhood newsletters and 2) doorto-door distribution of survey announcement flyers (see Appendix A). The neighborhood newsletters offer residents information about issues that are affecting their neighborhood and upcoming community events. The Sunnyside Newsletter is published monthly and distributed by hand to all households in the neighborhood. The Brooklyn neighborhood newsletter is published bi-monthly and is also distributed by hand to all households in the 
neighborhood. The advertisement for the survey was included in the July 2012 issue of each neighborhood's newsletter and distributed to households around mid- July $2012 .{ }^{21}$

Approximately two weeks after the release of the neighborhood newsletter survey announcements, I began to flyer the two neighborhoods. A 4x5 flyer contained a brief summary of the research purpose, contact information for questions or concerns, and the web survey URL (See Appendix A). Flyers were printed on a variety of colors in attempt to make the flyer "stand out" form other solicitations left at residential doors. In total 2,550 flyers (1,250 in each neighborhood) were distributed during a two week period in July and August of 2012. Since it was not possible to visit every household in the neighborhoods (because of time and cost constraints), I had to make the difficult decision to only flyer certain areas within each neighborhood. To make this selection, I analyzed neighborhood maps and chose streets throughout each neighborhood to flyer, hoping to distribute flyers fairly evenly across the geographic space. This approach allowed for all areas of the neighborhood to be represented at least somewhat.

Flyers were left on, or near household doors. Generally, flyers were placed between the doorknob and the doorframe or under the doormat to ensure that they would not blow away and be seen by residents. Flyering was generally done on weekend days, in hopes of being able to personally hand household residents the flyers when they were off work and in their yards. Approximately, five percent of the households that received flyers were given directly to a resident. When this occurred, the resident was provided with a brief verbal description of the research project and encouraged to participate.

\footnotetext{
${ }^{21}$ Since volunteers in the neighborhood distribute the newsletters, they often reach household porches at different times throughout the month, depending on volunteer availability.
} 
During the flyering a map was used to keep track of which households had been visited to ensure that no household was visited twice. The distribution of flyers in each neighborhood can be seen in Figure 5 and Figure 6 below.

Figure 5 - Map of Brooklyn Flyer Coverage

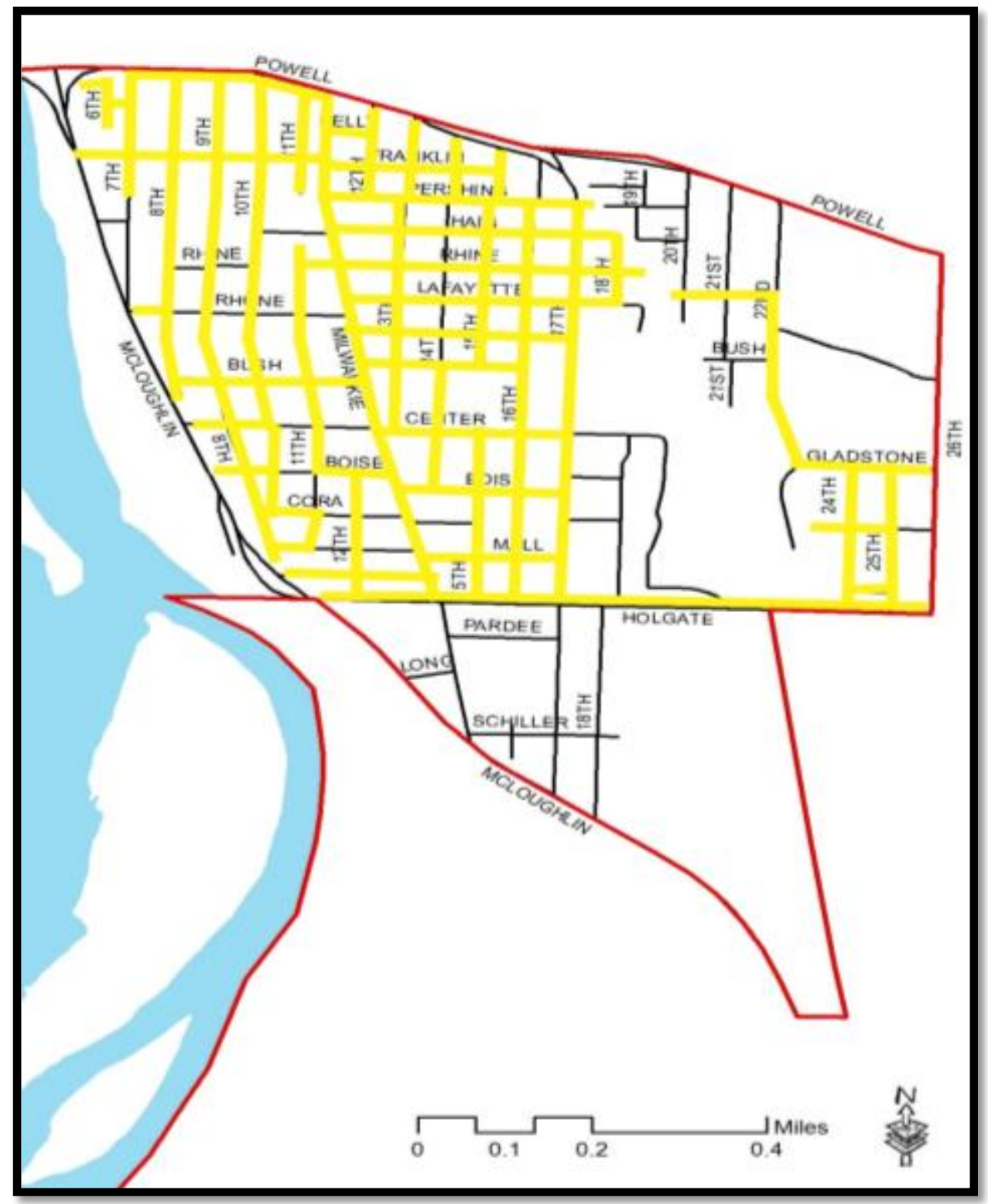




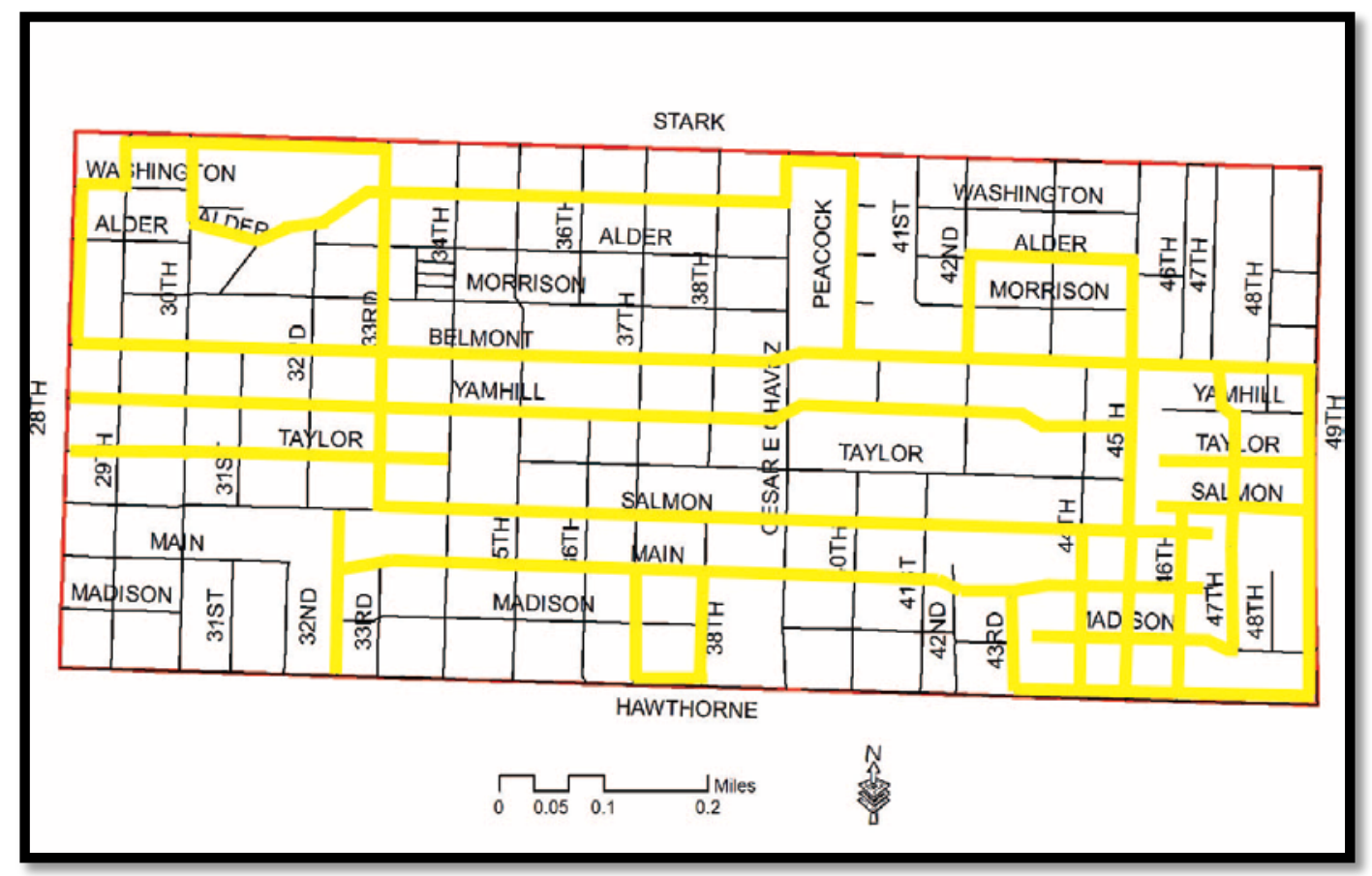

While distributing flyers in the neighborhoods, a number of apartment buildings were encountered where my assistant and I were unable to leave flyers due to restricted access. It should be noted, however, that there were relatively few (less that $10 \%$ ) of these restricted access multifamily buildings located in the two neighborhoods. The majority of multifamily housing was either large, slit-up houses with outside doors for individual units, or large apartment and condo complexes with outside doors for all units. Thus, not gaining access to restricted access buildings is expected to have a limited impact on the overall generalizability of results relating to multifamily residents in the neighborhoods. 


\section{Limitations}

Using a web-based survey instrument does have some limitations that can decrease the validity of survey findings. One specific limitation for this study is respondents who do not have access to the internet at their home. Unfortunately, due to the lack of resources, a door-to-door paper based survey component could not be administered. Thus, the generalizability of results to the two neighborhoods may be slightly diminished. Additionally, as data collection progressed, a number of potential respondents emailed and called me requesting assistance with the survey. Every attempt possible was made to assist those who were having difficulty with using the computer to access the website.

Non-response bias is also a concern in this study because this research focuses on a somewhat controversial topic. It is expected that individuals who hold proenvironmental views might be more likely to fill out the survey. Thus, a monetary incentive was offered in order to both increase the response rate for this survey and reduce non-response bias. The incentive was in the form of a \$100 Visa gift card. Each person who participated in the survey was asked if they would like to be entered into a drawing to win the gift card. Those who wished to be entered into the drawing provided either their email address or phone number. The drawing for the gift card occurred shortly after the close of the survey, and was mailed to the winning respondent.

Additional approaches were used to limit non-response bias. This included careful wording of the newsletter notice and the survey flyer. The survey flyer did not contain any verbiage indicating that they survey was about sustainability. Instead, information on 
the flyer only mentioned that the survey was about "their experiences living in the (Sunnyside/Brooklyn) neighborhood.” Since the newsletter notice was not only advertising the survey, but also informing residents about the purpose and intent, it was not possible to completely exclude the main topic of this research. However, the wording for the newsletter was personalized for each neighborhood and attempted to be clear and cordial.

\section{Questionnaire Design}

A web-based survey instrument was used to gather data at the household level for this research (See Appendix B). The survey had multiple sections that include various close-ended, multiple choice, and fill-in responses. It was divided into four sections, each focusing on different aspects of sustainability and the various aspects that are believed to influence sustainability in the neighborhood setting based on the literature reviewed. The majority of the questions were adapted from existing survey questions used in previous research. The use of existing questions will allow the results to be compared to other studies to illuminate trends (Singleton and Straits 2010, 277). Additionally, because the questions have been tested in prior research, the results are expected to have a greater degree of reliability and validity.

The first survey section was designed to gather information on residents’ perceptions of, and involvement in, their neighborhood. An important aspect of this research is to better understand how residing in a neighborhood effects a households overall sustainability. Thus, a question regarding length of residence was included to 
determine the amount of time the household residents have lived in the neighborhood. It is expected that those who have lived in the neighborhood longer will have been acculturated with the values of the neighborhood, more so than those who have just recently moved into the neighborhood. For those residents who moved into the neighborhood, a follow up question was asked to determine if they have changed their behaviors since living in the neighborhood, and what behaviors they have changed. Participation in neighborhood organizations, events, and activities are also asked about in the survey to determine level of involvement. Again, those respondents who are more involved in their neighborhood are expected to have assimilated into the culture of the neighborhood more so than those who have limited or no participation in the neighborhood.

The next few questions are designed to measure the degree of social capital and social cohesion within the two neighborhoods. Generally, measuring social constructs such as social capital and social cohesion is difficult. The survey questions are proxies which aim to gather information associated with these topics, but not directly ask about them. For example, higher rates of sharing conversations, things, and time with neighbors would suggest that there is more social cohesion in the neighborhood, and thus may indicate that there is some degree of social capital being promoted in the neighborhood. Survey questions in this section were partially adapted from the 2012 Neighborhood Life Survey which was conducted by researchers at Portland State University (Shandas, 2012).

Next, three questions asked respondents to describe their neighborhood identity, the neighborhood's level of sustainability, and their overall satisfaction with their 
neighborhood. It is important to have a clear understanding of how respondents view their neighborhood, from their own perspective and described in their own words. A question was included to measure whether or not respondents think their neighborhood is unique, compared to other neighborhoods in Portland. If respondents believe their neighborhood to be unique, a follow up, open ended question, asked the respondent to provide a brief description of what they feel makes their neighborhood unique. These responses will be thematically-coded during analysis to determine common themes and to describe how neighborhood identity is defined by residents themselves. Finally, two questions asked respondents to rate their neighborhood on its overall sustainability and their personal satisfaction with it in general. Taken together, these questions provide a more direct and subjective understanding of the neighborhoods under investigation.

The next section of the survey was designed to gather data on how sustainable households are in terms of their adherence to sustainable practices (e.g., recycling and composting practices), conservation measures (e.g., water and energy), and transportation habits (e.g., personal auto, public transit, bicycle, etc.). A series of questions was asked regarding sustainable practices and conservation measures. These questions focus on the frequency of energy and water saving behaviors and recycling and composting practices. ${ }^{22}$ More generally, this series of questions provides information on how sustainable households are in order to make comparisons between the neighborhoods.

One important indicator of an individual's willingness to reduce energy consumption is if they have completed home energy upgrades. Examples of energy

\footnotetext{
${ }^{22}$ These questions were also adapted in part from the 2012 Neighborhood Life Survey (Shandas, 2012).
} 
upgrades could include replacing old appliances, installing new windows, insulation, or solar panels. Respondents, who have completed household energy upgrades, were asked a follow up question to determine what upgrade(s) were completed. Since it is not possible to ascertain actual household energy use from households, a series of questions was asked to determine if households are "high" or "low" energy users. The first part of this series asked respondents for their typical household temperature settings during the winter and summer months. ${ }^{23}$ This was followed by questions asking what their typical natural gas and electricity bills are during the summer and winter. These questions provide general consumption data to determine if there are differences between the two neighborhoods in terms of actual energy usage.

The main purpose of the next survey section was to better understand the dynamics between the neighborhood and residents that may encourage the use of alternative modes of transportation. Transportation habits are an important aspect on how sustainable a household is, and are generally associated with the density of the built environment, close access to places where individuals need to go, and availability of alternative transportation infrastructure, such as transit stops, bike lanes, and sidewalks. Additionally, transportation represents a large portion of an individual's energy consumption. ${ }^{24}$ Survey questions were designed to gather information regarding respondent's travel behavior. For example, it is important to know if the respondent

\footnotetext{
${ }^{23}$ On average, heating and cooling accounts for 44\%of all energy used by households in 2005 (Average Expenditures by Energy End Uses, 2005). Thus, it is important to understand how residents control the climate in their homes.

${ }^{24}$ In 2010, transportation in the U.S. accounted for 28\% of all end-use energy consumption (Energy Consumption Estimates by Sector Overview, 2010).
} 
drives an automobile (and if so, how much they drive), if they bike, walk, or use public transportation. Questions for this portion of the survey were derived, in part, from a recent survey conducted in the Portland metropolitan area (Dill and Mohr, 2010).

Understanding individual's norms, values, and beliefs is an important aspect to this research. As discussed in above sections, it is often difficult to determine the influence of these social-psychological aspects in sustainable behaviors, especially related to energy use. However, it is important to determine if there are more sustainablyminded individuals in the Sunnyside Neighborhood or in the Brooklyn Neighborhood. The next series of questions asked about respondents general norms, values, and beliefs regarding nature and human activities and was adapted from a combination of existing surveys, including the New Environmental Paradigm (NEP) scale and the Residential End-Use Survey (REUS) (Pedersen, 2008).

Finally, standard demographic questions used by the U.S. Census were included. It is important to know what the household tenure is. Being an owner of a home, as opposed to a renter, is an important distinction to make in this research because renters are somewhat more limited in their ability to complete large-scale home energy efficiency upgrades or know about their energy usage (because electricity and natural gas are often included in the rent). Renters are also more likely to not pay for energy usage and may even pay a flat monthly rate for utilities. Other demographic questions asked include the respondent's income range, education level, age, employment status, and race or ethnicity. These questions were mainly used to verify that the respondents who 
participated in the survey accurately reflect to overall demographic composition of the two neighborhoods. 


\section{Chapter 5: Survey Results}

This chapter provides results from the quantitative and qualitative data analysis conducted on the survey data. The results are organized into four sections that correspond to the different research areas:

$\rightarrow$ The Neighborhood: Findings regarding neighborhood participation, community cohesion, neighborhood identity, neighborhood sustainability, and the effects of the perceived effects of the neighborhood on individual sustainability.

$\rightarrow$ The Household: Findings regarding individual household sustainability measures.

$\rightarrow$ Transportation: Findings regarding individual use of various types of transportation as well as reasons for discouraging and encouraging alternative transportation use. Maps of alternative transportation infrastructure in each neighborhood will be presented.

$\rightarrow$ Environmental Concern: This section presents findings on respondents' attitudes regarding the environment and sustainability.

$\rightarrow$ Demographics: This section provides a description of the demographic characteristics of the survey respondents compared to the demographic characteristics of the neighborhood as reported in the 2010 U.S. Census. 


\section{Engagement}

Neighborhood engagement is an important aspect of this research. A number of different questions were asked to determine the level of engagement respondents had in their neighborhood. The first question asked of respondents was if they participate in any neighborhood organizations or activities. Overall, similar trends in participation in neighborhood activities were found in both Brooklyn and Sunnyside (Table 2). Slightly less than one-third of Brooklyn residents (31\%) reported participating in neighborhood activates. Of the Brooklyn respondents who did participate in activities, 13\% reported attending other neighborhood gatherings and 15\% reported attending neighborhood association meetings. Slightly less Sunnyside residents (28\%) reported participating in neighborhood activities. Sunnyside residents reported frequenting other gatherings (14\%), neighborhood association meetings (11\%), and block parties or street fairs (11\%).

Table 2 - Participation in Neighborhood Organizations, Events, and Activities (Multiple Responses Allowed)

\begin{tabular}{|l|c|c|c|c|c|c|}
\hline \multirow{2}{*}{\multicolumn{1}{|c}{ Type of Activity }} & \multicolumn{2}{|c|}{ Brooklyn (n=142) } & Sunnyside (n=167) & \multicolumn{2}{c|}{ Total (n=309) } \\
\cline { 2 - 7 } & Count & Percent & Count & Percent & Count & Percent \\
\hline None & 98 & $69 \%$ & 120 & $72 \%$ & 218 & $71 \%$ \\
\hline Other neighborhood gatherings & 19 & $13 \%$ & 23 & $14 \%$ & 42 & $14 \%$ \\
\hline $\begin{array}{l}\text { Neighborhood association } \\
\text { meetings }\end{array}$ & 21 & $15 \%$ & 18 & $11 \%$ & 39 & $13 \%$ \\
\hline Block parties or street fairs & 4 & $3 \%$ & 19 & $11 \%$ & 23 & $7 \%$ \\
\hline $\begin{array}{l}\text { Newsletter delivery or } \\
\text { contributor }\end{array}$ & 6 & $4 \%$ & 14 & $8 \%$ & 20 & $6 \%$ \\
\hline Neighborhood clean-up & 9 & $6 \%$ & 9 & $5 \%$ & 18 & $6 \%$ \\
\hline Community gardening & 9 & $6 \%$ & 0 & $0 \%$ & 9 & $3 \%$ \\
\hline School gatherings or meetings & 5 & $4 \%$ & 4 & $2 \%$ & 9 & $3 \%$ \\
\hline
\end{tabular}

Note. Five “don’t know” responses were excluded from analysis. 
Survey participants were presented with four questions that were designed to better understand the social connections that existed within the two neighborhoods. Figure 7 through Figure 10 show the frequency of neighborhood social interactions. Overall, both neighborhoods reported fairly high rates of having conversations with their neighbors either weekly or daily. Sunnyside was slightly higher than Brooklyn in daily conversations (30\% and 36\% respectively); however, this difference was not found to be statistically significant (Figure 7).

Figure 7 - Have Conversations with Neighbors

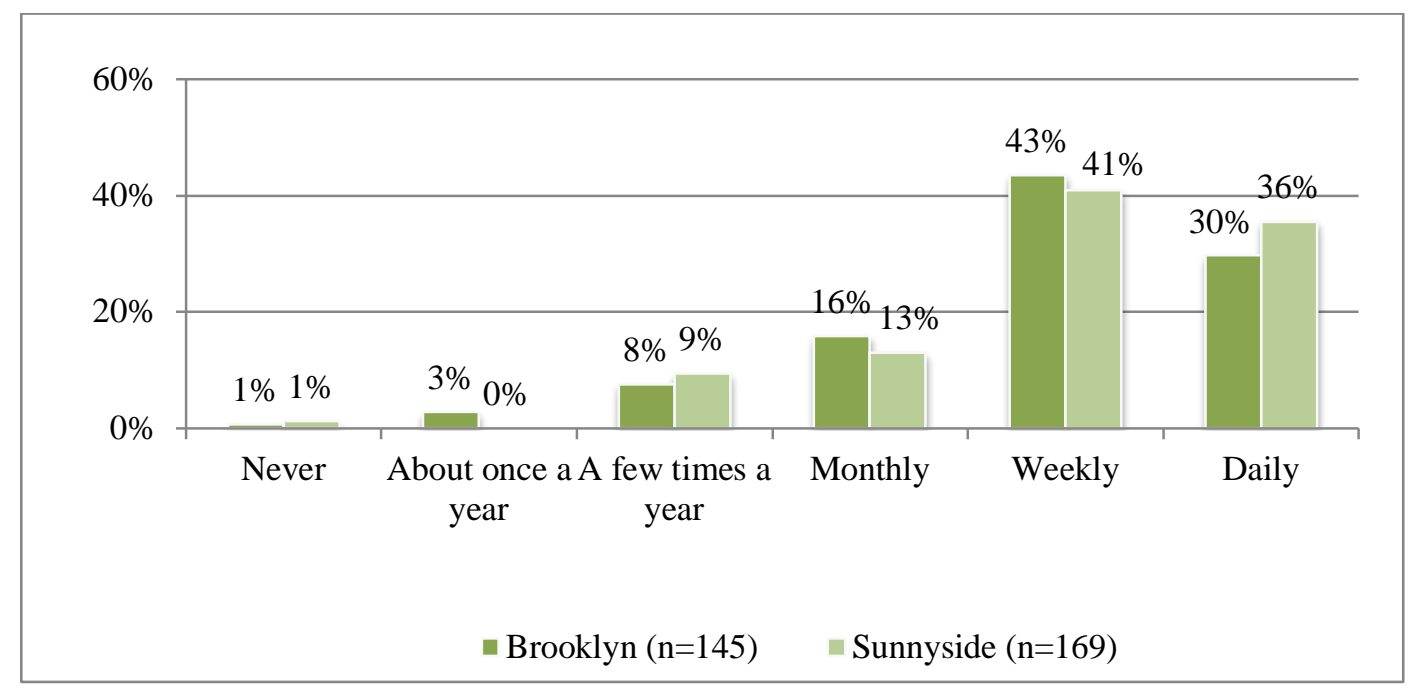

Overall, both neighborhoods reported less frequency of sharing things with neighbors than having conversations with neighbors (Figure 8). Roughly equal percentages of respondents from both neighborhoods reported sharing with neighbors “a few times a year” (27\% Brooklyn, 29\% Sunnyside). 
Figure 8 - Share with Neighbors

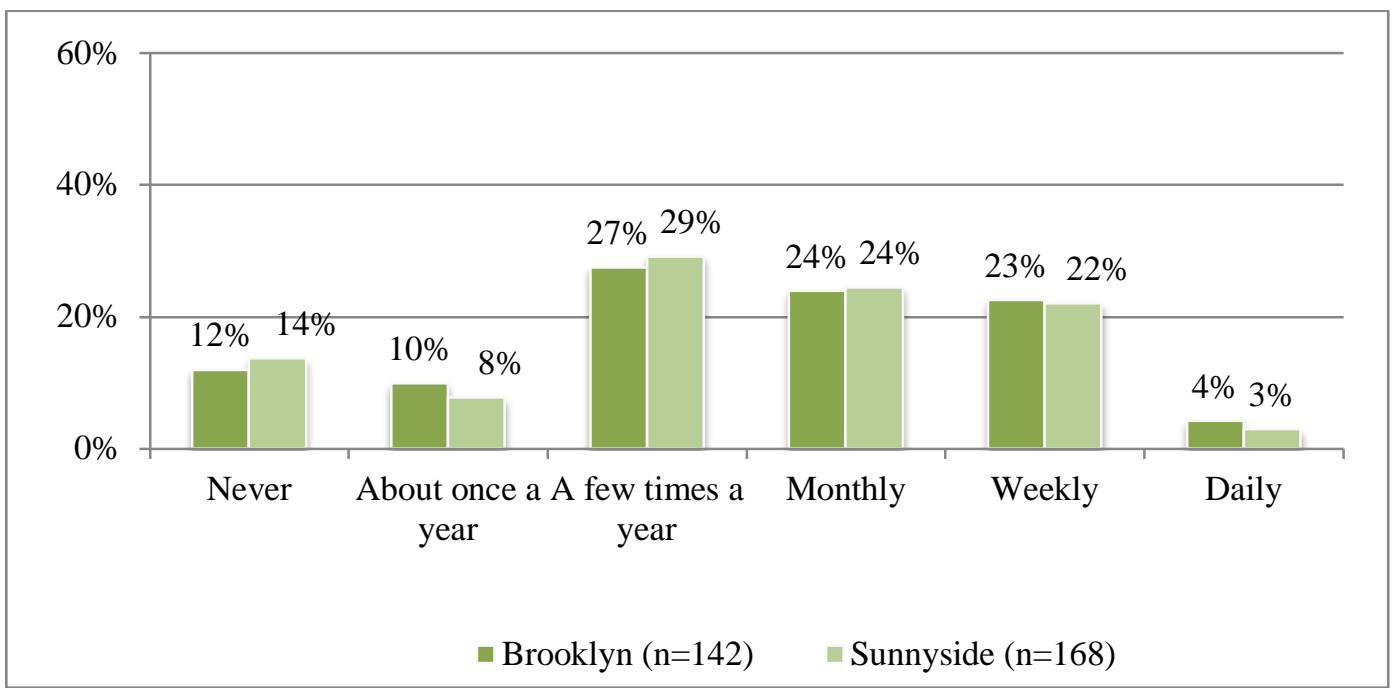

Note. Four “don’t know” responses were excluded from analysis.

Relatively few respondents reported they frequently have their neighbors over their house or go over to a neighborhoods house (Figure 9). Sunnyside respondents reported having neighbors over "a few times a year," more than Brooklyn respondents (22\% and 30\% respectively); however this difference was not found to be statistically significant.

Figure 9 - Have Neighbors Over

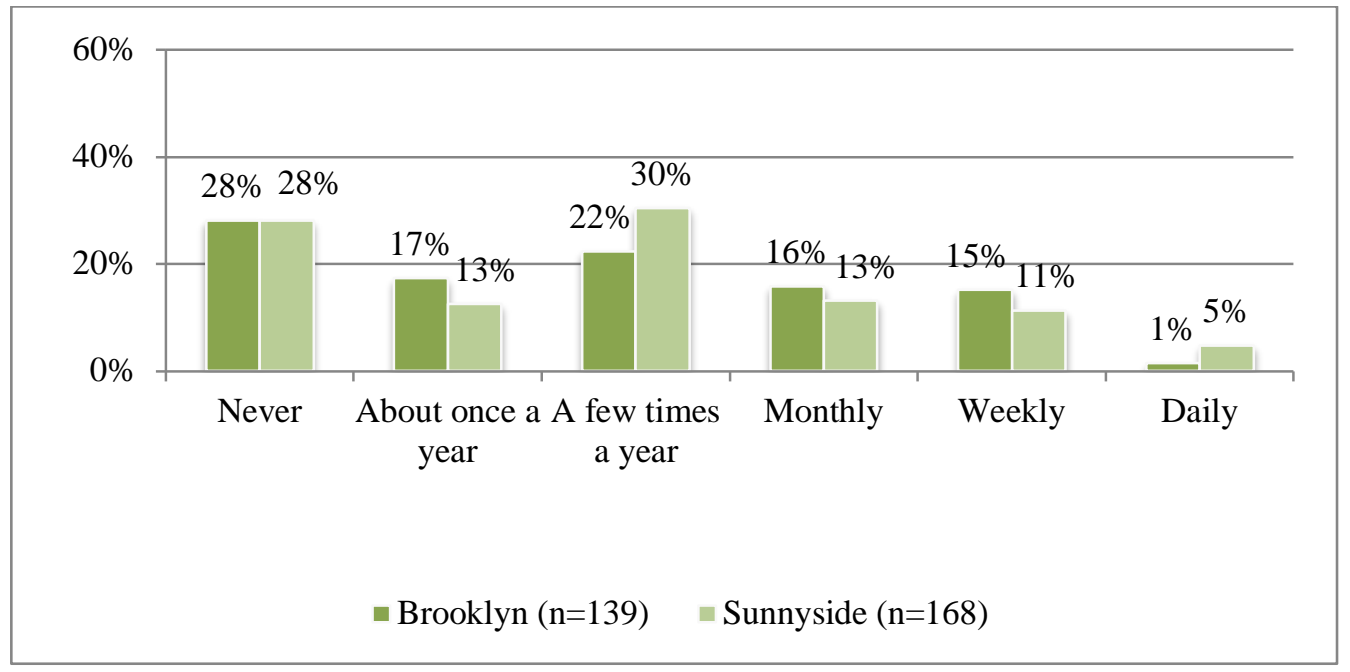

Note. Seven “don’t know” responses were excluded from analysis. 
Finally, there was a significant difference in the frequency of respondents shopping in their neighborhoods (Figure 10). Over half of Sunnyside respondents (55\%) reported shopping in their neighborhood daily, compared to Brooklyn residents (14\%). ${ }^{25}$

Figure 10 - Shop in Neighborhood

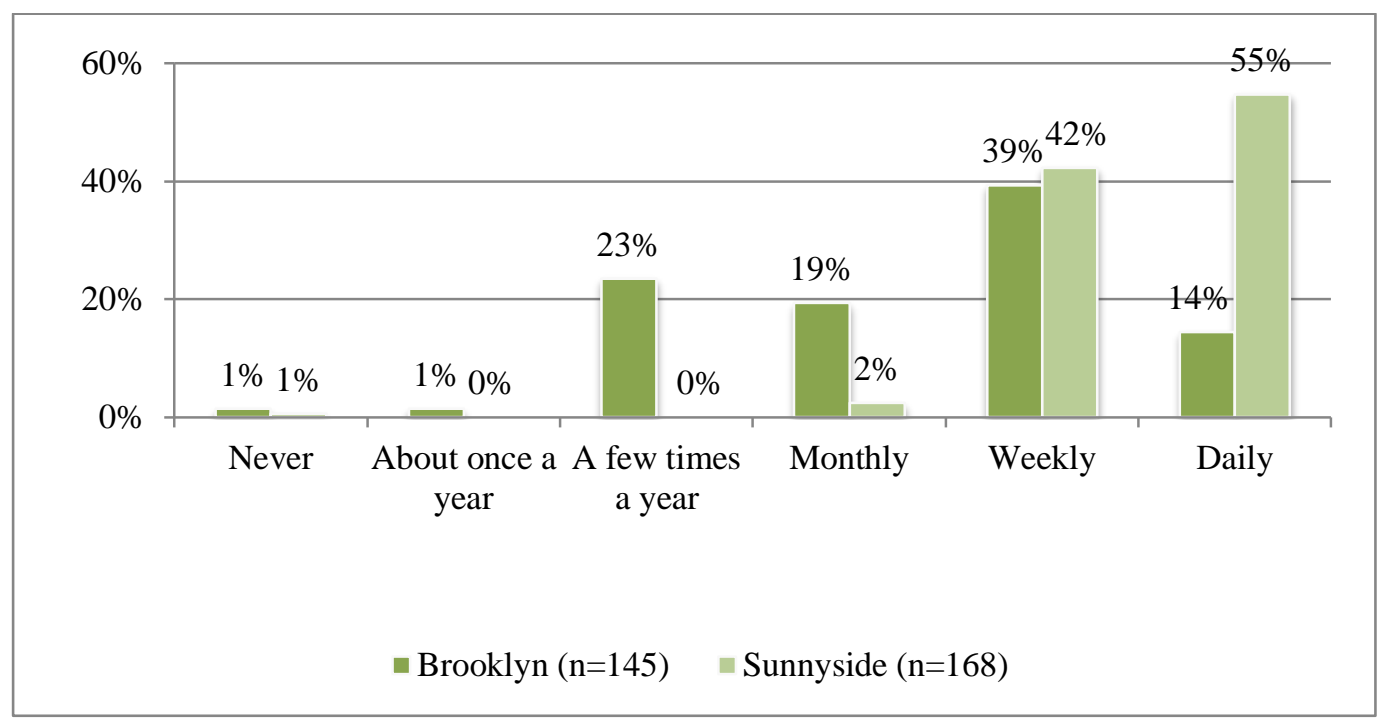

Note. One “don’t know” response was excluded from analysis.

To better understand the overall level of engagement in Sunnyside and Brooklyn, a composite measure was created using the reported frequencies of: "having conversations with neighborhoods," "sharing with neighbors," and "having neighbors over;" and whether or not the respondent had participated in neighborhood organizations. "Shopping in the neighborhood" was purposefully excluded when creating this metric because Sunnyside overwhelmingly reported shopping in the neighborhood "daily.” It is unclear if "shopping in the neighborhood" implied active engagement in the

${ }^{25} \chi^{2}(5, n=313)=97.68, p=.000$. 
neighborhood or simply passive consumption. Each frequency of engagement question was converted to a " 1 " to " 6 " scale, where " 1 " represented "never" and "6" represented "daily.” The mean of these metrics was assigned to each respondent. Respondents who said “don’t know" to any of the three questions were excluded from analysis.

After the mean level of engagement was calculated, respondents who also participated in neighborhood organizations or activities were given an additional "point" to their level of engagement score. This seemed to be the most appropriate way to incorporate participation into the engagement score. Overall, Sunnyside and Brooklyn residents did not significantly differ in their level of engagement. Sunnyside residents had a mean score of 4.02, and Brooklyn residents had a mean of 4.04 (out of a possible "7" point scale). These scores suggest that residents in both neighborhoods are moderately engaged in their neighborhoods.

Survey respondents were next asked to rate their agreement with four different social aspects of their neighborhood (Figure 11). Generally, respondents from both Brooklyn and Sunnyside agreed ("agree” or "strongly agree” on a five-point scale) that their neighbors want to make the neighborhood better. However, there were significant differences between the two neighborhoods in sharing values and forming supportive relationships with neighbors. Sunnyside respondents had higher levels of agreement to the statement "my neighbors share the same values as me" than Brooklyn respondents (94\% and 82\% respectively). ${ }^{26}$ Similarly, Sunnyside respondents agreed more with the

\footnotetext{
${ }^{26} \chi^{2}(1, n=314)=16.65, p=.001$.
} 
statement "qualities of the neighborhood support close-knit relationships" than Brooklyn residents (91\% and $78 \%$ respectively). ${ }^{27}$

Figure 11 - Social Aspects of Neighborhood

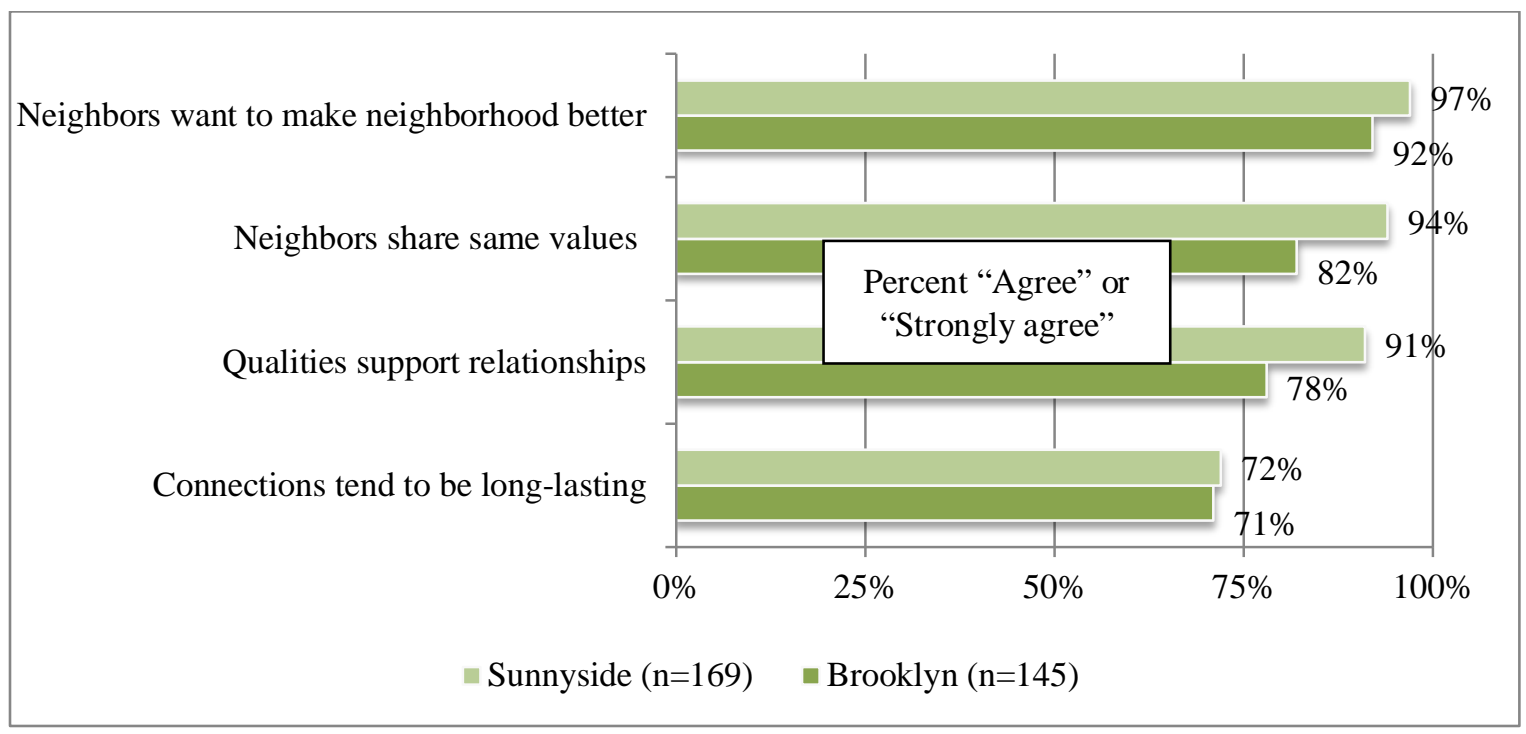

\section{Neighborhood Identity}

The perceived 'identity' of the Brooklyn and Sunnyside neighborhoods is central to this research. It was expected that the two neighborhoods would vary on the type of neighborhood identity. To determine what the neighborhood identity is according to residents, two questions were asked. First, respondents were asked if they believed their neighborhood has a unique identity compared to other neighborhoods in Portland. Respondents from both neighborhoods had similar views on this question, with over two-

${ }^{27} \chi 2(1, \mathrm{n}=314)=14.43, \mathrm{p}=.002$. 
thirds of respondents providing affirmative responses (Brooklyn - 69\% and Sunnyside $68 \%)$.

One open-ended question was asked of all respondents to more objectively determine what the identity of the Sunnyside and Brooklyn neighborhoods is (rather than judging that myself). Respondents provide a number of different reasons why they felt their neighborhood was unique. Qualitative thematic coding of each response provided rich, detailed insights into each neighborhood's identity. This also helped to limit the biases of trying to determine what that identity might be from an outsider's perspective. The following provides a detailed description of the Sunnyside and Brooklyn neighborhood according to respondents in the survey.

\section{Sunnyside Neighborhood Identity}

Of the 169 survey completed surveys in the Sunnyside neighborhood, 105 respondents provided their opinion of what the makes their neighborhood unique. A number of different themes emerged out of the qualitative coding of survey responses. Having an identity of 'sustainable' and 'environmental stewardship' is particularly important to this thesis’s main research question. Responses that mentioned sustainability or environmental responsibility were tabulated, resulting in approximately one in five Sunnyside respondents (18\%) mentioning sustainability in one form or another. Some respondents provided rich insights into why and how the neighborhood fosters sustainability:

"The local, sustainable, organic mantra that runs through Portland is exemplified in a neighborhood such as this. I feel we all support one another and encourage one another in these practices, as much as possible." 
"There seems to be a strong shared interest and value on Earth Stewardship, "green values", biking/gardening, the environmental school, walking to errands, and the like."

"A greater focus on sustainability and action to that end (swap shop, useful goods exchange, upcoming kitchen share), there are more efforts made at encouraging neighbors to participate in activities."

Many responses dealt with various aspects of transportation in Sunnyside:

"You can buy anything in this neighborhood and you don't' have to drive. I can get my hair done, go grocery shopping at the Fred Myer, get Thai food, clothing shopping etc. Generally, when I walk around I smile at people and they smile back and it's easy to make small chit chat. This is not the Pearl District baby!"

“[The neighborhood] has a walker and cyclist friendly ethos.”

"There's a lot of walking and biking, which is common throughout the city, in Sunnyside, you can bike to get anything you need."

"We can walk to many restaurants, two great grocery stores, bars, music venues, a movie theater, shops.”

'Walkability’ was frequently cited as something that sets Sunnyside apart from other neighborhoods. The reasons for this did not necessarily revolve around pedestrian infrastructure, but rather the ability to walk to desired destinations. For example, having two grocery stores, a number of different shops and restaurants, and other amenities (banks, pharmacies, etc.) within walking distance, were common reasons why residents described Sunnyside as being walkable. Many respondents also mentioned 'bikeability' as being something that creates a unique identity. Having bike parking corrals, bike boulevards, and a generally positive attitude towards cycling within the community, were all reasons why the Sunnyside neighborhood was said to be 'bikable.' Access to public 
transportation was mentioned less, however, it still seemed to be an important aspect of the neighborhood.

Sunnyside contains two businesses districts, the Belmont business district located in the middle of the neighborhood and the Hawthorne business district on the southern border. Each of these districts is famous for their local specialty shops and restaurants. Therefor it is not that surprising that the majority of responses mentioned the businesses in the neighborhood as being part of the neighborhood identity:

"The ideal ratio of businesses, homes, and parks makes Sunnyside unique."

"The businesses including retail shops, restaurants, nightlife are unique giving us a certain bohemian and rocker style."

Respondents tended to appreciate the proximity of these businesses and that they were 'locally-owned.’ A number of comments praised the neighborhood for lacking the typical chain businesses. Further, residents appreciated that other neighborhood residents also frequented these businesses:

"The "strip" of Belmont tends to be frequented by people who actually live in the neighborhood. I think the people in the neighborhood like the restaurants; bars, etc. (whereas in my mind people in other neighborhoods with high traffic conjectures tend to be unhappy with resultant traffic, noise, etc.)"

"There are a lot of small businesses that the community actively supports.”

Another common theme that emerged was that Sunnyside was 'family friendly' and stood out because of the Sunnyside Environmental School. A number of respondents mentioned seeing many younger families in the neighborhood. Additionally, many 
reported that they had moved to the neighborhood because they saw it as being family friendly and wanted their children to attend the nearby eco-friendly Sunnyside Environmental Elementary School:

"I think the citizens of Sunnyside are family-oriented, whether they do or do not have children."

"[The neighborhood is] sort of an educated, family centric version of Portlandia."

"My son starts kindergarten at Sunnyside Environmental (an environmental charter school) in the fall. I actually specifically moved into this neighborhood when I was pregnant in order that my son could go to this school."

"Lots of young, hip parents with kid give the neighborhood a younger, hip family vibe."

As mentioned, the Sunnyside Environmental Elementary School teaches using an environment-based curriculum. The school grounds contain many vegetable and herb gardens that students help plan, plant, and take care of. There is also a chicken coop with several hens that lay eggs and pen that once held a rescued pig. There are several rain catchment containers, cob-structure benches, and an information booth. Sunnyside School is often used for community activities such as swap meets, pot lucks, and other events. The school's sports field and gardens act as a de-facto community park when school is not in session.

Many respondents focused on the neighborhood 'feel' as what makes Sunnyside a unique place to live. When talking about the neighborhood feel, respondents focused on its bohemian culture saying it is "funky”, "quirky,” and "hip.” Community participation and cohesion were also mentioned as aspects that added to the neighborhood feel. Many 
respondents commented about how their neighbors are friendly and willing to lend a hand (or an ear) and how the community regularly comes together for events and social gatherings:

"The businesses including retail shops, restaurants, nightlife are unique giving us a certain bohemian and rocker style”

"Because our neighborhood includes SE Belmont and SE Hawthorne, we are one of the most famously "funky" neighborhoods in Portland."

"Very strong sense of community and sharing."

"We are more of a community, with events and neighbors actually talking to each other."

"Many neighbors have been living here for 20 or so years (including us) making our connection to each other and the neighborhood strong."

"People care for one another in many ways, e.g., neighborhood watch, when on vacation, water gardens, mow lawns, move out trash bins and back, feed pets."

Political and social beliefs were also mentioned a number of times. Sunnyside was described as being "liberal,” “progressive” and "free thinking.” Resident's mentioned that the neighborhood's acceptance of many different social groups, including low-income residents, minorities, and the LGBT community:

"In a city of progressives, Sunnyside is the most thoroughly liberal and progressive neighborhood that I know of."

A final theme that emerged focused on features of the built and natural environment that contributed to the livability and pride of the Sunnyside neighborhood. The 'historic character' of the neighborhood was mentioned a number of times by residents. Responses focused on how the older housing stock gave the neighborhood a 
unique feel. Respondents also mentioned the old store fronts along the commercial districts, old growth trees, and un-uniformed patterns of street layout.

"[The neighborhood] is thoroughly marked by its history. It is essentially the suburbs of east Portland around 1910. The architecture is varied and lovely."

"Houses are tightly spaced which lends to interaction."

"The houses and lots come in all shapes and sizes for different income levels, the streets are narrow and jig and jag."

Another feature of the built environment mentioned numerous times was the Sunnyside Piazza. Many respondents felt that this public space was the embodiment of what the neighborhood identity is. As mentioned previously, the Piazza is an intersection where residents come together every year re-painted the Sunnyside symbol, a bright yellow and orange sunflower. The neighborhood clearly identifies with and takes great pride in the Sunnyside Piazza:

"We have an enormous sunflower painted right in the middle of the street at 33rd and Belmont. The community keeps the corner clean and maintains beautiful barrels at each corner full of flowers. Our sunflower is so unique that tourists and even tours show up daily during the spring and summer. This is a neighborhood effort because many people show up every year, kids, adults, dogs, to paint and party. In addition, there's a Swap Box at the corner of Belmont and 33rd where the community "swaps" books and magazines. Our corner helps to put the "weird" in "Keep Portland Weird" although it's sad that communities coming together to work should be considered weird in some places."

"The Sunnyside Piazza gives the neighborhood a unique character. Love the street art that crops up (little horses by the old horse rings in the street, yarn art on utility poles, creative touches by homeowners, etc.). Very livable and vibrant with a sense of play." 
"The sunflower is a big draw and makes people happy. Other neighborhoods have caught on, but Sunnyside was the first!"

\section{Brooklyn Neighborhood Identity}

Of the 145 surveys completed in the Brooklyn neighborhood, 97 respondents provided their opinion of what the makes their neighborhood a unique place. Unlike the Sunnyside neighborhood, there was no mention of sustainability or environmental stewardship in their comments. Instead, topics tended to focus on Brooklyn's location, diversity, and its built environment. Additionally, there were a number of responses that focused on negative aspects of the neighborhood. The neighborhood's proximity to Downtown Portland and other SE neighborhoods was one of the most mentioned things that made Brooklyn unique to residents who live there:

"Brooklyn is quiet and feels pretty insulated, and yet it is relatively close to everything: downtown, inner SE shopping districts, etc. for its location you would expect it to be more 'happening', with more shops and street activity."

"Very centrally located to downtown, inner SE, but very quiet, not as trendy as Sellwood."

"Brooklyn is neatly placed among major roads and highways, that make going to work or coming home a breeze."

This location comes with its disadvantages, however. Many respondents also lamented about the roads and rail yards, saying they are dangerous, noisy, and have been detrimental to the livability of the neighborhood:

"Inner city neighborhood with rail yard noise and now light rail construction noise and zoning allowances for parking stress and noise." 
Another common theme that emerged in the responses was the geography and built environment of the neighborhood. Again, there was a mix of positive and negative responses regarding these topics. Surprisingly, a number of respondents commented that the neighborhood is unique because it has physical boundaries (roads, railroads, rivers), describing it as being an "island,” "bounded,” “isolated,” “cut off spatially,” "boxed-in,” “surrounded,” and “hidden.” However, some respondents felt this insularly effect was detrimental to development in the area, and suggested changes in land-use to combat the effects of these barriers:

"The way its bounded by railroad tracks and Willamette river and major roads makes the neighborhood boundary very defined."

"The fact that it's in some ways cut off spatially yet is still close in and easy to get to downtown"

"This relative quietness and prime location make Brooklyn unique. That and the fact that it is 'boxed in' - by trains and huge, un-crossable roads (Powell, Holgate, 99). This makes you kind of feel kind of trapped unless you're driving in a car."

"I must admit that our neighborhood is somewhat culturally void and I blame our geographic isolation - walled off by Powell, McLoughlin."

"It is an interesting mix of rentals and owner-occupied homes, and all types of housing. It is kind of a island, being surrounded by 3 major roadways and the train tracks, which can make it a little less walking friendly."

"Our neighborhood has well defined/dividing borders, i.e. the river, train tracks.”

"It's location makes it feel closed off; like a hidden gem from the rest of the city." 
As discussed above, the Brooklyn neighborhood has a rich history. Its identity of being a historic neighborhood was evident in respondents' comments. Most of these comments focused on the historic housing stock located in Brooklyn. Many residents appreciate and take pride in these older homes dating back to the 1890s:

"The Brooklyn neighborhood is unique because it offers the humble charm of historic homes, blended with affordable apartment and duplex housing."

"People who appreciate the history of the neighborhood and its buildings."

"It is very old with historic homes and trees."

"It is very hodgepodge around here....you have beautiful historic homes next to hideous 1970's apartments."

Respondents also appreciated the older businesses that exist in the

neighborhood, such as the Aladdin Theater. As was seen in the Brooklyn

Neighborhood Plan, there is still some tension between homeowners and renters

in the neighborhood. Many respondents complained that the apartment buildings

were giving the neighborhood a "bad image," and wished they would be more

cared for:

"Brooklyn carries an extremely high load of density as a result of an overabundance of apartment buildings that, say, East Moreland does NOT contribute to. This issue is the one singular issue that hampers Brooklyn from being all it could be. The question is why does Brooklyn have these $4,5,6$, and larger complexes among its single family homes when the a fore mentioned neighborhood does NOT contribute towards density? If proper zoning was implemented NOW Brooklyn has a fighting chance of making a positive significant for the better!” 
There were a number of social aspects that respondents said contributed to Brooklyn’s neighborhood identity. Many residents described Brooklyn as being a “socially diverse” and "accepting” neighborhood. They tended to identify with Brooklyn as being a place where ethnic populations have lived in the past and still do. Many respondents also viewed the neighborhood as being a "working-class" neighborhood:

"Attracts creative and intellectuals but thankfully lack pretension; maintains vestiges of its working class roots."

"Old German neighborhood with neighbors who have been in the hood for several generations and plan to stay."

"Strong historical ties to the Italian/Catholic families and the Brooklyn rail yard."

"We also are a small, working class neighborhood that seems to have a lot in common with each other."

Brooklyn residents tended to mention age diversity more than the Sunnyside neighborhood residents did. Having a larger elderly population in the neighborhood seemed to resonate with many Brooklyn residents:

"Brooklyn seems less affluent and has more "old" residents (both people who have lived there $30+$ years, and who are older) than either neighboring Ladd's Addition or Sellwood (pretty similar to Westmoreland)."

"There is a community of older people in this neighborhood that can be missing in some other places in Portland."

Some respondents mention that neighbors were friendly and always willing to chat or help out: 
"The people of Brooklyn neighborhood are friendly and loyal to their neighborhood bars and businesses. Even if you don't always mingle with the neighbors, when you do, it's always a pleasant experience."

This was countered by a number of responses indicated that many residents keep to themselves, but are still friendly:

"Unique, yes - although not favorable. We have lived in the neighborhood almost 3 years, and our neighbors still do not speak to us, when passing by our yard, etc - often pretending to be on the cell phone or simply looking the other way. This is quite unlike anything we have experienced in other Portland neighborhoods"

Finally, many Brooklyn residents commented on how the neighborhood is still relatively "unknown" in Portland. Some residents held a favorable opinion about this status, while others believed that Brooklyn was "ripe" for development. It seems that the neighborhood is in a constant state of transition. Desirable based on its location, the Brooklyn neighborhood maybe poised to change into something new. Many feared the process of gentrification encroaching on the neighborhood, while at the same time wishing that there were more stores, the neighborhood was cleaner, and there was more community cohesion:

"I wish we had a decent grocery store. Still have to drive for that. I think one aspect that makes it unique is that many people don't know it's here. However, since we are close to McLoughlin Blvd and the Ross Island Bridge, we tend to get transients traveling through our streets." "Brooklyn is not really known by others in the city that does not live here. Brooklyn isn't a destination area like Division, Hawthorne, Pearl, etc." "feels like a special undiscovered gem."

"I have lived in the Brooklyn neighborhood for 15 years, I have seen it change some, however it hasn't changed as much as other neighborhoods in Portland, that is one thing that makes it unique." 
"It is seemingly unaffected by the very unbecoming new tide of yuppie pseudo progressive influence that is drowning Portland in so called sustainable business which is really just sleek strip malls with overpriced boutiques."

"It's not gentrified; it is easy-going and fairly quiet."

"The potential for development is also a strong, unique asset for Brooklyn."

"The challenge will probably be not to let the trend towards gentrification of close-in urban neighborhoods ruin what makes us unique."

\section{Neighborhood Sustainability}

Respondents were next asked a question to gather information regarding their subjective opinions of how sustainable they think their neighborhood was (Figure 12). Since the idea of 'sustainability' is often ambiguous and difficult for many people to understand, a brief definition was provided to respondents. ${ }^{28}$ Overall, respondents from both neighborhoods reported high levels (on a scale from 1 "not sustainable at all” to 10 “completely sustainable”) of neighborhood sustainability (Brooklyn $M=6.57$, Sunnyside $M=6.91)$. These high ratings could be the result of the City of Portland's overall commitment to sustainability. Sunnyside respondents had a ten-point difference in

\footnotetext{
${ }^{28}$ The definition for sustainability used was adapted from the Brundtland Commission's "Our Common Futures" report and read: Being "sustainable" refers to the ability of a neighborhood and its residents, to improve and maintain their collective quality of life, socially and economically, now and in the future, while at the same time having a minimal impact on the environment (using less resources, making less of an impact, and preserving biodiversity).
} 
providing an "8” than Brooklyn respondents, however, the differences between the two neighborhoods were not found to be significantly different.

Figure 12 - Level of Neighborhood Sustainability

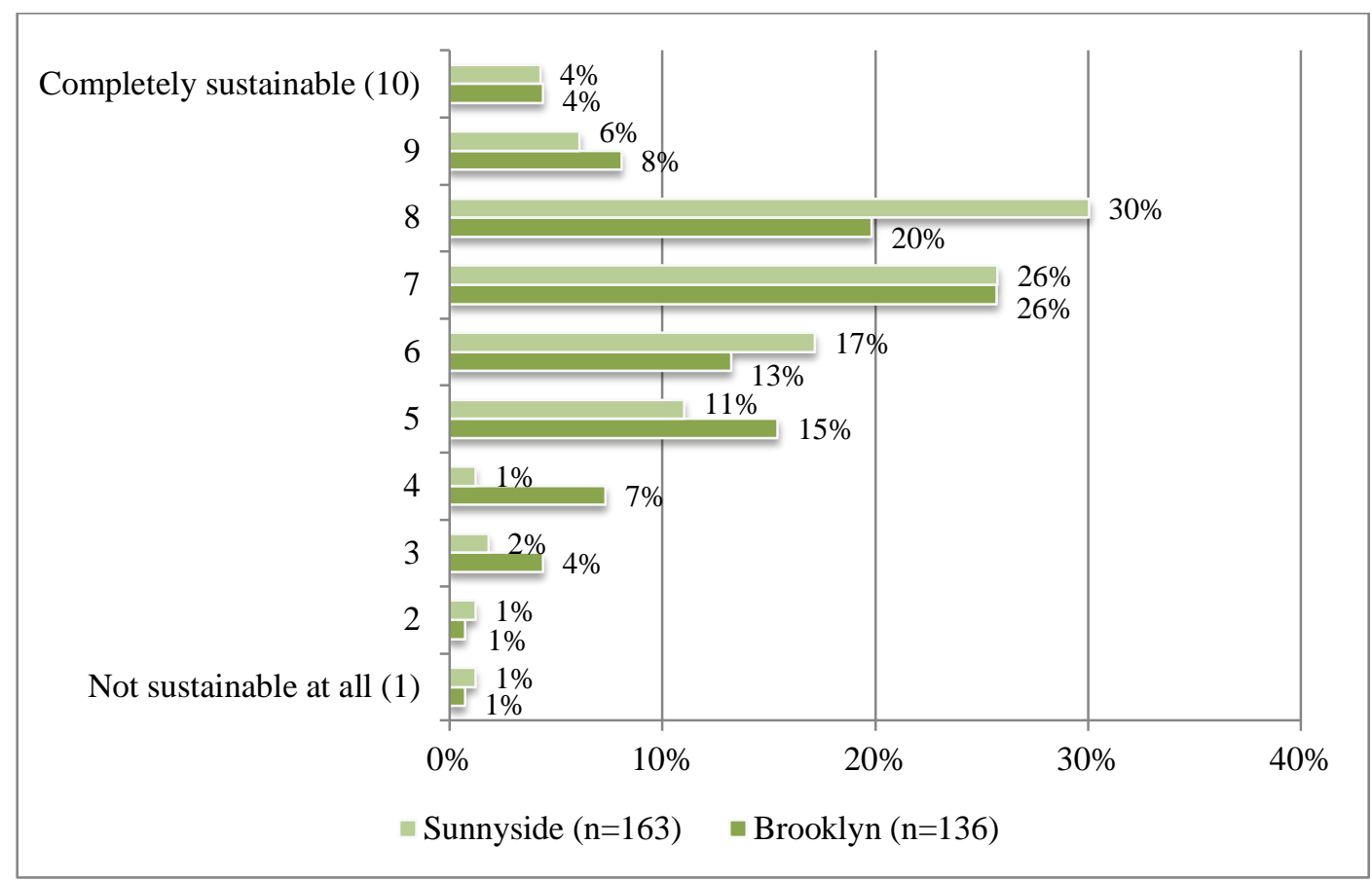

Note. 15 “don’t know” responses were excluded from analysis.

One concern identified early on in this research is that residents of the Sunnyside neighborhood may report more sustainable behavior not because of the neighborhood identity, but rather because they were inclined to participate in such behaviors prior to moving into the neighborhood. In an attempt to address this issue, questions were asked of respondents to determine their reasons for moving into the neighborhood and how influential the neighborhood has been in fostering sustainable practices at home. The average Brooklyn and Sunnyside respondent both reported residing in their neighborhood for approximately 11 years (Brooklyn - M=10.99, Sunnyside $-\mathrm{M}=11.32$ ). 
Table 3 provides a breakdown of coded reasons respondents provided for moving to their neighborhood. For Brooklyn, half of respondents reported moving to the neighborhood for both access to destination (50\%) and housing affordability (49\%).

Nearly half of Sunnyside respondents (46\%) reported moving to the neighborhood because of neighborhood amenities. Interestingly, there is a stark difference between the two neighborhoods in terms of moving to the neighborhood because of the walkability or bikability of the neighborhood (Brooklyn 2\% and Sunnyside 30\%). It is important to note that not one respondent from either neighborhood reported moving to their neighborhood because of a desire to be more sustainable.

Table 3 - Reasons for Moving to the Neighborhood (Multiple Responses Allowed)

\begin{tabular}{|c|c|c|c|c|c|c|}
\hline \multirow{2}{*}{ Reason for Moving } & \multicolumn{2}{|c|}{ Brooklyn (n=138) } & \multicolumn{2}{|c|}{ Sunnyside (n=161) } & \multicolumn{2}{|c|}{ Total $(n=299)$} \\
\hline & Count & Percent & Count & Percent & Count & Percent \\
\hline Access to destinations & 69 & $50 \%$ & 39 & $24 \%$ & 108 & $36 \%$ \\
\hline Housing affordability & 67 & $49 \%$ & 37 & $23 \%$ & 104 & $35 \%$ \\
\hline Neighborhood amenities & 17 & $12 \%$ & 74 & $46 \%$ & 91 & $30 \%$ \\
\hline Neighborhood feel / Ascetics & 16 & $12 \%$ & 38 & $24 \%$ & 54 & $18 \%$ \\
\hline General location & 26 & $19 \%$ & 27 & $17 \%$ & 53 & $18 \%$ \\
\hline Alternative transportation & 22 & $16 \%$ & 30 & $19 \%$ & 52 & $17 \%$ \\
\hline Walkability / Bikeability & 3 & $2 \%$ & 48 & $30 \%$ & 51 & $17 \%$ \\
\hline Neighborhood familiarity & 17 & $12 \%$ & 21 & $13 \%$ & 38 & $13 \%$ \\
\hline Sense of community & 6 & $4 \%$ & 17 & $11 \%$ & 23 & $8 \%$ \\
\hline Family friendly & 8 & $6 \%$ & 13 & $8 \%$ & 21 & $7 \%$ \\
\hline $\begin{array}{l}\text { Similar ideologies / } \\
\text { worldviews }\end{array}$ & 4 & $3 \%$ & 12 & $7 \%$ & 16 & $5 \%$ \\
\hline Natural environment & 5 & $4 \%$ & 7 & $4 \%$ & 12 & $4 \%$ \\
\hline Safety & 4 & $3 \%$ & 6 & $4 \%$ & 10 & $3 \%$ \\
\hline Housing availability & 4 & $3 \%$ & 4 & $2 \%$ & 8 & $3 \%$ \\
\hline Always lived in neighborhood & 2 & $1 \%$ & 1 & $1 \%$ & 3 & $1 \%$ \\
\hline Other & 12 & $9 \%$ & 19 & $12 \%$ & 31 & $10 \%$ \\
\hline
\end{tabular}

Note. Seven “don’t know” and eight “refused” responses were excluded from analysis. 
Next respondents were asked to rate how influential their neighborhood has been to them in regards of adopting sustainable practices (Figure 13). Overall Sunnyside respondents reported their neighborhood being more influential in their adoption of sustainable practices than Brooklyn respondents (Sunnyside $\mathrm{M}=3.15$, Brooklyn $\mathrm{M}=$ $2.80) .^{29}$

Figure 13 - Neighborhood Influence on Sustainable Practices

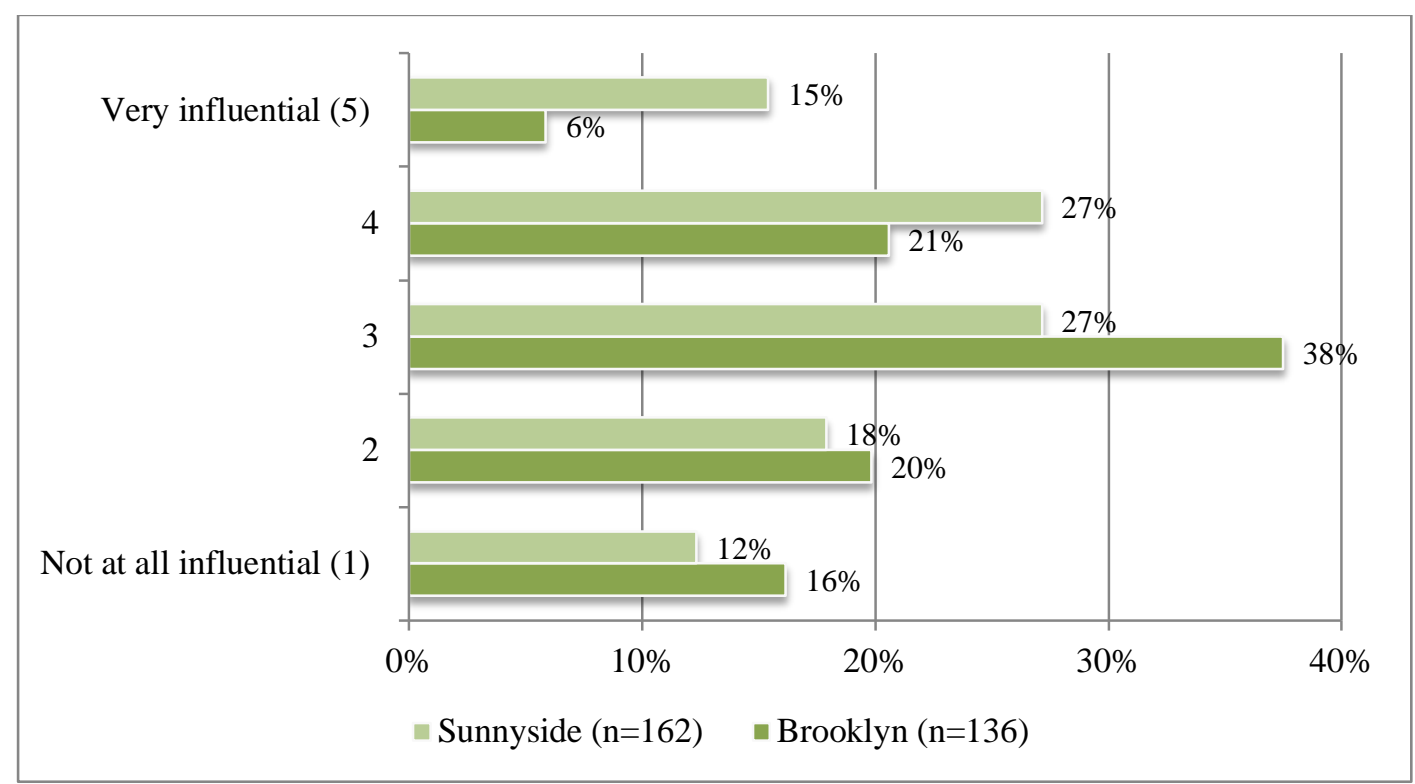

Note. 12 “don’t know” and four "refused” responses were excluded from analysis.

Sustainable features in the neighborhood such as rain-water catchment barrels, solar panels, and gardening were hypothesized to have an influence on individual behavior. The evidence for this theory was found to be inconclusive based on reported influence by respondents (Figure 14). It should be noted however, that 12 Brooklyn respondents reported that they do not see sustainable features in their neighborhood,

\footnotetext{
${ }^{29} \mathrm{t}(296)=2.62, p=.011$
} 
whereas not one Sunnyside respondent reported not seeing sustainable these types of features.

Figure 14 - Influence of Sustainable Neighborhood Features

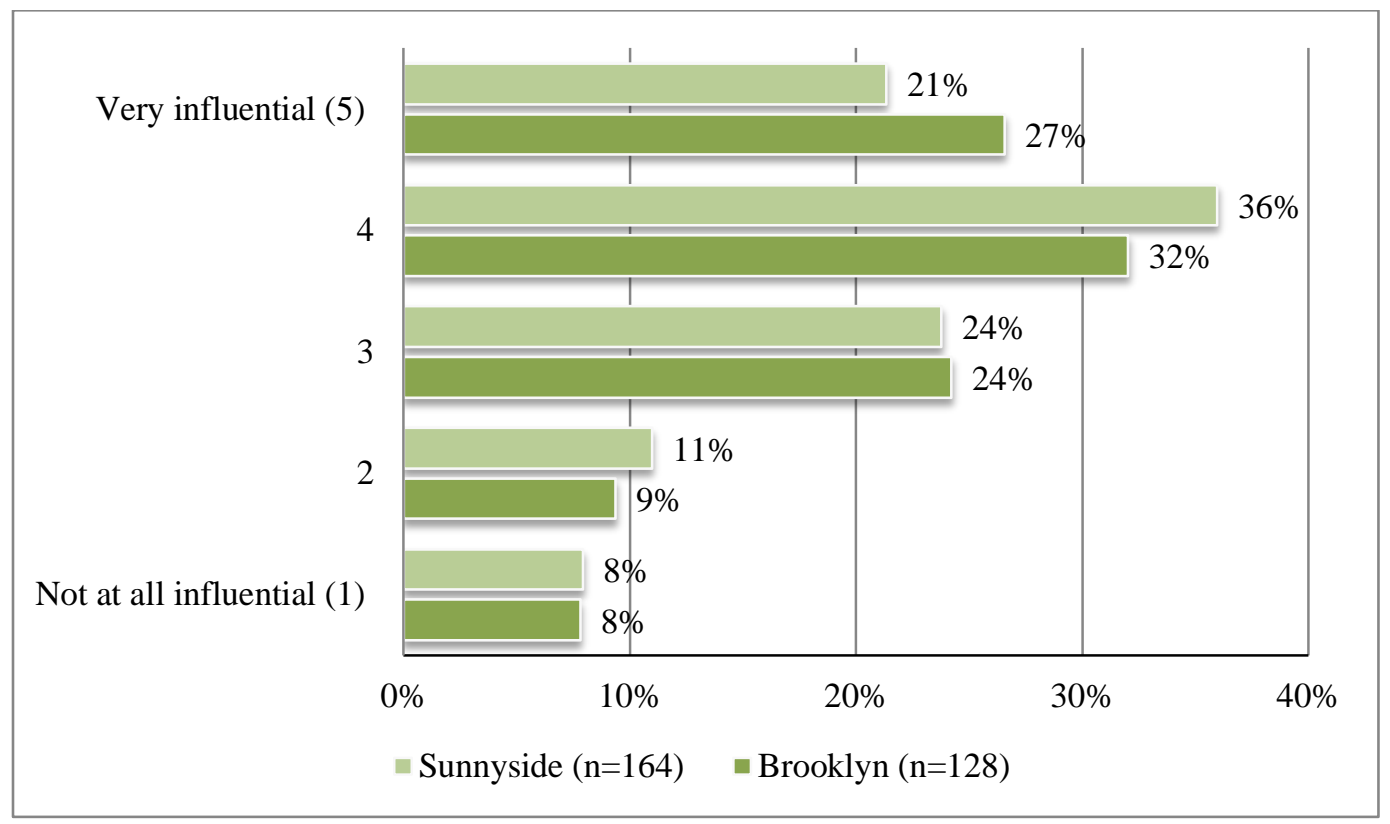

Note. Nine “don’t know” and one “refused” response was excluded from analysis.

Overall, approximately two-thirds of respondents (Brooklyn - 62\% and Sunnyside - 64\%) reported that their neighborhood has caused them to be more sustainable (Table 4). Very few respondents reported that their neighborhood has had a negative effect on their sustainable behaviors.

Table 4 - Effect of Neighborhood on Sustainability

\begin{tabular}{|l|c|c|c|c|c|c|}
\hline \multirow{2}{*}{ Effect } & \multicolumn{2}{|c|}{ Brooklyn (n=139) } & Sunnyside (n=164) & \multicolumn{2}{c|}{ Total (n=303) } \\
\cline { 2 - 7 } & Count & Percent & Count & Percent & Count & Percent \\
\hline More sustainable & 86 & $62 \%$ & 105 & $64 \%$ & 191 & $63 \%$ \\
\hline Less sustainable & 4 & $3 \%$ & 3 & $2 \%$ & 7 & $2 \%$ \\
\hline Stayed the same & 49 & $35 \%$ & 56 & $34 \%$ & 105 & $35 \%$ \\
\hline Total & 139 & $100 \%$ & 164 & $100 \%$ & 303 & $100 \%$ \\
\hline
\end{tabular}

Note. Eight “don’t know” and three “refused” responses were excluded from analysis. 
A follow-up question was asked to better understand how respondents' neighborhoods have affected their level of sustainability. Table 5 presents reported causes of increased sustainable behaviors. Categories were derived from coding of open-ended responses. The highest reported cause for both neighborhoods is having the ability to compost (Brooklyn $-40 \%$ and Sunnyside $-33 \%$ ). This is perhaps not surprising being that the City of Portland recently rolled out their residential composting program to all residents in Portland. Reports of community support of sustainability were slightly higher in Sunnyside (18\%) than in Brooklyn (12\%), however this difference was not found to be significant. There was a significant difference in reporting having access to amenities as being a cause of increased sustainability (Brooklyn $-1 \%$ and Sunnyside $-10 \%){ }^{30}$

Table 5 - Causes of Increased Sustainable Behaviors

\begin{tabular}{|l|c|c|c|c|c|c|}
\hline \multirow{2}{*}{\multicolumn{1}{|c|}{ Cause }} & \multicolumn{2}{|c|}{ Brooklyn (n=86) } & \multicolumn{2}{c|}{ Sunnyside (n=105) } & \multicolumn{2}{c|}{ Total (n=191) } \\
\cline { 2 - 7 } & Count & Percent & Count & Percent & Count & Percent \\
\hline Ability to compost & 34 & $40 \%$ & 34 & $33 \%$ & 68 & $36 \%$ \\
\hline More energy efficient home & 26 & $30 \%$ & 20 & $19 \%$ & 46 & $24 \%$ \\
\hline Ability to recycle & 23 & $27 \%$ & 22 & $21 \%$ & 45 & $24 \%$ \\
\hline Decrease in car use & 11 & $13 \%$ & 19 & $18 \%$ & 30 & $16 \%$ \\
\hline Community support & 10 & $12 \%$ & 19 & $18 \%$ & 29 & $15 \%$ \\
\hline Ability to garden & 12 & $14 \%$ & 11 & $11 \%$ & 23 & $12 \%$ \\
\hline Access to public transit & 8 & $9 \%$ & 5 & $5 \%$ & 13 & $7 \%$ \\
\hline Access to amenities & 1 & $1 \%$ & 10 & $10 \%$ & 11 & $6 \%$ \\
\hline Access to sustainable services & 5 & $6 \%$ & 4 & $4 \%$ & 9 & $5 \%$ \\
\hline Awareness or responsibility & 1 & $1 \%$ & 6 & $6 \%$ & 7 & $4 \%$ \\
\hline Water use reduction & 4 & $5 \%$ & 3 & $3 \%$ & 7 & $4 \%$ \\
\hline Bike infrastructure & 2 & $2 \%$ & 4 & $4 \%$ & 6 & $3 \%$ \\
\hline Education & 2 & $2 \%$ & 4 & $4 \%$ & 6 & $3 \%$ \\
\hline Cost of energy & 4 & $5 \%$ & 1 & $1 \%$ & 5 & $3 \%$ \\
\hline Other & 9 & $10 \%$ & 12 & $11 \%$ & 21 & $11 \%$ \\
\hline
\end{tabular}

${ }^{30} \chi^{2}(1, \mathrm{n}=184)=6.303, \mathrm{p}=.012$. 
As mentioned above, few respondents reported that living in their neighborhood has caused them to become less sustainable. Those respondents in Brooklyn reported becoming less sustainable because of being further away from amenities such as schools and grocery stores, increases in waste, and an increases in income (causing an increase in eating out and purchasing goods). Sunnyside respondents reported not having access to composting in their new apartment and moving into an older, less efficient home.

\section{Household Sustainability}

It is an important aspect of this research to determine if household sustainable behaviors and energy consumption differ between the Brooklyn and Sunnyside neighborhoods. The following section presents findings regarding household sustainable behaviors. Seven questions were selected that correspond to various sustainable behaviors households may or may not participate in. Each respondent was asked how frequently he or she performs each behavior. No significant differences between the two neighborhoods were found in terms or electricity saving behaviors (Figure 15), water saving behavior (Figure 16), heating or cooling adjustments (Figure 17), curbside recycling (Figure 18), recycling hard to recycle materials (Figure 19), purchasing energy efficient products (Figure 20), and composting (Figure 21). One difference that was found to be marginally significant was respondents reporting "never” on for these seven questions. Brooklyn respondents were more likely to report "never” doing these sustainable behaviors than Sunnyside residents. ${ }^{31}$

\footnotetext{
${ }^{31} t(312)=1.102, \mathrm{p}<.050$
} 
Figure 15 - Electricity Saving Behaviors

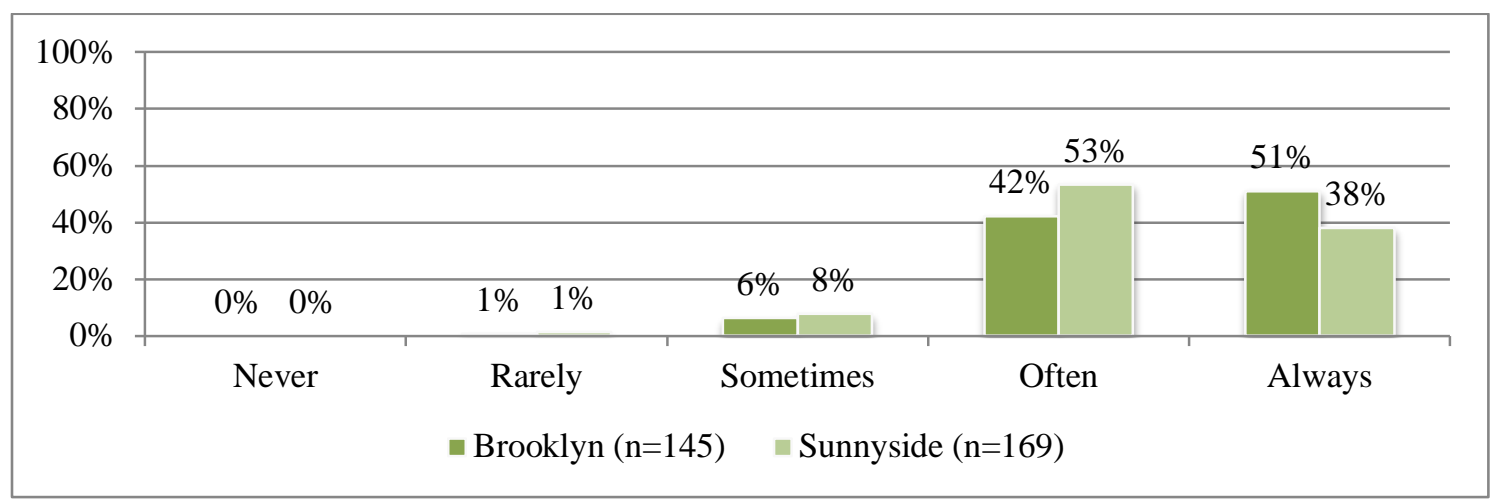

Figure 16 - Water Saving Behaviors

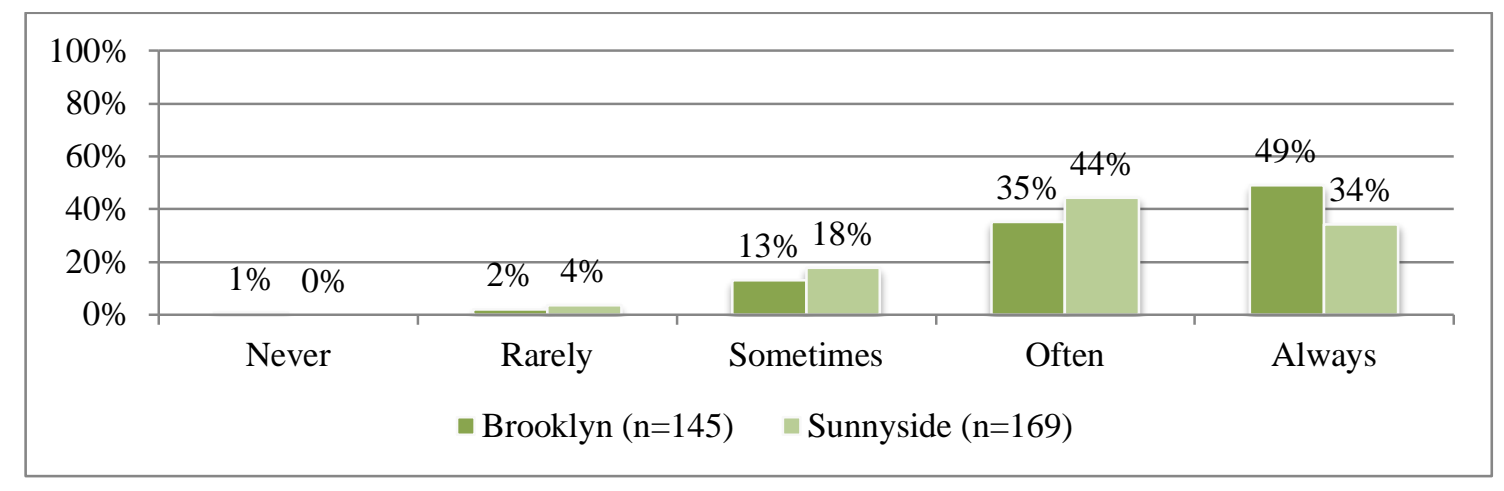

Figure 17 - Heating or Cooling Adjustments to Save Energy

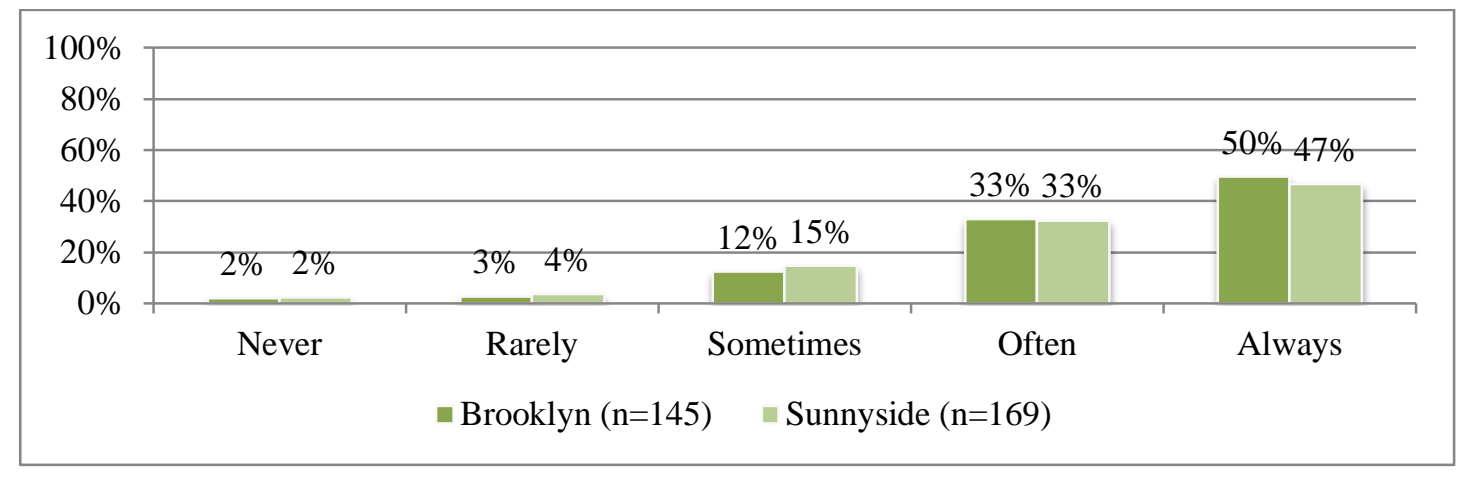


Figure 18 - Recycling Paper, Metals, Plastics, and Glass

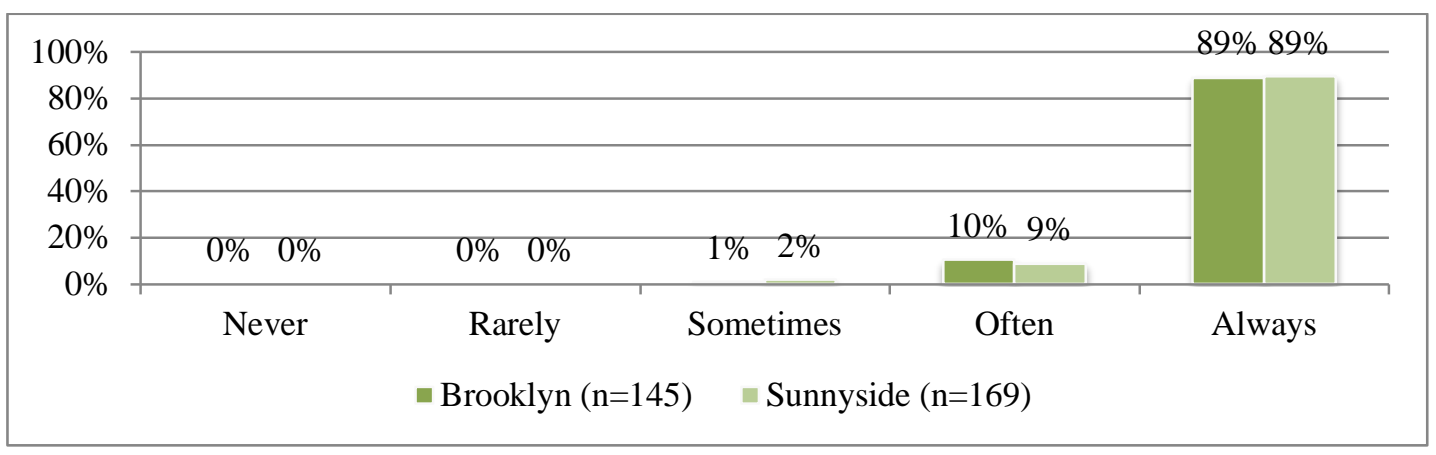

Figure 19 - Taking Hard to Recycle Materials to Drop-off Locations

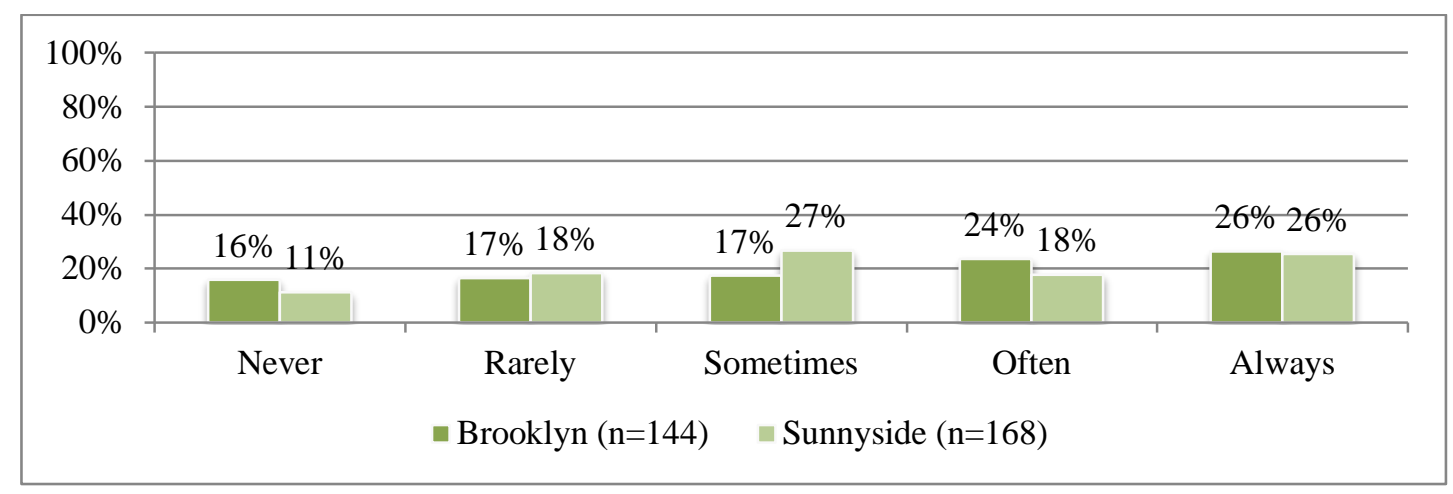

Figure 20 - Purchasing Energy Efficient Products

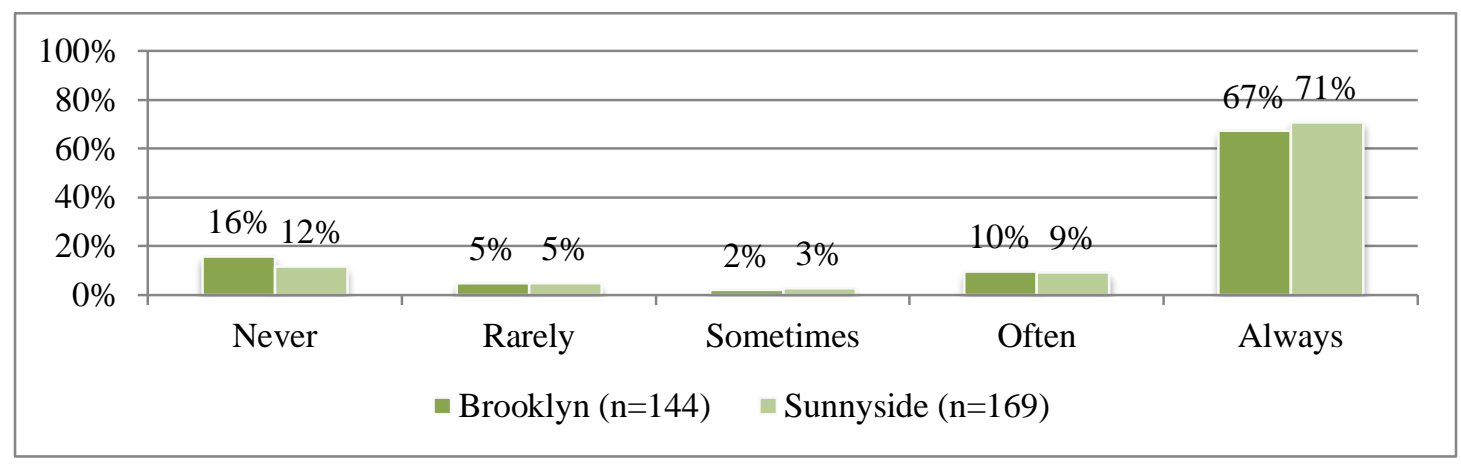


Figure 21 - Composting Food Scraps

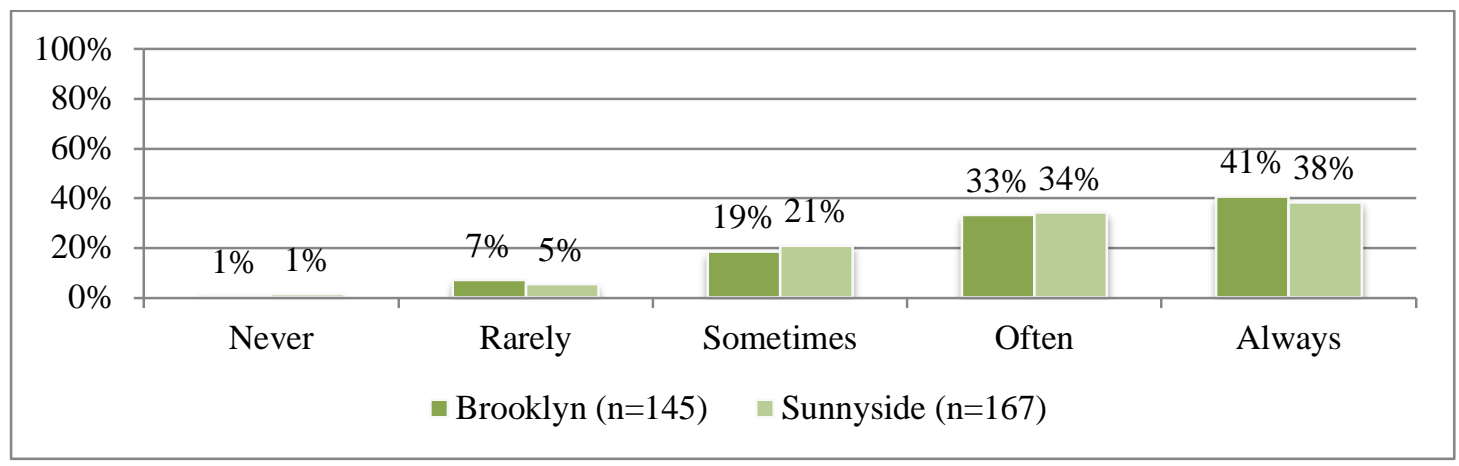

A composite score was created using the seven questions about household sustainable behaviors (discussed above). Each question was converted to a scale of " 1 " (meaning “never”) to “5” (meaning “always”). The mean was taken for each respondent’s answers to these questions to create a household sustainability score for each respondent. Respondents that refused to answer any of the seven questions, or responded with “don’t know” were excluded from analysis. Overall, there was no significant difference between the two neighborhoods in terms of their average household sustainable behavior score. The Sunnyside neighborhood had an overall score of 4.13 and the Brooklyn neighborhood had a score of 4.19. It should be noted, however, that both of these scores were fairly high, indicating high levels of household sustainable behaviors.

Another indicator of increased sustainability is an individual's willingness to perform energy efficiency upgrades on their home. Overall, half of both Brooklyn and Sunnyside residents reported that they had performed energy efficiency upgrades on their home within the past five years (Table 6). The most common upgrades preformed were insulation (Brooklyn - 18\% and Sunnyside 22\%), replacing windows (Brooklyn - 15\% and Sunnyside 19\%), and upgrades to furnaces (Brooklyn - 13\% and Sunnyside 15\%). 
There were no significant differences between the two neighborhoods in terms of performing an upgrade or types of upgrades performed.

Table 6 - Energy Efficiency Upgrades Performed (Multiple Responses Allowed)

\begin{tabular}{|c|c|c|c|c|c|c|}
\hline \multirow{2}{*}{ Upgrade } & \multicolumn{2}{|c|}{ Brooklyn (n=128) } & \multicolumn{2}{|c|}{ Sunnyside (n=145) } & \multicolumn{2}{|c|}{ Total $(n=273)$} \\
\hline & Count & Percent & Count & Percent & Count & Percent \\
\hline None & 65 & $51 \%$ & 72 & $50 \%$ & 137 & $50 \%$ \\
\hline Insulation & 23 & $18 \%$ & 32 & $22 \%$ & 55 & $20 \%$ \\
\hline Windows & 19 & $15 \%$ & 27 & $19 \%$ & 46 & $17 \%$ \\
\hline Furnace & 16 & $13 \%$ & 22 & $15 \%$ & 38 & $14 \%$ \\
\hline Clothes washer & 17 & $13 \%$ & 9 & $6 \%$ & 26 & $10 \%$ \\
\hline Water heater & 9 & $7 \%$ & 17 & $12 \%$ & 26 & $10 \%$ \\
\hline Appliances (General) & 10 & $8 \%$ & 12 & $8 \%$ & 22 & $8 \%$ \\
\hline Refrigerator & 11 & $9 \%$ & 11 & $8 \%$ & 22 & $8 \%$ \\
\hline Clothes dryer & 12 & $9 \%$ & 5 & $3 \%$ & 17 & $6 \%$ \\
\hline Dishwasher & 7 & $5 \%$ & 10 & $7 \%$ & 17 & $6 \%$ \\
\hline CFL / LED lighting & 8 & $6 \%$ & 7 & $5 \%$ & 15 & $5 \%$ \\
\hline Solar PV & 4 & $3 \%$ & 5 & $3 \%$ & 9 & $3 \%$ \\
\hline $\begin{array}{l}\text { Water related (aerators } \\
\text { / catchment / etc.) }\end{array}$ & 5 & $4 \%$ & 4 & $3 \%$ & 9 & $3 \%$ \\
\hline Air sealing & 3 & $2 \%$ & 5 & $3 \%$ & 8 & $3 \%$ \\
\hline Air conditioner & 2 & $2 \%$ & 3 & $2 \%$ & 5 & $2 \%$ \\
\hline Other & 11 & $9 \%$ & 11 & $8 \%$ & 22 & $8 \%$ \\
\hline
\end{tabular}

Note. 36 "don't know" and four "refused" responses were excluded from analysis.

A number of indicators were used to determine actual resource use in the

Sunnyside and Brooklyn neighborhoods. Since it was not possible to obtain actual energy household energy use, a proxy measure was used. As mentioned, increasing or decreasing temperature settings in the home can have a notable effect on how much energy is used. Two sets of questions were asked of respondents in order to determine average temperature settings and average energy bills for both summer and winter (used as a proxy for overall energy use). Again, there was no significant difference between the two neighborhoods for both of these measures (Table 7). 
Table 7 - Average Temperature and Cost of Energy

\begin{tabular}{|c|c|c|}
\hline \multicolumn{2}{|c|}{ Sunnyside } & Brooklyn \\
\hline Average Temperature & $73.5^{\circ} \mathrm{F}$ & $75^{\circ} \mathrm{F}$ \\
\hline Summer & $66.3^{\circ} \mathrm{F}$ & $66.15^{\circ} \mathrm{F}$ \\
\hline Winter & $\$ 55.71$ & $\$ 54.70$ \\
\hline Average Energy Cost (Electric) & $\$ 82.92$ & $\$ 77.16$ \\
\hline Summer & & \\
\hline Winter & $\$ 29.37$ & $\$ 28.77$ \\
\hline Average Energy Cost (Gas) & $\$ 84.10$ & $\$ 84.20$ \\
\hline Summer &
\end{tabular}

Data on subscribers to Portland General Electric’s (PGE) Green Power Program ${ }^{32}$ was also reviewed to determine if there was any difference between the two neighborhoods in subscription to the program. Unfortunately, it was not possible to get exact figures on how many subscribers were in each neighborhood, but it was possible to get aggregated data by zip code for residential participation. The two zip codes that fall within the Sunnyside Neighborhood (97214 and 97215), both have a 24.3\% to 27\% penetration rate of PGE's Green Power Program, which is the highest rate in the Portland metropolitan area (Green Power). The Brooklyn neighborhood (entirely contained in the 97202 zip code) was somewhat lower than Sunnyside, with a $21.6 \%$ to $24.3 \%$ participation rate (Green Power).

\footnotetext{
${ }^{32}$ PGE's Green Power Program offers customers three renewable power options that they can opt-into for a small cost increase per kWh. The three options are Green Source (a supply mix consisting of wind, lowimpact Hydro, biomass, and geothermal sources), Clean Wind (traditional supply mix of nuclear, coal, natural gas, and hydro plus wind), and Habitat Support (an add on to the Green Source and Clean Wind options that provides habitat support and restoration for Salmon and other fish species) (Green Power).
} 
Finally, water usage between the two neighborhoods was analyzed to determine if there were any differences. Data for 2010 was supplied by the Portland Water Bureau. These data were imported into ArcGIS to limit it to the Sunnyside and Brooklyn neighborhood boundaries. On average, Sunnyside residents used 9,761 gallons of water quarterly and Brooklyn used 10,120 gallons quarterly (n=300 and n=244 respectively). Although Sunnyside residents used slightly less water in 2010 than their Brooklyn counterparts, the difference was not found to be statistically significant.

\section{Transportation}

Transportation generally makes up a large portion of an individual’s total energy expenditure. Respondents were asked various questions about how they get around the city and what aspects of their neighborhood either hinder or encourage their use of alternative forms of transportation (i.e., walking, cycling, or public transportation). To begin, it is important to understand the availability of public transportation and cycling infrastructure in the two neighborhoods. Figure 22 and Figure 23 (below) are maps of alternative transportation infrastructure in the two neighborhoods. The Brooklyn neighborhood has a number of bus lines traversing the neighborhood boundaries. This offers quick access to the downtown area for most residents in the neighborhood. Cycling infrastructure (i.e., bike lanes and boulevards) is limited in the neighborhood. The Brooklyn neighborhood is lacking in bike infrastructure, other than the Springwater 
Corridor (located on the banks of the Willamette River). ${ }^{33}$ It is difficult and inconvenient for Brooklyn residents to use this multi-use path due to access issues to the Willamette River.

When reviewing the Sunnyside transportation map (Figure 23), one can see that the public transportation infrastructure is similar to the Brooklyn neighborhood. The neighborhood has three frequent service bus lines (lines that operate every 15 minutes during peak hours) that transverse the neighborhood. One obvious difference between the neighborhoods is Sunnyside's bicycle routes. Currently, there are two well-used routes that run north to south in the eastern section of the neighborhood, and one route that nearly run the entire length of the neighborhood from the east to west. Another difference between the two neighborhoods that these maps do not illustrate is the walkability of the neighborhoods. Both neighborhoods are complete with easily accessible sidewalks, however, unlike Sunnyside, pedestrians in Brooklyn must contend with busy traffic on Milwaukee Avenue and Powell Boulevard, both of which are wide streets with fast moving cars.

\footnotetext{
${ }^{33}$ The Springwater Corridor is a multi-use path that is only accessible to pedestrians and cyclists. This route allows for easy commuting between downtown Portland and the Sellwood neighborhood.
} 
Figure 22 - Alternative Transportation Infrastructure in the Brooklyn Neighborhood

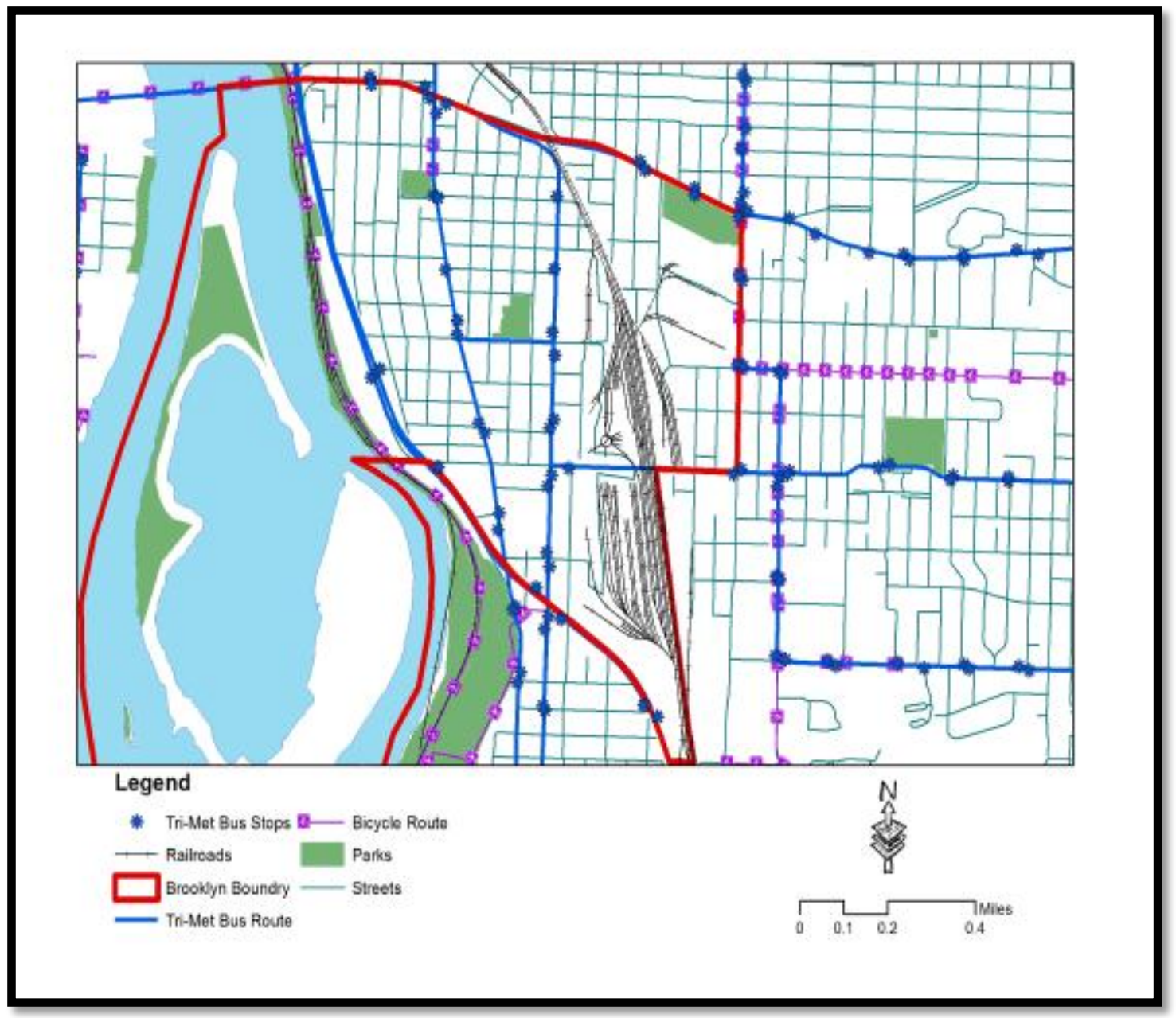


Figure 23 - Alternative Transportation Infrastructure in the Sunnyside Neighborhood

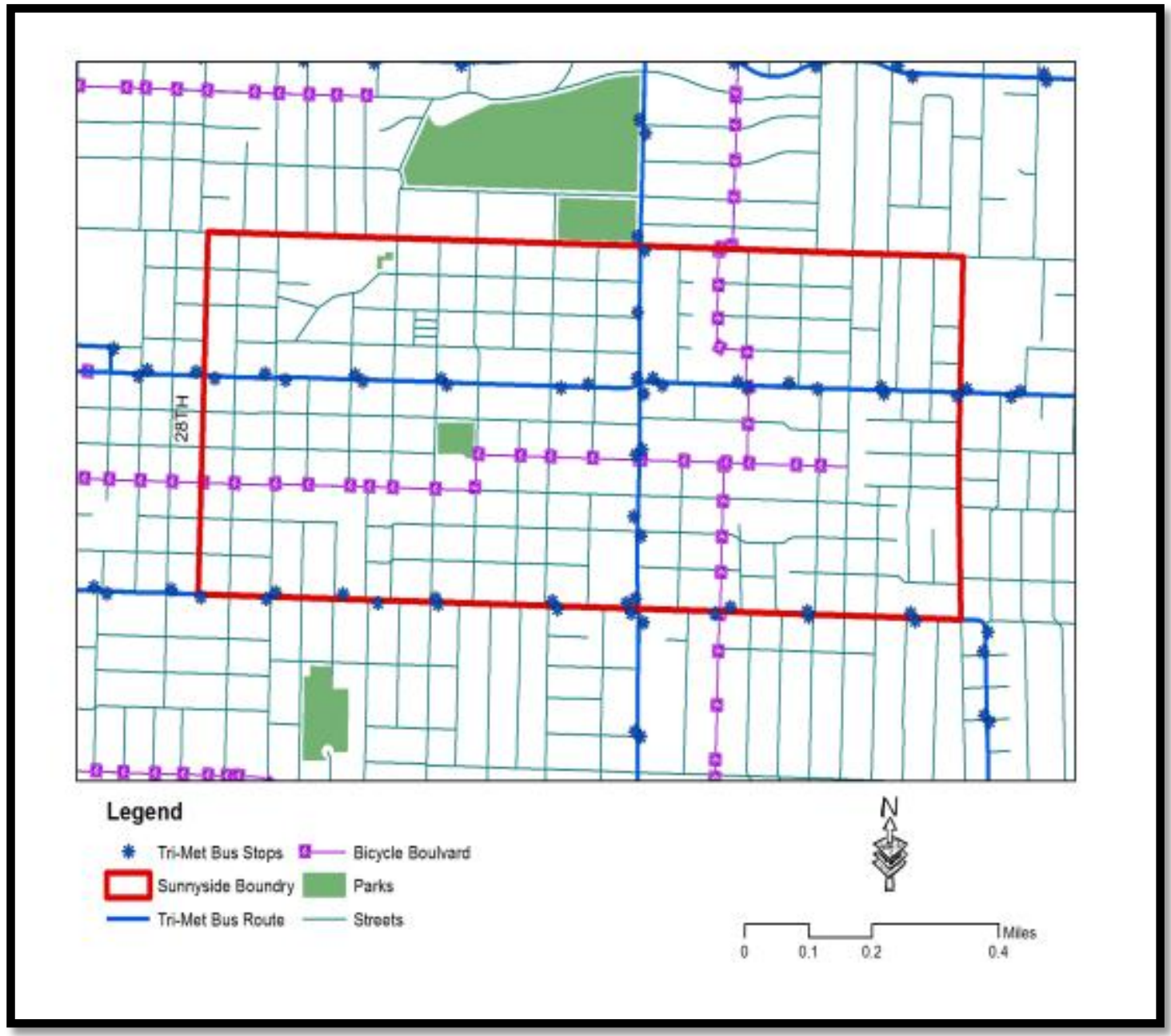

The two neighborhoods did not differ in terms of vehicle ownership. Nearly all residents of the Brooklyn and Sunnyside neighborhoods owned or leased at least one vehicle (90\% and 89\% respectively). Similarly, there were no significant differences found in vehicle use between the two neighborhoods. Approximately half of respondents reported driving between ten and 59 miles per week (Brooklyn - 50\% and Sunnyside 46\%, Table 8). 
Table 8 - Number of Miles Driven Each Week

\begin{tabular}{|l|c|c|c|c|c|c|}
\hline \multirow{2}{*}{ Miles Driven } & \multicolumn{2}{|c|}{ Brooklyn (n=131) } & \multicolumn{2}{c|}{ Sunnyside (n=158) } & \multicolumn{2}{c|}{ Total (n=289) } \\
\cline { 2 - 7 } & Count & Percent & Count & Percent & Count & Percent \\
\hline Does not drive & 19 & $15 \%$ & 26 & $17 \%$ & 45 & $16 \%$ \\
\hline Less than 10 miles & 5 & $4 \%$ & 16 & $10 \%$ & 21 & $7 \%$ \\
\hline $\mathbf{1 0}$ to $\mathbf{1 9}$ miles & 17 & $13 \%$ & 20 & $13 \%$ & 37 & $13 \%$ \\
\hline $\mathbf{2 0}$ to $\mathbf{3 9}$ miles & 30 & $23 \%$ & 28 & $18 \%$ & 58 & $20 \%$ \\
\hline $\mathbf{4 0}$ to $\mathbf{5 9}$ miles & 18 & $14 \%$ & 24 & $15 \%$ & 42 & $15 \%$ \\
\hline $\mathbf{6 0}$ to 99 miles & 17 & $13 \%$ & 14 & $9 \%$ & 31 & $11 \%$ \\
\hline $\mathbf{1 0 0}$ miles or more & 25 & $19 \%$ & 30 & $19 \%$ & 55 & $19 \%$ \\
\hline Total & 131 & $100 \%$ & 158 & $100 \%$ & 289 & $100 \%$ \\
\hline
\end{tabular}

Note. Twenty-five “don’t know” responses were removed from analysis.

The two neighborhoods did differ in reported walking and public transportation usage. Overall, Sunnyside respondents were more likely to report walking daily in their neighborhood than Brooklyn residents (Brooklyn - 49\% and Sunnyside - 68\%, Figure 24). ${ }^{34}$ Interestingly, public transportation use did differ between the neighborhoods. As mentioned above, public transportation infrastructure in the two neighborhoods is fairly similar. The only difference is Brooklyn's close proximity to downtown Portland, which would lead to the assumption that Brooklyn would be more likely to utilize this service. This however, was not found to be the case. Sunnyside neighborhood respondents were more likely to report using public transit than their Brooklyn counterparts (Figure 25). ${ }^{35}$ One of the biggest differences between the two neighborhoods was reporting "never" using public transportation. Ten percent of Sunnyside respondents reported never using public transportation, whereas more than double the amount of Brooklyn residents (21\%) reported "never" using public transportation.

\footnotetext{
${ }^{34} \chi^{2}(6, \mathrm{n}=312)=19.92, \mathrm{p}=.003$.

${ }^{35} \chi^{2}(6, n=312)=15.478, p=.017$.
} 
Figure 24 - Reported Walking in the Neighborhood

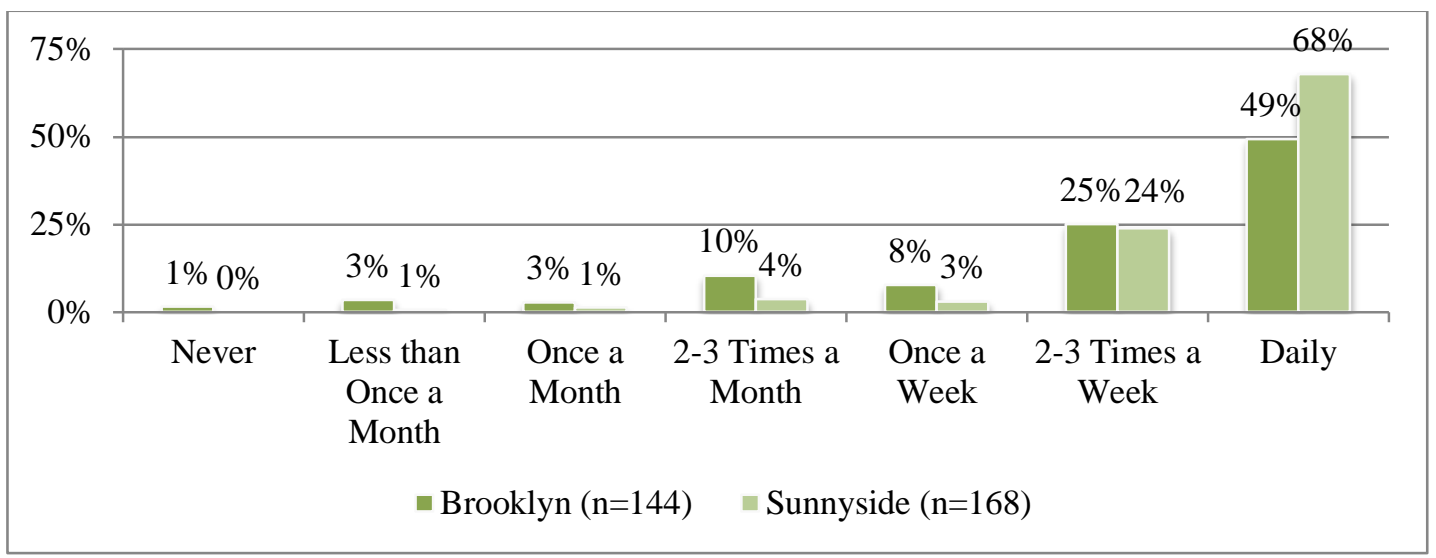

Note. Two “don’t know” responses were excluded from analysis.

Figure 25 - Reported Public Transportation Use

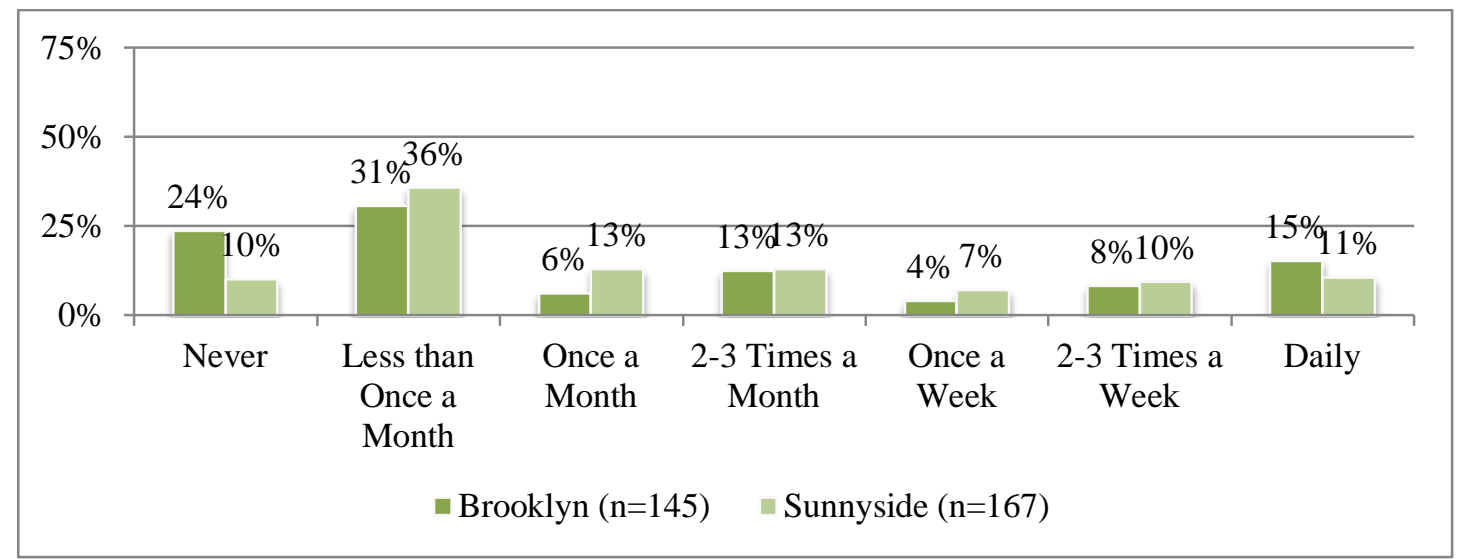

Note. One “don’t know” and one “refused” response was excluded from analysis.

Surprisingly, there were no significant differences between the two

neighborhoods in terms of bicycle usage (Figure 26). It is difficult to explain why this may be, however, one possible explanation is that both neighborhoods have excellent access to public transportation, and thus residents may prefer to utilize public transit over cycling. 
Figure 26 - Reported Bicycle Use

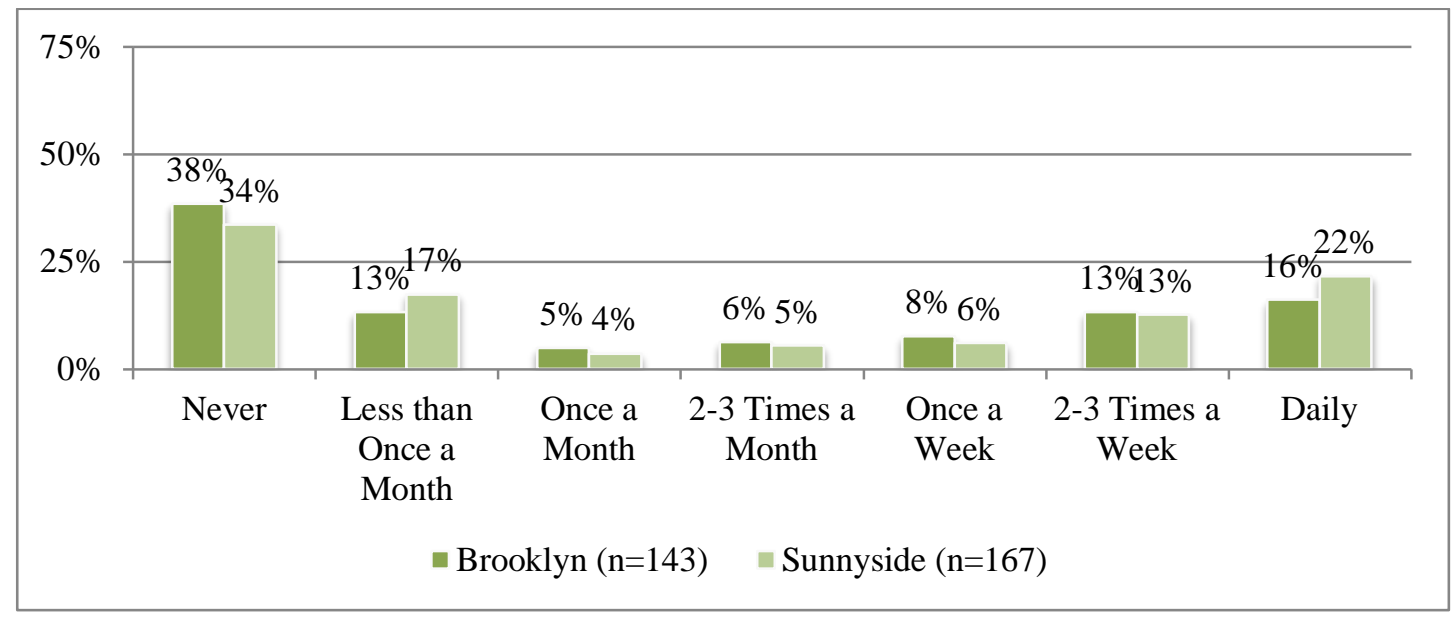

Note. Two “don’t know” and two “refused” responses were excluded from analysis.

Respondents were next asked what aspects of their neighborhood either encouraged or discouraged their use of alternative transportation. Table 9 provides a breakdown of responses that were provided by respondents that encourage alternative transportation use. There were a number of significant differences between the two neighborhoods. First, Sunnyside respondents were much more likely to report having nearby destination as an encouraging factor to using alternative transportation (Brooklyn $-61 \%$ and Sunnyside $-93 \%) .{ }^{36}$

Surprisingly, Sunnyside residents were also more likely to report nearby transit stops an encouraging aspect of their neighborhood compared to Brooklyn respondents (Brooklyn - 71\% and Sunnyside - 83\%). ${ }^{37}$ Seeing others using alternative transportation (mainly biking and walking) was also more likely to be an encouraging aspect in the Sunnyside neighborhood compared to Brooklyn (Brooklyn - 31\% and Sunnyside -

\footnotetext{
${ }^{36} \chi^{2}(1, \mathrm{n}=312)=47.22, \mathrm{p}=.001$.

${ }^{37} \chi^{2}(1, n=312)=6.89, p=.009$.
} 
49\%). ${ }^{38}$ Finally, the presence of bicycle infrastructure in Sunnyside was more likely to be reported as an encouraging aspect to alternative transportation use than Brooklyn (Brooklyn $-22 \%$ and Sunnyside $-46 \%)^{39}$

Table 9 - Aspects that Encourage Alternative Transportation Use (Multiple Responses Allowed)

\begin{tabular}{|c|c|c|c|c|c|c|}
\hline \multirow{2}{*}{ Encouragement } & \multicolumn{2}{|c|}{$\begin{array}{c}\text { Brooklyn } \\
(n=144)\end{array}$} & \multicolumn{2}{|c|}{$\begin{array}{c}\text { Sunnyside } \\
(n=168)\end{array}$} & \multicolumn{2}{|c|}{ Total $(n=312)$} \\
\hline & Count & Percent & Count & Percent & Count & Percent \\
\hline Nothing & 9 & $6 \%$ & 3 & $2 \%$ & 12 & $4 \%$ \\
\hline Nearby destinations & 88 & $61 \%$ & 157 & $93 \%$ & 245 & $79 \%$ \\
\hline Nearby transit stops & 102 & $71 \%$ & 140 & $83 \%$ & 242 & $78 \%$ \\
\hline $\begin{array}{l}\text { Seeing other people using alternative } \\
\text { transportation }\end{array}$ & 44 & $31 \%$ & 83 & $49 \%$ & 127 & $41 \%$ \\
\hline Bicycle infrastructure & 32 & $22 \%$ & 78 & $46 \%$ & 110 & $35 \%$ \\
\hline Low levels of vehicle traffic / Safety & 47 & $33 \%$ & 59 & $35 \%$ & 106 & $34 \%$ \\
\hline The built environment & 5 & $3 \%$ & 7 & $4 \%$ & 12 & $4 \%$ \\
\hline Other & 6 & $4 \%$ & 13 & $8 \%$ & 19 & $6 \%$ \\
\hline
\end{tabular}

Note. One “don’t know” and one “refused” response was removed form analysis.

In terms of aspects that discourage use of alternative transportation, nearly half of Brooklyn respondents (43\%) and nearly two-thirds of Sunnyside respondents (62\%) reported no aspects that discourage use (

Table 10). The only significant difference between the two neighborhoods was not having close destinations in the neighborhood. Nearly one-third or Brooklyn respondents (30\%) reported this as a discouraging factor to using alternative transportation, whereas only one respondent in the Sunnyside neighborhood reported this being a factor. ${ }^{40}$

\footnotetext{
${ }^{38} \chi^{2}(1, n=312)=11.41, p=.001$

${ }^{39} \chi^{2}(1, n=312)=19.89, p=.001$

${ }^{40} \chi^{2}(1, n=300)=51.62, p=.001$
} 
Table 10 - Aspects that Discourage Alternative Transportation Use (Multiple Responses Allowed)

\begin{tabular}{|l|c|c|c|c|c|c|}
\hline \multirow{2}{*}{\multicolumn{1}{|c}{ Discouragement }} & \multicolumn{2}{c|}{ Brooklyn (n=135) } & \multicolumn{2}{c|}{$\begin{array}{c}\text { Sunnyside } \\
\text { (n=165) }\end{array}$} & \multicolumn{2}{c|}{ Total (n=300) } \\
\cline { 2 - 7 } & Count & Percent & Count & Percent & Count & Percent \\
\hline Nothing & 58 & $43 \%$ & 102 & $62 \%$ & 160 & $53 \%$ \\
\hline Safety of walking or biking & 36 & $27 \%$ & 33 & $20 \%$ & 69 & $23 \%$ \\
\hline $\begin{array}{l}\text { No close destinations in } \\
\text { neighborhood }\end{array}$ & 41 & $30 \%$ & 1 & $1 \%$ & 42 & $14 \%$ \\
\hline $\begin{array}{l}\text { No access to transit stops / Hassel } \\
\text { of public transit / Cost }\end{array}$ & 6 & $4 \%$ & 15 & $9 \%$ & 21 & $7 \%$ \\
\hline $\begin{array}{l}\text { Lack of bicycle or pedestrian } \\
\text { infrastructure }\end{array}$ & 15 & $11 \%$ & 5 & $3 \%$ & 20 & $7 \%$ \\
\hline Disability & 4 & $3 \%$ & 6 & $4 \%$ & 10 & $3 \%$ \\
\hline Other & 5 & $4 \%$ & 8 & $5 \%$ & 13 & $4 \%$ \\
\hline
\end{tabular}

Note. Five “don’t know” and seven “refused” responses were removed form analysis.

\section{Environmental Concern}

Respondents were asked a series of five questions adapted from the New Ecological Paradigm (NEP) scale. These questions were designed to determine the level of environmental concern one possesses. Each respondent was asked to respond to each statement using a five-point scale, where " 1 ” meant "strongly disagree” and " 5 " meant "strongly agree.” To limit the bias from the order of questions effecting answers to subsequent questions, these five questions were randomly presented to survey respondents.

Table 11 presents the mean ratings given to each of the five statements. Overall, respondents from both neighborhoods exhibited fairly high levels of environmental concern. After normalizing scores (recoding so that all scores were in the same negative to positive direction) Sunnyside had a mean score of 4.37 and Brooklyn 4.43 (for all 
statements combined). The difference between these and individual scores was not found to be significant.

Table 11 - Mean Ratings of Environmental Concern

\begin{tabular}{|l|c|c|c|}
\hline \multicolumn{1}{|c|}{ Statement } & \multicolumn{2}{|c|}{ Mean Score } \\
\cline { 2 - 4 } & $\begin{array}{c}\text { Brooklyn } \\
\text { (n=145) }\end{array}$ & $\begin{array}{c}\text { Sunnyside } \\
\text { (n=169) }\end{array}$ & $\begin{array}{c}\text { Total } \\
\text { (n=314) }\end{array}$ \\
\hline $\begin{array}{l}\text { "I really don't care much about natural resources use and see } \\
\text { little reason to conserve." }\end{array}$ & 1.28 & 1.23 & 1.25 \\
\hline $\begin{array}{l}\text { "There's not very much an individual can do to conserve } \\
\text { natural resources that will have an impact in the long run." }\end{array}$ & 1.55 & 1.64 & 1.60 \\
\hline $\begin{array}{l}\text { "We could all use less or fewer natural resources than we do } \\
\text { and if many people conserved, we could make a difference.” }\end{array}$ & 4.4 & 4.29 & 4.34 \\
\hline $\begin{array}{l}\text { "Regardless of whether it makes a difference, everyone has a } \\
\text { moral obligation to do the best they can to conserve natural } \\
\text { resources." }\end{array}$ & 4.16 & 3.91 & 4.03 \\
\hline $\begin{array}{l}\text { "I would rather just pay more for natural resources rather } \\
\text { than be asked to conserve them." }\end{array}$ & 1.55 & 1.53 & 1.54 \\
\hline
\end{tabular}

\section{Demographics}

The final section of the survey asked respondents a number of demographic questions to determine if survey respondents matched the overall population of the neighborhood as determined by the 2010 U.S. Census. Since systematic random sampling was not used for this research, the demographic findings below do not match the actual population of the neighborhood. This finding diminishes the possibility of being able to generalize these results to the overall population of the neighborhoods.

Over half of survey respondents from both neighborhoods owned their homes (both 58\%) with the remaining reporting they rented their home (both 42\%). Of those respondents renting their home, over half of Brooklyn respondents (57\%) reported living in a multi-unit apartment complex, whereas less than one-third of Sunnyside respondents (30\%) reported living in this type of rental unit (Table 12). 
Table 12 - Type of Rental Unit

\begin{tabular}{|l|c|c|c|c|c|c|}
\hline \multirow{2}{*}{\multicolumn{1}{c|}{ Type }} & \multicolumn{2}{c|}{ Brooklyn (n=58) } & Sunnyside (n=69) & \multicolumn{2}{c|}{ Total (n=127) } \\
\cline { 2 - 8 } & Count & Percent & Count & Percent & Count & Percent \\
\hline Split or shared house/ multiple units & 14 & $24 \%$ & 30 & $43 \%$ & 44 & $35 \%$ \\
\hline Multi-unit apartment complex & 33 & $57 \%$ & 21 & $30 \%$ & 54 & $43 \%$ \\
\hline Single-family house & 11 & $19 \%$ & 17 & $25 \%$ & 28 & $22 \%$ \\
\hline Total & 58 & $100 \%$ & 69 & $100 \%$ & 127 & $100 \%$ \\
\hline
\end{tabular}

Note. One “don’t know” and three “refused” responses were removed form analysis.

The majority of survey respondents were female (Brooklyn - 71\% and Sunnyside 61\%). Overall, most survey respondents for each neighborhood were between 25 and 34 years of age (Brooklyn - 27\% and Sunnyside 32\%).

Table 13 - Age Groups of Survey Respondents

\begin{tabular}{|l|c|c|c|c|c|c|}
\hline \multirow{2}{*}{ Age } & \multicolumn{2}{|c|}{ Brooklyn (n=144) } & Sunnyside (n=167) & \multicolumn{2}{c|}{ Total (n=311) } \\
\cline { 2 - 7 } & Count & Percent & Count & Percent & Count & Percent \\
\hline $\mathbf{1 8 - 2 4}$ & 8 & $6 \%$ & 5 & $3 \%$ & 13 & $4 \%$ \\
\hline $\mathbf{2 5 - 3 4}$ & 39 & $27 \%$ & 53 & $32 \%$ & 92 & $30 \%$ \\
\hline $\mathbf{3 5 - 4 4}$ & 41 & $28 \%$ & 31 & $19 \%$ & 72 & $23 \%$ \\
\hline $\mathbf{4 5 - 5 4}$ & 18 & $13 \%$ & 32 & $19 \%$ & 50 & $16 \%$ \\
\hline $\mathbf{5 5 - 6 4}$ & 26 & $18 \%$ & 34 & $20 \%$ & 60 & $19 \%$ \\
\hline $\mathbf{6 5 - 7 5}$ & 9 & $6 \%$ & 11 & $7 \%$ & 20 & $6 \%$ \\
\hline $\mathbf{7 6}$ or over & 3 & $2 \%$ & 1 & $1 \%$ & 4 & $1 \%$ \\
\hline Total & 144 & $100 \%$ & 167 & $100 \%$ & 311 & $100 \%$ \\
\hline
\end{tabular}

Note. Three "refused" responses were removed form analysis.

Roughly half of survey respondents from both neighborhoods were employed full-time (Brooklyn - 41\% and Sunnyside 48\%, Table 14). Interestingly, over one-third of respondents from both neighborhoods reported having a master's degree or higher (Brooklyn - 34\% and Sunnyside 37\%, Table 15). This could be a potential bias in the survey and most likely is not representative of either neighborhood. 
Table 14 - Employment Status

\begin{tabular}{|l|c|c|c|c|c|c|}
\hline \multirow{2}{*}{\multicolumn{1}{|c}{ Status }} & \multicolumn{2}{c|}{ Brooklyn (n=145) } & \multicolumn{2}{c|}{ Sunnyside (n=167) } & \multicolumn{2}{c|}{ Total (n=312) } \\
\cline { 2 - 7 } & Count & Percent & Count & Percent & Count & Percent \\
\hline Full time for an employer & 60 & $41 \%$ & 80 & $48 \%$ & 140 & $45 \%$ \\
\hline Part time for an employer & 27 & $19 \%$ & 19 & $11 \%$ & 46 & $15 \%$ \\
\hline Self-employed & 25 & $17 \%$ & 20 & $12 \%$ & 45 & $14 \%$ \\
\hline Unemployed & 15 & $10 \%$ & 12 & $7 \%$ & 27 & $9 \%$ \\
\hline Retired & 11 & $8 \%$ & 21 & $13 \%$ & 32 & $10 \%$ \\
\hline Student & 7 & $5 \%$ & 15 & $9 \%$ & 22 & $7 \%$ \\
\hline Total & 145 & $100 \%$ & 167 & $100 \%$ & 312 & $100 \%$ \\
\hline
\end{tabular}

Note. Two "refused” responses were removed form analysis.

Table 15 - Educational Attainment

\begin{tabular}{|l|c|c|c|c|c|c|}
\hline \multirow{2}{*}{\multicolumn{1}{|c}{ Education }} & \multicolumn{2}{|c|}{ Brooklyn (n=143) } & \multicolumn{2}{c|}{ Sunnyside (n=167) } & \multicolumn{2}{c|}{ Total (n=310) } \\
\cline { 2 - 7 } & Count & Percent & Count & Percent & Count & Percent \\
\hline High school graduate & 4 & $3 \%$ & 1 & $1 \%$ & 5 & $2 \%$ \\
\hline $\begin{array}{l}\text { Some college or other } \\
\text { post-secondary education }\end{array}$ & 33 & $23 \%$ & 31 & $19 \%$ & 64 & $21 \%$ \\
\hline College graduate & 40 & $28 \%$ & 60 & $36 \%$ & 100 & $32 \%$ \\
\hline Some post-graduate & 17 & $12 \%$ & 13 & $8 \%$ & 30 & $10 \%$ \\
\hline Master's degree or higher & 49 & $34 \%$ & 62 & $37 \%$ & 111 & $36 \%$ \\
\hline Total & 143 & $100 \%$ & 167 & $100 \%$ & 310 & $100 \%$ \\
\hline
\end{tabular}

Note. Four "refused” responses were removed form analysis.

Unsurprisingly, reported annual household income for both neighborhoods was

fairly high. Approximately one-third of respondents from both neighborhoods reported an annual income between $\$ 50,000$ and $\$ 99,999$ a year (before taxes) (Brooklyn - 32\% and Sunnyside 38\%, Table 16).

Table 16 - Annual Household Income

\begin{tabular}{|l|c|c|c|c|c|c|}
\hline \multirow{2}{*}{ Income } & \multicolumn{2}{|c|}{ Brooklyn (n=132) } & Sunnyside (n=149) & \multicolumn{2}{c|}{ Total (n=281) } \\
\cline { 2 - 7 } & Count & Percent & Count & Percent & Count & Percent \\
\hline Less than \$10,000 & 5 & $4 \%$ & 9 & $6 \%$ & 14 & $5 \%$ \\
\hline $\mathbf{\$ 1 0 , 0 0 0}-\mathbf{\$ 1 4 , 9 9 9}$ & 9 & $7 \%$ & 8 & $5 \%$ & 17 & $6 \%$ \\
\hline $\mathbf{\$ 1 5 , 0 0 0}-\mathbf{\$ 2 4 , 9 9 9}$ & 13 & $10 \%$ & 13 & $9 \%$ & 26 & $9 \%$ \\
\hline $\mathbf{\$ 2 5 , 0 0 0}-\mathbf{\$ 3 4 , 9 9 9}$ & 20 & $15 \%$ & 14 & $9 \%$ & 34 & $12 \%$ \\
\hline $\mathbf{\$ 3 5 , 0 0 0}-\mathbf{\$ 4 9 , 9 9 9}$ & 25 & $19 \%$ & 17 & $11 \%$ & 42 & $15 \%$ \\
\hline $\mathbf{\$ 5 0 , 0 0 0}-\mathbf{\$ 7 4 , 9 9 9}$ & 28 & $21 \%$ & 36 & $24 \%$ & 64 & $23 \%$ \\
\hline
\end{tabular}




\begin{tabular}{|l|c|c|c|c|c|c|}
\hline \multirow{2}{*}{\multicolumn{1}{|c}{ Income }} & \multicolumn{2}{|c|}{ Brooklyn (n=132) } & Sunnyside (n=149) & \multicolumn{2}{c|}{ Total (n=281) } \\
\cline { 2 - 7 } & Count & Percent & Count & Percent & Count & Percent \\
\hline $\mathbf{\$ 7 5 , 0 0 0}$ - \$99,999 & 14 & $11 \%$ & 21 & $14 \%$ & 35 & $12 \%$ \\
\hline $\mathbf{\$ 1 0 0 , 0 0 0}$ or more & 18 & $14 \%$ & 31 & $21 \%$ & 49 & $17 \%$ \\
\hline Total & 132 & $100 \%$ & 149 & $100 \%$ & 281 & $100 \%$ \\
\hline
\end{tabular}

Note. Six “don’t know” and 27 "refused” responses were removed form analysis.

Finally, respondents were provided a number of categories and asked to best

describe their race and/or ethnicity (Table 17). White or Caucasian was reported by

almost all respondents in both neighborhoods.

Table 17 - Race or Ethnicity

\begin{tabular}{|l|c|c|c|c|c|c|}
\hline \multirow{2}{*}{\multicolumn{1}{|c|}{ Race }} & \multicolumn{2}{|c|}{ Brooklyn (n=138) } & \multicolumn{2}{c|}{$\begin{array}{c}\text { Sunnyside } \\
\text { (n=165) }\end{array}$} & \multicolumn{2}{c|}{ Total (n=303) } \\
\cline { 2 - 7 } & Count & Percent & Count & Percent & Count & Percent \\
\hline White or Caucasian & 134 & $97 \%$ & 160 & $97 \%$ & 294 & $97 \%$ \\
\hline Asian or Asian American & 5 & $4 \%$ & 5 & $3 \%$ & 10 & $3 \%$ \\
\hline Spanish, Hispanic, or Latino & 2 & $1 \%$ & 8 & $5 \%$ & 10 & $3 \%$ \\
\hline Black or African American & 1 & $1 \%$ & 1 & $1 \%$ & 2 & $1 \%$ \\
\hline $\begin{array}{l}\text { American Indian or Alaskan } \\
\text { Native }\end{array}$ & 0 & $0 \%$ & 1 & $1 \%$ & 1 & $0 \%$ \\
\hline
\end{tabular}

Note. 11 "refused” responses were removed form analysis. 


\section{Chapter 6: Discussion}

In the following chapter, findings will be discussed in relation to literature presented in Chapter 3. My main research question was: How does neighborhood identity affect household-level sustainable behaviors? Prior to collecting data, eight hypotheses were formulated based on this question:

1. Sunnyside residents have a more environmentally sustainable identity than Brooklyn residents.

2. Sunnyside households are more sustainable than Brooklyn households.

3. Sunnyside residents participate in neighborhood organizations and have more social contacts than Brooklyn residents.

4. Residents that 1) interact with their neighbors and 2) participate in neighborhood organizations have higher reported levels of household sustainability.

5. Sunnyside residents exhibit more environmental concern than Brooklyn residents.

6. The neighborhood that has more alternative transportation choices have more reported use of those transportation modes than the neighborhood with less alternative transportation choices.

7. Sunnyside residents are more likely to change their behaviors to be more sustainable after moving into the neighborhood than Brooklyn residents.

8. The presence of sustainable features in the neighborhood influence how sustainable its residents are. 


\section{Hypothesis 1}

The first hypothesis tested was that Sunnyside residents would report their neighborhood as having a more environmentally sustainable identity than Brooklyn residents. The qualitative data gathered, along with neighborhood documents, support this hypothesis. Sunnyside, unlike Brooklyn, has a clear policy of promoting adherence to sustainable behaviors amongst its residents and local businesses. This difference is evident in each of the neighborhood’s plan. The 1991 Brooklyn Neighborhood Plan does not mention sustainability or environmental stewardship as being a priority for the neighborhood. Instead, Brooklyn focuses on reuniting a divided neighborhood and promoting the neighborhood's historic features and identity. The 1999 Sunnyside Neighborhood Plan, on the other hand, established an environment policy, which aimed to increase environmental awareness among residents and limit the neighborhood's impact on the natural environment. Since establishing this policy, Sunnyside has made some progress. Neighborhood initiatives (such as encouraging participation in Southeast Uplift's Solarize Southeast project, providing information regarding sustainability to residents through the neighborhood newsletter, and encouraging community engagement to increase levels of social sustainability) are currently being promoted throughout the neighborhood. The Sunnyside Neighborhood Association has established a Sustainability Committee, which aims to move sustainable initiatives forward in the neighborhood. ${ }^{41}$

Residents of Sunnyside also clearly identify with the 'sustainable' identity of the neighborhood. As mentioned in Chapter 5, one in five Sunnyside residents mentioned

\footnotetext{
${ }^{41}$ It should be noted, however, that according to neighborhood stakeholders very few residents attend sustainability committee meetings.
} 
sustainability or environmental stewardship when explaining what made Sunnyside unique from other neighborhoods. Conversely, no Brooklyn residents reported sustainability or environmental stewardship as being defining characteristics of their neighborhood. This suggests that neighborhood organizations, such as neighborhood associations, can be influential in fostering sustainability among neighborhood residents, at least in terms of what they think their neighborhood identity is. When looking at data gathered about how residents perceived their neighborhood's level of sustainability (using a scale of “ 1 ” to “10” where “ 1 ” meant "not at all sustainable” and 10 meant "completely sustainable”), there was not a significant difference between the two neighborhoods (Brooklyn $M=6.57$, Sunnyside $M=6.91$ ). This finding is contrary to what one would expect. You would think that if people identify with the neighborhood as having a sustainable identity that there might be a difference in perceived sustainability that would be apparent in these ratings. There are a number of possible explanations for this finding. Forest and Ade (2001) argue that the neighborhood is an important arena of socialization. However, they acknowledge that neighborhood boundaries are fluid in terms of socialization and influence on residents' behavior may be as much influenced by what is occurring within the boundaries as what is occurring outside the neighborhood boundaries.

Another explanation is that residents simply do not view sustainability as a neighborhood scale issue. Their idea of sustainability (rightly so) may go beyond neighborhood boundaries and be influenced by how they feel about the City of Portland in general. For example, when residents consider sustainability, things such as recycling 
and composting are likely to come to mind. In survey responses, recycling and composting practices (which are city-wide programs) were the most commonly reported aspects of what they thought made their neighborhood sustainable. This finding suggests that fostering a sustainable identity may be more effective at the city or regional level, rather than at the neighborhood level.

\section{Hypothesis 2}

When looking at the actual behavior of residents, the influence of a neighborhood identity was not as clear. The second hypothesis tested was that Sunnyside residents would exhibit more sustainable behaviors than Brooklyn residents. First, respondents were asked how influential the neighborhood has been in their adoption of sustainable practices. Overall Sunnyside residents reported their neighborhood being more influential in their adoption of sustainable practices than Brooklyn residents. Respondents were then asked how much influence their neighborhood had on seven specific sustainable behaviors: electricity saving, water saving, heating and cooling adjustments, recycling, composting, and sustainable purchasing. Overall, no significant differences were found between Sunnyside and Brooklyn on these indicators. However, Brooklyn residents were more likely to report "never" performing any of these sustainable behaviors. In other words, more Brooklyn residents were completely unwilling, or unable to, practice certain sustainable behaviors. These findings suggest that Sunnyside and Brooklyn residents may be equally sustainable in their practices; however, Sunnyside residents may be slightly more willing to practice sustainable behaviors than Brooklyn residents. 
Another aspect of sustainability analyzed was residents' use of electricity, natural gas, and water. Unfortunately, specific household-level data for electricity and natural gas could not be obtained because of strict non-disclosure rules utility companies must abide by. Instead, self-reported temperature and billing costs were collected and used for analysis. With any self-reported data, there are concerns of the reliability of the data provided; however, this was the best approach available. Overall, the Sunnyside and Brooklyn neighborhoods did not differ in terms of their energy usage.

Water usage was also analyzed to determine if there were differences between the two neighborhoods. There was not a significant difference between the Sunnyside and Brooklyn neighborhoods in the amount of water households used. Additionally, since the survey results were anonymous, there was no way to connect responses to actual water usage to determine if there was a relationship between attitudes towards the environment and general household sustainability and water usage. Research has suggested that community-based social marketing can be effective in reducing residential water usage.

The lack of difference in water usage most likely indicates that neither neighborhood has made efforts to encourage residents to use less water.

\section{Hypothesis 3}

The level of social cohesion and social capital within the neighborhoods was also analyzed. In the third hypothesis, I thought that Sunnyside residents would report having more social contacts and participate in more neighborhood organizations than Brooklyn residents. This hypothesis was found to be only partially supported. Sunnyside residents reported participating in block parties and street fairs more than Brooklyn residents. 
Sunnyside has a yearly street fair, and Brooklyn does not. Still, with almost three-quarters of respondents from both neighborhoods reporting not participating in any neighborhood organizations, events, or activities, there is a clear need for more community engagement in both cases. The level of participation between the two neighborhoods was not significant. Since both had low levels of participation, residents may not be exposed to existing neighborhood-level outreach. This could partially explain why there is a lack of difference between the neighborhoods' level of sustainability, but may also be related to non-response bias.

The second part of this hypothesis dealt with interactions between residents. Theoretically, increases in social interactions should produce greater social cohesion and capital within a neighborhood. There is mixed evidence on the degree in which social capital and cohesion can influence sustainable behaviors, particularly in terms of household energy use. Normative beliefs are motivational in behavior change. Social norms are established through what individuals perceive to be normative through socialization. Knowing this basic social theory, survey questions were designed to determine the level of social interaction between residents in each neighborhood. It was important to determine if one neighborhood had higher reported levels of social contact with neighbors to see if this interaction could be influencing sustainable behaviors.

Respondents were asked to report the frequency of their social contact with neighbors and their agreement with four social aspects of their neighborhood. There was not a significant difference between the neighborhoods in the amount and type of interaction residents had with neighbors, both were low. One exception was the 
frequency of shopping within the neighborhoods. Sunnyside residents were significantly more likely to report shopping within the neighborhood on a daily basis. With the amount of local businesses in Sunnyside, compared to Brooklyn, this finding was not surprising. Previous research suggests that a dense built environment, and increased access to amenities, can increase social capital, community connections, and overall sustainability. Arguably, Sunnyside is more walkable and has more access to local amenities than Brooklyn. However, there was no difference in the strength of community connections within each neighborhood, therefore the connection between easy access to amenities and increased social capital was not supported by this research.

The neighborhoods did differ in terms of reported social aspects. Sunnyside residents were significantly more likely to report that their neighbors shared similar values with them and that the neighborhood supported relationships between neighbors. One would expect that increases in interaction between neighbors would have a positive effect on the degree of social capital and cohesion present, but this was not the case. It is possible that another variable, not addressed by this research, is influencing these social aspects, or that again, Sunnyside residents may be more idealistic and rating these aspects higher than they are in reality. Either way, it is not clear why interactions among neighbors were equal but the ratings on other social aspects (such as shared values and neighborhood supporting relationships) did differ.

\section{Hypothesis 4}

The next hypothesis tested in this research was that higher levels of engagement in the neighborhood (interacting with neighbors and participating in neighborhood 
organizations) will result in higher reported levels of household sustainability. To test this hypothesis, a composite score was created that provided each respondent with an engagement score between " 1 ” and "7," with "1" indicating no engagement and "7” indicating high engagement. Respondents were then categorized into either "low engagement" or "high engagement," depending on their composite score. For example, a respondent with a score of 5.6 would be assigned to the high engagement category, and a respondent with a 3.2 would be assigned to the low engagement category. A t-test was then used to determine if the two groups differed significantly in their level of sustainability (using the sustainability composite score of frequency of performing sustainable household behaviors).

The results from this analysis produced interesting findings suggesting that engagement does influence sustainability at some level. Sunnyside residents who had reported high engagement levels had a mean sustainable behavior score of 4.2 and those who reported low levels of engagement scored a 4.0. ${ }^{42}$ This difference was found to be marginally significant. ${ }^{43}$ Brooklyn residents who reported high levels of engagement also scored a 4.2 for their level of sustainable behavior. For those that had low levels of engagement, their sustainability score dropped to 4.1, which did not differ significantly from those residents who reported high engagement in their neighborhood.

However, when looking at the differences between high verses low levels of engagement, regardless of what neighborhood the respondent was in, it was found that

\footnotetext{
${ }^{42}$ On a 5 point scale, where 1 indicates low frequency of performing sustainable behaviors and 5 indicates a high frequency of performing sustainable behaviors

${ }^{43} \mathrm{t}(158)=-1.856, p=.065$
} 
those respondents who reported high levels of neighborhood engagement were significantly more likely to engage in sustainable behaviors more frequently (high engagement, $M=4.2$; low engagement, $M=4.1) .{ }^{44}$ Even though the difference in these scores is small, these findings suggest that being socially active in one's community and participating in community organizations can impact adherence to sustainable behaviors. This is perhaps because the more socially invested or the more social capital someone has in their neighborhood, the more likely they are to care about their community and desire to sustain it.

\section{Hypothesis 5}

Respondents were asked a series of five questions to gage their overall concern for the environment. Responses were combined to form a mean score of environmental concern for each respondent. Overall, concern for the environment did not differ between the two neighborhoods; both Sunnyside and Brooklyn residents show high levels of concern for the environment. Furthermore, statistical tests performed on whether high environmental concern was related to adherence to sustainable household behaviors were inconclusive. These findings do not support my initial hypothesis that there would be a difference in environmental concern between Sunnyside and Brooklyn residents. A possible explanation for both neighborhoods exhibiting similar concern for the environment could be because both neighborhoods are located in the same city. Portland is a unique American city because of its commitment to the environment over the past few decades. As discussed, Portland has pursued environmentally friendly and

\footnotetext{
${ }^{44} \mathrm{t}(293)=-2.243, p=.026$
} 
sustainable policies since the 1970s. It is expected that Portland's identity has a profound impact on its resident's attitudes toward the environment.

\section{Hypothesis 6}

An individual's transportation choices can have a significant impact on their level of sustainability. As discussed in Chapter 2, transportation constitutes a large portion of an individual's $\mathrm{CO}^{2}$ emissions. There were some interesting transportation differences between the Sunnyside and Brooklyn neighborhoods. First, vehicle ownership was found to be approximately the same for both neighborhoods, with about $90 \%$ of respondents reporting that they owned at least one car. Similarly, the number of miles driven each week was found to be virtually the same for each neighborhood.

When reviewing transportation infrastructure in the neighborhoods, it was apparent that they both have a similar density of public transportation infrastructure, however, Sunnyside has more complete and accessible bicycle infrastructure. Thus, it would be expected that both neighborhoods would have similar usage of public transportation and Sunnyside residents would report cycling more. This, however, was not supported by collected data. Sunnyside residents reported using public transportation more often than Brooklyn residents. This could be due to the Sunnyside neighborhood being generally more walkable, and thus more residents are willing to walk to transit stops. Adding support to this theory is that over two-thirds of Sunnyside residents reported walking in their neighborhood daily compared to less than half of Brooklyn residents. 
Surprisingly, there was no significant difference between the neighborhoods in terms of bicycle usage. Approximately one in five respondents reported riding a bicycle daily in their neighborhood. This was unexpected considering Sunnyside would seem to have more bicycle infrastructure than Brooklyn, which about half of Sunnyside residents

attributed to encouraging them to use alternative transportation (compared to one-fifth of Brooklyn residents). Reasons for this anomaly are not apparent. It could be that since Brooklyn is physically closer to downtown, residents are more apt to commute to work via bicycle regardless of whether or not the biking infrastructure is in place. In Sunnyside, people are more likely to use public transportation to go downtown since the Sunnyside neighborhood is slightly further away. Overall, data were inconclusive; Sunnyside has more biking infrastructure but reported less biking that Brooklyn residents, and Brooklyn has slightly more transit infrastructure, but Brooklyn residents reported using public transit less than Sunnyside residents.

\section{Hypothesis 7}

The next hypothesis tested was to see if Sunnyside residents became more sustainable after moving into the neighborhood than Brooklyn residents. I asked this question because I suspected that people might be moving into Sunnyside because of its sustainable identity, so I wanted to see if it was the neighborhood influencing people's behavior, or if the type of people moving to Sunnyside were already sustainably-minded people. Respondents were asked if, since moving into the neighborhood, their behaviors have become more or less sustainable. Nearly two-thirds of residents from both neighborhoods reported that they have become more sustainable since living there. 
Very few respondents from either neighborhood reported that their neighborhood had a negative effect on sustainable behaviors. Respondents who indicated their behaviors had become more sustainable were asked what aspects of the neighborhood might have caused this increase in sustainability. Nearly two in five respondents from both neighborhoods reported that the ability to compost increased their sustainability.

Curbside composting is relatively new for Portland residents. Curbside compost pick-up was debuted in October of 2011. It is therefore not surprising that this is salient in the minds of residents from both neighborhoods. Next, respondents mentioned the ability to recycle as being a factor in increased household sustainability. Again, these findings suggest that when considering sustainable practices, city-provided services (such as composting, recycling, and public transportation) are the most salient in the minds of respondents. ${ }^{45}$ This finding provides further evidence that the 'neighborhood' may not be a very useful unit of analysis when analyzing how ‘sustainable identity’ influences behavior.

\section{Hypothesis 8}

The next hypothesis tested was that the presence of sustainable features in the neighborhood would influence the level of sustainability in a household. Over half of residents from both neighborhoods (57\% - Sunnyside, 59\% - Brooklyn) reported that sustainable features (such as solar panels, rainwater catchment, gardening, etc.) seen in their neighborhood were influential on their behaviors. This finding shows that visible

\footnotetext{
${ }^{45}$ It is not surprising that composting and recycling are popular among residents because both are highly visible markers of sustainability and do not require changes in consumption.
} 
sustainable features do spread throughout neighborhoods, if a person sees their neighbors' substance gardening or installing a rainwater catchment; they are more likely to copy their neighbor and also do that activity, a sort of "Keeping up with the Joneses" sustainability-wise. However, there was not a significant difference in influence of these factors on sustainability between the two neighborhoods; both Sunnyside and Brooklyn residents who said these visible features were influential to them, were still equally sustainable in their behaviors, overall. 


\section{Conceptual Model Revisited}

The conceptual model discussed in Chapter 1 provided the framework for which this research was structured. All the hypotheses discussed are based on interactions among various parts of the conceptual framework. After conducting this research, I reflected on my conceptual model, determined what aspects worked and did not work, as well as developed recommendations of what should be added to the original model. An updated version of the model based on the findings of this research can be seen in Figure 27.

The first major change made to the conceptual model was adding the city or region in the background. As my results suggested, the neighborhoods in this research may be too similar to be able to "tease out" the influence of the neighborhood from the influence of the city. Additionally, influence on sustainable household behaviors may be more dependent on the city than individual neighborhoods because aspects such as recycling, composting, and transportation infrastructure are influenced at the city or regional level. The neighborhood has very little influence on these types of activities.

Next, I repositioned some of the aspects that I had in my original conceptual model, starting with neighborhood identity. In my new model I placed neighborhood identity in-between the city and the neighborhood. Since the neighborhood is within the city, the city should be expected to have a large influence on what the neighborhood identity is. I also adjusted how neighborhood identify interacts with household sustainability and individual behaviors. My research did not find direct connections between neighborhood identity and increased sustainability. However, with so many 
Sunnyside residents indicating that sustainability was part of their neighborhood identity, it is likely that it is having some effect on behaviors. For example, Sunnyside residents that had high levels of engagement in their neighborhood were slightly more likely to adhere to sustainable behaviors. This was not found to be the case in the Brooklyn neighborhood. Thus, neighborhood identity may be indirectly influencing neighborhood engagement, which in turn could influence sustainable behaviors. More research is needed to explore this specific connection.

Finally, I added a number of different factors that my research originally did not cover, factors that are likely influencing household-level sustainability as well. Regulations and policies regarding sustainability programs were important aspects not covered in this research. Policies and regulations can make it easier or more difficult for a household to practice sustainable behaviors. The economic climate can also play a role in one's ability to purchase sustainable products and perform energy upgrades to their home. Finally, cultural influences, as well as one's individual upbringing, could be influencing individual behaviors. 


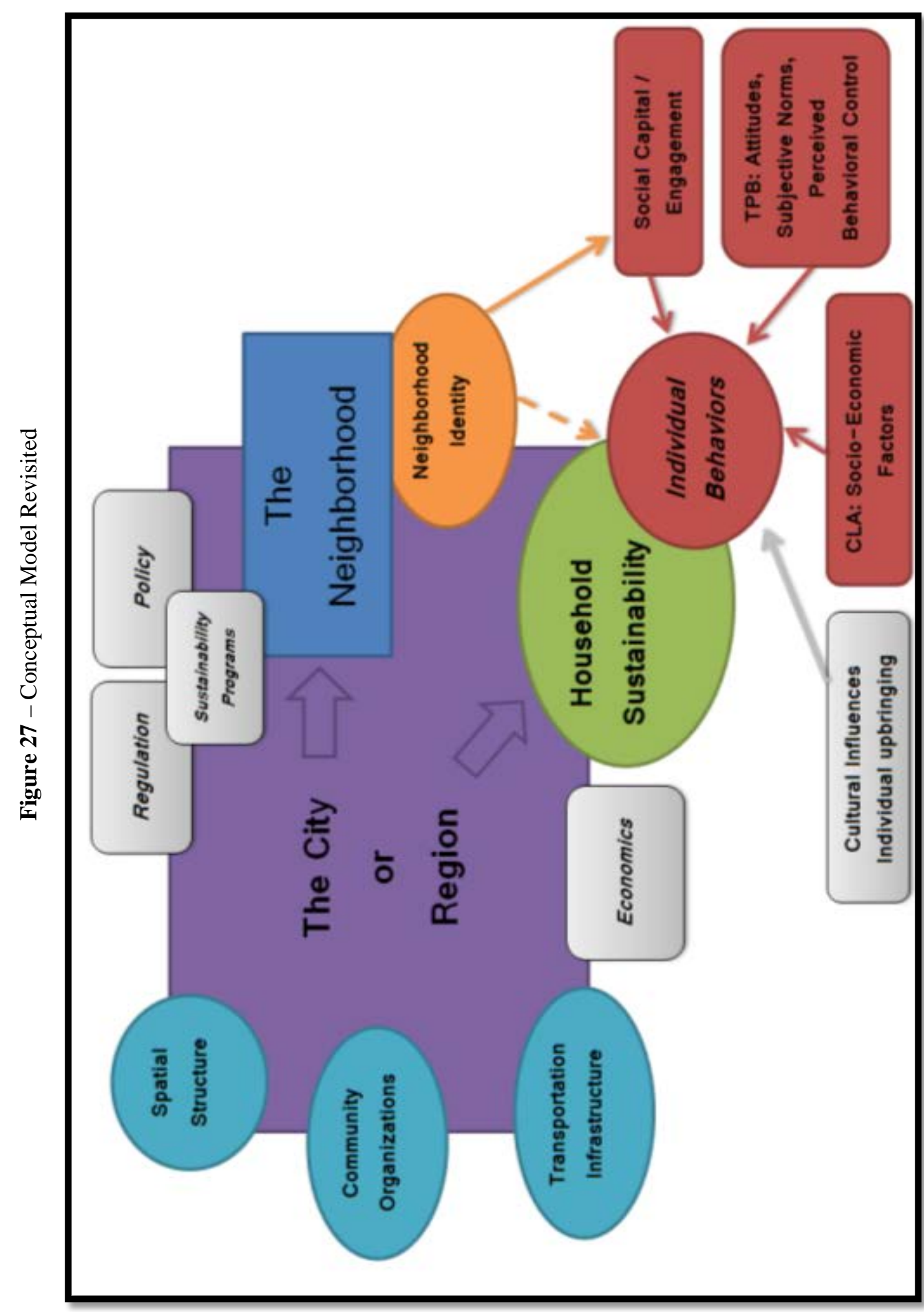




\section{Chapter 7: Conclusion}

\section{Study Limitations}

With the time and resources available for this thesis, there were a number of unavoidable limitations. All efforts were made to create a research design that would produce valid and reliable results. Questions were designed to be as clear and unbiased as possible. Data sources consisted of web-based surveys, personal interviews with neighborhood stakeholders, as well as quantitative residential water use data. Still, the study had some limitations that affected the validity, reliability, and generalizability of the results.

The first limitation was that there was no systematic sampling technique administered when selecting participants for the web-based survey, resulting in some non-response bias. Respondents who participated in the web-survey may have been more sustainable than those who did not participate. This could skew the results, making it appear that the two study neighborhoods are more sustainable than they actually are. Furthermore, potential respondents who did not have access to the internet were excluded from the survey, which may be an entirely different population than those who had internet access. Attempts to limit the effects of this non-response bias included: 1) multiple recruitment attempts (door-to-door survey flyering and neighborhood newsletter announcements), 2) assisting individuals who were not computer savvy, and 3) offering a monetary incentive to complete the survey.

Relying on self-reported energy use data was another limitation to this research. Asking individuals to provide average temperature settings and estimates of utility bill 
costs most likely resulted in some precision-error. This, however, was unavoidable, considering the tremendous difficulty in acquiring actual residential billing data from utility companies. Fortunately, water use data at the household level was acquired which provided more precision in actual resource usage. Still, these data were only available for 2010, two years prior to when this research was conducted. Having billing data from the actual time of the study would have increased the validity of the results. This limitation is most likely minimal considering most individuals, especially homeowners, may not relocate very frequently.

Finally, the ability to generalize these results is limited since it was a case study of two specific neighborhoods. Case studies provide deep insight into a particular topic area, but are generally not useful in establishing solid evidence about a particular area of research of which to generalize from. Since Portland is somewhat of an anomaly in terms of sustainability compared to other cities in the U.S., research in other cities would most likely produce different results. Perhaps cities such as San Francisco or Seattle could be comparable since these cities have sustainability programs similar to ones in place in Portland. The key to extrapolating these results to other cities would be finding a city that is similar to Portland in terms of demographics, sustainability programs, and policies. This research could be used as a starting point for other research; however, I feel that the research design should be changed to achieve more substantive results. 


\section{Suggestions for Future Research}

The research model created and utilized for this thesis should be revised based on the findings. In this research model, the household was the unit of analysis, with individuals in the household influencing how sustainable the household was overall, and the neighborhood influencing the household. Influences that can affect an individual's willingness to adhere to sustainable behaviors included: socio-economic factors, social capital, attitudes, norms, intensions, and perceived behavioral control. Particularly, aspects related to social capital were focused on in this research. However, in my findings the connection between social capital and sustainable behavior existed, but were weak. The updated research model provided in Chapter 6 included other aspects that were found to be influential in this research, such as the city/region and policies/regulations. Adding these variables would perhaps allow for a researcher to isolate the effects of city-based or regionally-based sustainability initiatives from neighborhood initiatives.

As discussed, there are two other reasons that might explain why a neighborhood could report having a sustainable identity, but not report high levels of sustainable behaviors. The lack of difference between the neighborhoods' level of sustainability found in this study, suggest that engendering sustainable identities and behaviors may be more effective at the city or regional level, rather than at the neighborhood level. People may attribute their adherence to sustainable behaviors to city-wide initiatives (e.g., recycling, composting, etc.) and may not view sustainability as a neighborhood scale issue. Thus, future research should look at neighborhoods that are very different than the city they are in to isolate the effects of the neighborhood. 
Another factor that may have influenced these inconclusive findings is that the two neighborhoods were demographically similar to each other, concealed the differences that may have existed. Both Sunnyside and Brooklyn are located in Southeast Portland, under the jurisdiction of Southeast Uplift. Since both neighborhoods were demographically similar (a purposeful research design decision) their willingness and adherence to sustainability may be effected more by their similar socio-economic factors, rather than external factors such as neighborhood programs. Again, I felt that having demographically similar neighborhoods was a valid way to try to rule out other variables that may affect household sustainability and isolate the effect, if any, of neighborhood identity. However, since the city these two neighborhoods are in is arguably one of the most sustainable in the U.S., it may be the city influencing household sustainable behavior rather than the neighborhood.

Future research should also adapt the questioning used in this research to be more precise and better operationalized. For example, a number of questions asked in the survey attempted to understand the degree of social cohesion that existed in the neighborhoods. These questions generally pertained to the frequency of interactions among neighbors. These questions did not, however, ask what topics were discussed with neighbors or look at the quality of these conversations. For example, are these interactions just mundane conversations about the weather? Are they talking about neighborhood concerns? Or are they actually talking about sustainability issues (i.e., conversing about issues regarding climate change, how to recycle certain materials, participation in green energy programs, or inquiries into sustainable products such as 
solar panels or rain water catchment)? Although these sustainability topics may not be part of regular conversations, it would be interesting to see if these topics ever come up in conversations with neighbors and how much those conversations may be influencing behaviors. Additionally, questioning about sustainable behaviors should be more indepth. Asking how often someone takes out the recycling or compost is important, but questions may need to be more specific. For example, asking about behaviors surrounding household lighting, water use, purchasing decisions and so forth, may provide a more nuanced picture of how sustainable a household actually is.

Methodologically, web-surveys may not be the best approach for data collection on this topic. Future research should implement a systematic sampling procedure, where sample is selected in order to mirror the population of the neighborhood. Ideally, a similar survey could be administered either door-to-door or via telephone. Additionally, since much insight is lost in closed-ended survey questions, in-depth interviews should be conducted with residents to better understand their subjective experiences living in the neighborhood. Additionally, in-depth interviews could uncover other reasons why a household is sustainable (or not) or tease out the effect of the neighborhood verses the city by asking multiple follow-up questions based on their responses.

\section{Conclusion}

This research sought to better understand the connections between neighborhood identity, social cohesion, and social capital in adopting sustainable behaviors. The main question for this research was: how does neighborhood identity affect household-level 
sustainable behaviors? Overall, the findings of this study are somewhat inconclusive, mainly because the research did not take into account the role of the city in household sustainability. There was not sufficient evidence to support that neighborhood identity directly impacts sustainable practices, household energy, or water consumption.

The findings do suggest that neighborhood identity might have an indirect effect on household sustainability. Residents of the Sunnyside neighborhood indicated more willingness to participate in sustainable activities than Brooklyn residents. This finding suggests that the Sunnyside neighborhood's sustainability initiatives are influencing residents' attitudes and beliefs on some level. This increased idealism might be affecting their increased willingness to participate in sustainable behaviors. This finding shows that there is a need to better understand the connection between neighborhood identity and personal beliefs, and how those things may, or may not, coalesce into actions. An increased understanding of the complex relationships between beliefs and actions could inform the creation of more effective neighborhood and city-level sustainability programs and policies.

Another indirect impact of neighborhood identity was the effect of neighborhood engagement on household sustainability. There was no difference in terms of engagement or level of sustainability between the two neighborhoods, however, Sunnyside residents who reported high levels of engagement were somewhat more likely to report greater adherence to sustainable behaviors than Brooklyn residents were. This is perhaps an indirect effect of having a neighborhood with a sustainable identity. Additionally, when looking at engagement's effect on adherence to suitable behaviors with the two 
neighborhoods combined, data suggests that increased engagement has a positive effect on the level of sustainability. This is an important policy finding. Cities should continue to encourage their citizenry to engage in their communities if they want to promote sustainability.

Neighborhood identity and its ability to influence residents' behaviors should be an area of continued research. Results demonstrated that residents of the Sunnyside neighborhood had indeed subscribed to the 'sustainable identity' of the neighborhood. However, without clear directives from the neighborhood, or funding for sustainable projects and outreach, this identity is not translating into behavior change per say. Sustainability is a fairly nebulous topic that often comes with many interpretations. One person's definition of being sustainable may be completely different than their neighbors. Residents of both neighborhoods reported their neighborhood as being fairly sustainable. However, are the two neighborhoods truly sustainable? Is there room for improvement? One could argue that the Sunnyside and Brooklyn neighborhoods are more sustainable than other U.S. neighborhoods, but I would argue that these neighborhoods are still a long way from being “completely sustainable,” or as sustainable as their residents would like to believe. 


\section{References}

"2010 Portland Neighborhood Demographic Data." (2010) Office of Neighborhood Involvement. City of Portland.

$<$ http://www.portlandonline.com/oni/index.cfm?c=56506\& $>$.

Abrahamse, W., L. Steg, C. Vlek, and T. Rothengatter. (2005) "A Review of Intervention Studies Aimed at Household Energy Conservation." Journal of Environmental Psychology 25.3273-91.

Allcott, Hunt. (2011). "Social Norms and Energy Conservation." Journal of Public Economics 95.9-10 (2011): 1082-095.

"Average Expenditures by Energy End Uses.” (2005). U.S. Energy Information Administration (EIA). U.S. Department of Energy. Web. $<$ http://38.96.246.204/emeu/recs/recs2005/hc2005_tables/c $>$.

Berry, Chip. (2009) "2009 Residential Energy Consumption Survey." U.S. Energy Information Administration (EIA). U.S. Department of Energy. Web.

Bin, Shuri, and Hadi Dowlatabadi. (2005). "Consumer Lifestyle Approach to US Energy Use and the Related CO2 Emissions." Energy Policy 33.2, 197-208.

Bourdieu, P. (1986). The Forms of Capital. (J. E. Richardson, Ed.) Handbook of Theory of Research for the Sociology of Education, 218-220, 241-258.Greenwood Press.

Burns, A., Acres, C., Ryker, E., \& Baribeau, D. (1999). Retrieved from City of Portland $<$ http://www.portlandonline.com/shared/cfm/image.cfm?id=91052>.

"City Repair." City Repair. N.p., n.d. Web. 24 Sept. 2012. Web. < http://cityrepair.org> 
Clayton, S., \& Opotow, S. (2003). Identity and the Natural Environment: The Psychological Significance of Nature. (S. Clayton \& S. Opotow, Eds.)Representations of the Local Environment as Threatened by Global Climate Change Toward a Contextualized Analysis of Environmental Identity in a Coastal Area (Vol. vi, p. 353). MIT Press.

Codoban, Natalia and Kennedy, Christopher. (2008). "Metabolism of Neighborhoods." Journal of Urban Planning and Development 134.1, 21-31.

Conklin, Tiffany (2012). "Street Art, Ideology, and Public Space.” Portland State University Master Thesis.

Davis, Stacy C., Susan W. Diegel, and Robert G. Boundy. (2010). Transportation Energy Data Book Edition 29. Oak Ridge, TN: Oak Ridge National Laboratory, 2-1.

Diesendorf, Mark. (2002). “Integrated Bios stems for Sustainable Development.” Rural Industries Research and Development Corporation.

Dill, Jennifer, and Cynthia Mohr. (2010). Long Term Evaluation of Individualized Marketing Programs for Travel Demand Management. Rep. no. TRB RiP: 14681. Oregon Transportation Research and Education Consortium. Web. $<$ http://www.otrec.us/project/160>.

"Energy Consumption Estimates by Sector Overview." (2010). Annual Energy Review 2010. U.S. Department of Energy. Web. $<$ http://www.eia.gov/totalenergy/data/annual/pdf/sec2_4.pdf >.

Fishbein, M and Ajzen I (1975). Belief, Attitude, Intention and Behavior: an introduction to theory and research. Addison-Wesley, Reading, MA. 
Forest, Ray and Kearns Ade (2001). Social Cohesion, Social Capital and the Neighborhood. Urban Studies, 38(12), 2125-2143.

Gram-Hanssen, Kirsten. (2010). "Residential Heat Comfort Practices: Understanding Users." Building Research \& Information 38.2, 175-86.

"Green Power Oregon." (2010). Green Power Oregon-Renewable Energy \& Sustainability | Green Power Oregon. Web. $<$ http://www.greenpoweroregon.com/home.aspx $>$.

Grootaert, Christiaan, and Bastelaer Thierry. (2002). Understanding and Measuring Social Capital a Multidisciplinary Tool for Practitioners. Washington, D.C.: World Bank.

Haneckow, D. (2007). House of Inman, House of Poulsen. Web. $<$ http://www.cafeunknown.com/2007/01/had-i-have-known-of-its-existencethis.html>.

Harrison, J., McKinney, S., Feldman, S., Galantha, J., \& Hamlin, M. Bureau of Planning, (1991). Brooklyn neighborhood plan. Web. $<$ http://www.portlandonline.com/shared/cfm/image.cfm?id=88621 $>$.

Heede, Richard. (2002). Cool Citizens: Everyday Solutions to Climate Change: Household Solutions. Rep. no. C02-12. Boulder: Rocky Mountain Institute. Hidalgo, M. C. and B. Hernandez (2001). "Place Attachment: Conceptual and Empirical Questions." Journal of Environmental Psychology 21(3): 273-281. 
"HowStuffWorks." (2011). "What Percentage of Air Pollution Is Due to Cars?"

Howstuffworks "Auto " Web. <http://auto.howstuffworks.com/percentage-of-airpollution-due-to-cars.htm>.

IEA 2010. (2010). Key World Energy Statistics. International Energy Agency. Web. <www.iea.org/textbase/nppdf/free/2010/key_stats_2010.pdf>.

Jabareen, Y. R. (2006). "Sustainable Urban Forms: Their Typologies, Models, and Concepts. “Journal of Planning Education and Research 26.1, 38-52.

Jacobs, Jane. (1961). The Death and Life of Great American Cities. [New York]: Random House.

Joerges, B. \& Muller, H. (1983). "Energy conservation programs for consumers: a comparative analysis of policy conflicts and program results in eight western countries.” Journal of Economic Psychology 4, 1-35.

Kasulis, J. J., Huettner, D. A. \& Dikeman, N.J. (1981). “The feasibility of changing electricity consumption patterns.” Journal of Consumer Research 8, 279-290.

Kenny, J. F., Barber, N. L., Hutson, S. S., Linsey, K. S., Lovelace, J. K., \& Maupin, M. A. (2009). Estimated Use of Water in the United States in 2005 Circular 1344. Water (Vol. 1344, p. 52). US Geological Survey Washington, DC.

Lutzenhiser, L. (1992). "A Cultural Model of Household Energy Consumption." Energy 17.1, 47-60.

Lutzenhiser, L. (1993). "Social and Behavioral Aspects of Energy Use." Annual Review of Energy and the Environment 18.1, 247-89 
Lutzenhiser, L. (2002). "Greening the Economy from the Bottom Up? Lessons in Consumption from the Energy Case." Readings in Economic Sociology. New York: Blackwell, 345-56.

Lutzenhiser, L and Gossard, M.H. (2000). “Lifestyle, Status and Energy Consumption.”

Proceedings of the 2000 ACEEE Summer Study of Energy Efficiency in Buildings, 8, 207-221. Washington, D.C.: American Council for an Energy-Efficient Economy.

MacColl, E. Kimbark. (1979). The Growth of a City: Power and Politics in Portland, Oregon, 1915-1950. Portland, Or.: Georgian.

McKenzie-Mohr, D. (2000). Fostering Sustainable Behavior Through Community-Based Social Marketing. American Psychologist, 55(5), 531-537.

McMichael, M. (2007). Social capital and energy efficiency in urban householders. Management, 168(8), 1113-1126.

McMichael, Megan. (2007). "Dynamics of Consumption." A Social Capital Approach to Household Energy Consumption. Proc. of ECEEE 2007 Summer Study. 9th ed. 1897-905.

"NHTSA - National Statistics." (2010). FARS Encyclopedia. National Highway Traffic Safety Association. Web. <http://www-fars.nhtsa.dot.gov/Main/index.aspx>. Nuclear-free zone. (2012). Retrieved from http://en.wikipedia.org/wiki/Nuclearfree_zone 
Park, Robert. (1916). "Suggestions for the investigations of human behavior in the urban environment.” American Journal of Sociology 20.5, 577-61.

Park, Robert Ezra, E. W. Burgess, Roderick Duncan McKenzie, and Louis Wirth. (1925). The City. Chicago, IL: University of Chicago.

Pedersen, Marc. (2008). Segmenting Residential Customers: Energy and Conservation Behaviors. Rep. BC Hydro and Power Authority.

"Residential Sector." (2010). Buildings Energy Data Book. U.S. Department of Energy. Web. <http://buildingsdatabook.eren.doe.gov/ChapterIntro2.aspx>.

Richmond, P. (1996). Silencing hemp radicals. PDXS. Retrieved from <http://www.marijuanalibrary.org/PDXS_Silencing_091696.html>.

Rollero, C., \& De Piccoli, N. (2010). Place attachment, identification and environment perception: An empirical study. Journal of Environmental Psychology, 30(2), 198-205.

Rosa, Eugene A., Gary E. Machlis, and Kenneth M. Keating. (1988)."Energy and Society." Annual Review of Sociology 14.1, 149-72.

Scannell, L., \& Gifford, R. (2010). Defining place attachment: A tripartite organizing framework. Journal of Environmental Psychology, 30(1), 1-10.

Seligman, C., Kriss, M., Darley, J., Fazio, R. H., Beck,L. J. \& Pryor, J. B. (1979). "Predicting Summer Energy Consumption from Homeowner’s Attitudes." Journal of Applied Social Psychology, 9, 70-90.

Semenza, J. C. (2003). The Intersection of Urban Planning, Art, and Public Health: The Sunnyside Piazza. American Journal of Public Health, 93(9), 1439-1441. 
Shandas, V., Rao, M., \& McSharry-McGrath, M. (2012). Implication of Climate Change on Residential Water Use in Portland, Oregon. Journal of Water and Climate Change, 3(3), 225-238.

Shandas, Vivek. (2012) Neighborhood Life Survey. Retrieved from http:// http://soma.research.pdx.edu/.

Singleton, Royce, and Bruce C. Straits. (2010). Approaches to Social Research. New York: Oxford UP.

SE Uplift. (2012). "Neighborhood Sustainability." Southeastuplift.org. SE Uplift. Web. $<$ http://www.southeastuplift.org/files/sustainability\%20.pdf>.

Solarize southeast. (2010). Web. <http://www.southeastuplift.org/content/solarize-se>. Southeast uplift's mission. (n.d.). Web.

$<$ http://www.southeastuplift.org/content/se_uplift_mission>.

Steam Dummy. (n.d.). In Wikipedia. Web.

$<$ http://en.wikipedia.org/wiki/Steam_dummy>.

Streetcar line histories. (2010). Web.

$<$ http://myplace.frontier.com/ trolley503/StreetcarLines.html $>$.

"Sunnyside Environmental School - About Us." Portland Public Schools. (2011). Web. <http://www.pps.k12.or.us/schools/sunnyside/194.htm>.

"Sunnyside Neighborhood Energy - About Us." (2008). Sunnyside Neighborhood Energy (SunNE). Web.

$<$ http://sunnysideneighborhoodenergy.wikispaces.com/Welcome>. 
"Sunnyside Sustainability Committee." (2008). Sunnyside Neighborhood Association. Web. $<$ http://www.sunnysideneighborhood.com/index.php?option=com_content\&task= section\&id=5\&Itemid=59>.

The baba. (2012). Retrieved from http://belmontdistrict.org/baba/index.html

“Top World Energy Consumers 2009.” (2009). U.S. Energy Information Administration (EIA). U.S. Energy Information Administration. Web. $<$ http://www.eia.gov/countries/>.

"Transition US - About Us." (2011). Transition US. Web. $<$ http://www.transitionus.org/about-us $>$.

Transportation Energy Data Book - Edition 29." (2011). Untitled. United States Department of Energy. Web. <http://cta.ornl.gov/data/download29.shtml>. United States. (2011). Department of Energy. Energy Efficiency and Renewable Energy. Buildings Energy Data Book. Web. 25 May 2011

United Kingdom. Parliamentary Office of Science and Technology (POST). (2005). Household Energy Efficiency. Westminster: UK Parliament. Uzzell, D., Pol, E., \& Badenas, D. (2002). Place Identification, Social Cohesion , and Environmental Sustainability. Environment, 34(1), 26-53.

Valera, S., and J. Guardia. (2002). "Urban Social Identity and Sustainability: Barcelona's Olympic Village." Environment and Behavior 34.1, 54-66.

Vandenbergh, Michael P. (2007). The Carbon-Neutral Individual. New York University Law Review, 82. 
Vaske, J. J., \& Kobrin, K. C. (2001). Place Attachment and Environmentally Responsible Behavior. Journal of Environmental Education, 32(4), 16-21.

Vorkinn, M., \& Riese, H. (2001). "Environmental concern in a local context. The significance of place attachment.” Environment and Behavior 33, 249-263.

Waldron, Ben. (2011). "Sunnyside Neighbors Preparing for the 'Long Emergency' | Neighborhood Notes." Portland Oregon Neighborhood News \& Events | Neighborhood Notes.

Warren, D.I. and Clifford, D.L. (1975). Local Neighborhood Social Structure and Response to the Energy Crisis of 1973-74. [Ann Arbor]: University of Michigan.

Wilhite, H., Shove, E., Lutzenhiser, L., Kempton, W. (2000). “Twenty years of energy demand management: we know more about individual behavior but how much do we really know about demand?”, in: 2000 Summer Study Proceedings of the American Council for an Energy-Efficient Economy, Washington, D. C., pp. 8435-8453.

Yin, Robert K. (2003). Case Study Research: Design and Methods. Thousand Oaks, CA: Sage Publications. 


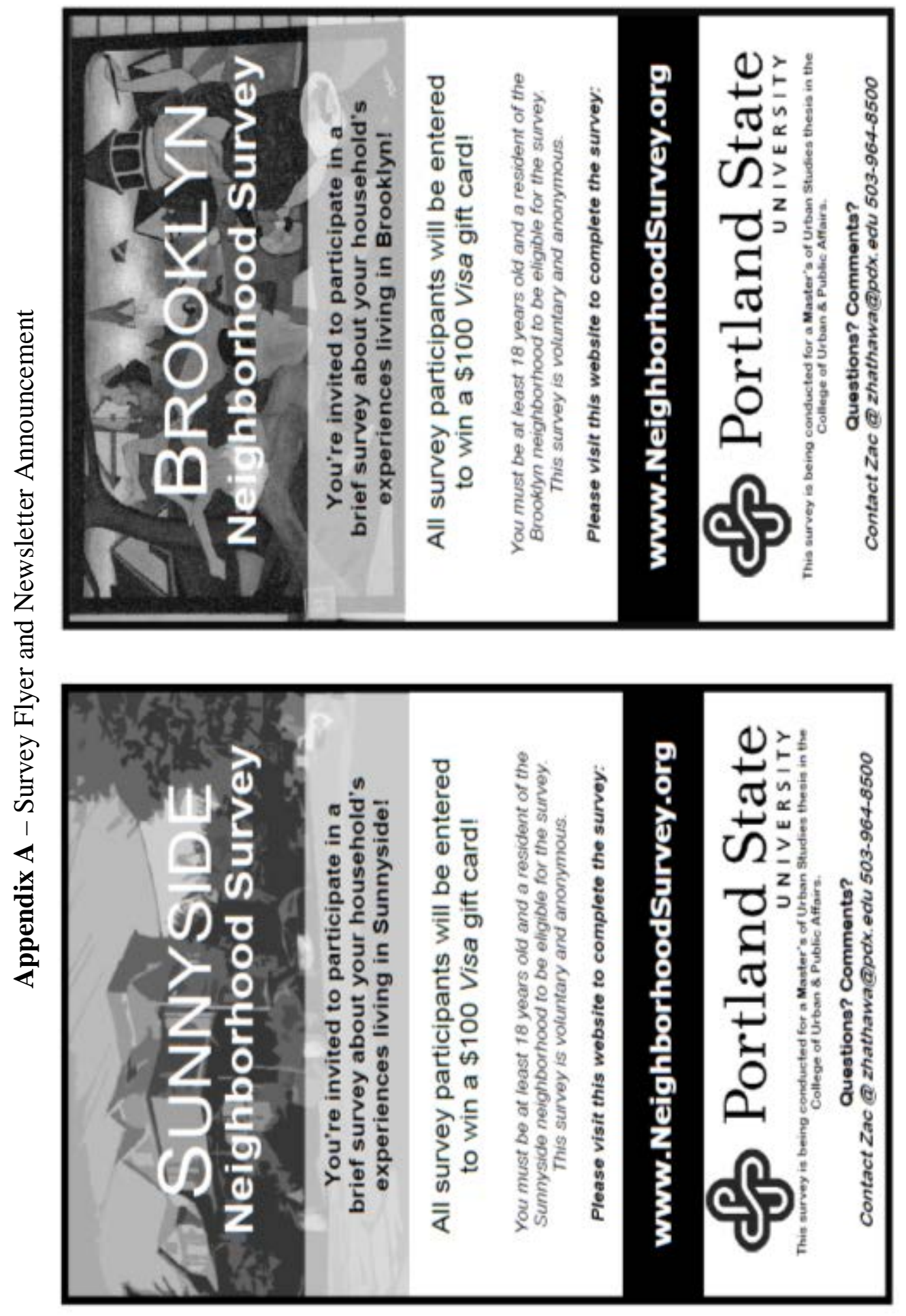




\section{Neighborhood Sustainability Survey - Newsletter Article}

Hi, my name is Zac Hathaway and I am a Masters of Urban Studies student at Portland State University. Beginning last month, I have been conducting a survey in the Brooklyn and Sunnyside neighborhoods for my thesis. The purpose of the survey is to better understand how neighborhood identity affects residential sustainability. This short 10 minute survey will gather data to be used in my thesis. The information gathered could also benefit the community of Sunnyside by providing residents and neighborhood organizations with important information regarding its use of resources, and how to ensure that this community is a thriving and welcoming environment for all for many years to come. I hope that you will take the time to fill out the survey. I'm very interested in hearing everyone's experiences here in the Brooklyn neighborhood, both positive and negative.

Please visit this website by August $\mathbf{3 0}^{\text {th }}$ to complete the survey:

\section{www.NeighborhoodSurvey.org}

All participants will be entered into a drawing to receive a \$100 Visa gift card.

Participants must live in the Brooklyn neighborhood and be 18 years of age or older. This survey is voluntary and anonymous. Please feel free to email or call me if you have questions about this research: or

Your participation is very much appreciated! Thank you. 


\section{Appendix B - Survey Instrument}

Welcome to the Neighborhood Sustainability Survey! This survey is being conducted by a Portland State University graduate student as part of a thesis project. This study aims to gather information about Portland neighborhood residents' household and transportation habits.

This survey should take less than 10 minutes. All information provided will be strictly confidential. Your participation is voluntary and anonymous and you may choose to skip any question or stop at any time. If you complete the survey, you will be entered into a drawing, and have the chance to win a \$100 Visa gift card.

Please click 'Next' to begin your survey.

Elig. Do you currently live within the Sunnyside or Brooklyn neighborhood?

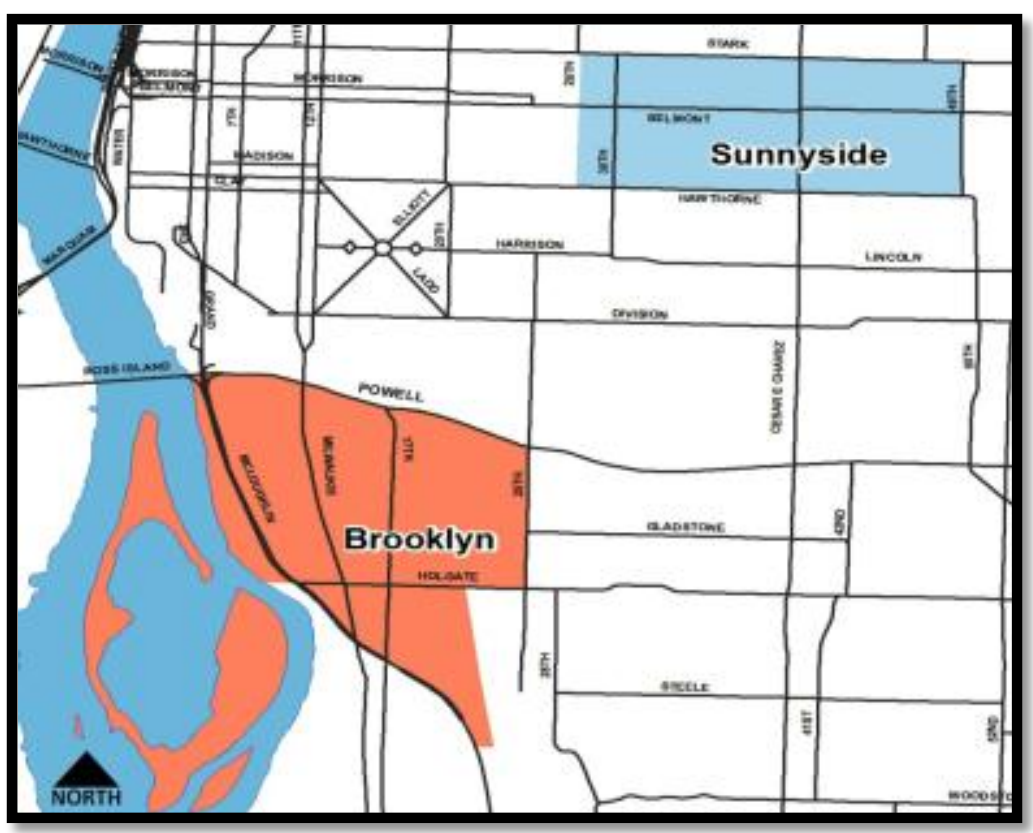


Sunnyside neighborhood (in blue) and the Brooklyn neighborhood (in red)

Please note: The Sunnyside neighborhood boundaries are SE Stark Street to the north, SE $40^{\text {th }}$ Avenue to the east, SE Hawthorne Boulevard to the south, and SE $28^{\text {th }}$ Avenue to the west) The Brooklyn neighborhood boundaries are SE Powel Boulevard to the north, SE $26^{\text {th }}$ Avenue and the Union Pacific rail yard to the east, SE McLoughlin Boulevard to the south, and the Willamette River to the west.

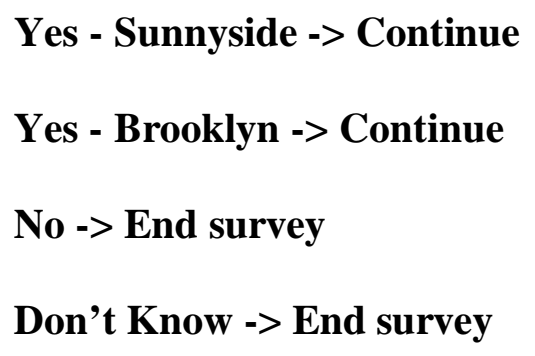

[NEIGHBORHOOD SECTION - measuring social capital, social cohesion, and neighborhood identify]

Q1. To verify, are you 18 years of age or older? Yes / No => End survey, not eligible

Q2. Do you participate in local neighborhood organizations, events, or activities? For example, neighborhood association meetings or committees, Southeast Uplift, graffiti removal, etc.

\section{Yes No -> Skip to Q3}

\section{Don't know}

\section{Refused}

[IF YES] Q2a. Please list all local neighborhood organizations, events, or activities you participate in:

Q3. How often do you do the following? [MATRIX] 
SCALE: Never / Rarely / A few times a year / Monthly / Weekly /Daily/Don't know

Q5a. Have conversations with your neighbors

Q5b. Share things with neighbors (i.e., food, tools, etc.)

Q5c. Have neighbors over to your home

Q5d. Shop in your neighborhood

Q4. To what extent do you agree or disagree with the following statements about the (Sunnyside/Brooklyn) neighborhood? [MATRIX]

SCALE: Strongly disagree / Disagree / Agree / Strongly agree / Don't know

Q6a. Qualities of the neighborhood support close-knit relationships

Q6b. The connections I make with people in the neighborhood tend to be longlasting

Q6d. My neighbors share the same values as me

Q6f. My neighbors want to make my neighborhood a better place Q5. Do you think the (Sunnyside/Brooklyn) neighborhood has a unique identity compared to other neighborhoods in Portland?

Yes No -> Skip to Q6

Don't know

Refused

[IF YES] Q5a. Please briefly explain what you think makes the (Sunnyside/Brooklyn) neighborhood unique, compared to other neighborhoods in Portland: 
Q6. Using a scale of 1 to 10 , with 1 meaning 'Not Sustainable at all' and 10 meaning 'Completely Sustainable', how sustainable do you think your neighborhood is? Note: Being "sustainable” refers to the ability of a neighborhood and its residents, to improve and maintain their collective quality of life, socially and economically, now and in the future, while at the same time having a minimal impact on the environment (using less resources, making less of an impact, and preserving biodiversity).

Scale: 1 - 10

Don't know

Refused

[HOUSEHOLD SECTION - Measuring how sustainable the household is]

The next set of questions asks about various aspects of your household.

Q7. In your home, how often do you engage in the following? [MATRIX]

SCALE: Never / Rarely / Sometimes / Often / Always / Not applicable

Q7a. Try to save electricity (i.e., turn off lights when not in use, unplug small appliances when not in use)

Q7b. Try to save water (i.e., wash only full loads of dishes and/or clothes, limit shower time, faucet aerators)

Q7c. Heating or cooling adjustments to save energy (i.e., thermal insulation on windows, lower thermostat in winter)

Q7d. Recycle paper, metals, plastics, and glass. 
Q7e. Take hard-to-recycle products (i.e., plastic, light bulbs, Styrofoam, etc.) to drop off locations

Q7f. Purchase energy efficient products (i.e., CFL or LED light bulbs, appliances, electronics, etc.)

Q7g. Compost food scraps

Q8. Over the past 5 years, have you completed any major energy-efficiency upgrades to your home? This could include (among other things), purchasing energy-efficient appliances, installing new insulation, or installing solar panels, etc.

Yes / No -> skip to Q9

[If Yes] Q8a. What energy-efficiency upgrades have you completed in your home?

Q9. What is the average temperature that you keep your home in the...

Q9a.Winter Don't know / Refused

Q9b. Summer Don't know / Refused

Q10a. During the winter, on average, how much is your natural gas bill? Enter approximate dollar amount (__

Don't pay for natural gas

Don't know / Refused

Q10b. During the winter, on average, how much is your electricity bill?

Enter approximate dollar amount (__

Don't pay for electricity

Don't know / Refused 
Q10c. During the summer, on average, how much is your natural gas bill?

\section{Enter approximate dollar amount (}

Don't pay for natural gas

Don’t know / Refused

Q10d. During the summer, on average, how much is your electricity bill?

Enter approximate dollar amount (

Don't pay for electricity

Don't know / Refused

[TRANSPORTATION - Measuring transportation usage to determine overall sustainability]

The next few questions are about your transportation habits.

Q11. Do you, or anyone else in your household, own an automobile?

Yes / No / Refused

Q12. About how many miles per week do you drive an automobile?

Note: This can include car-share vehicles such as Zipcar, Car2go, Getaround, etc. Please do not include miles driven for work purposes.

\section{Miles / I Don’t drive}

Q13. In general, how often do you walk around the (Sunnyside/Brooklyn) neighborhood for any reason (i.e., work, school, errands, enjoyment, walking dog, exercise, etc.)? Never

Less than once a month 
One to three times a month

About once per week

More than once a week

Q14. In general, how often do you ride a bicycle from your home to destinations you need to go?

Never

Less than once a month

One to three times a month

About once per week

More than once a week

Q15. In general, how often do you take the bus, streetcar, or MAX to get somewhere?

Never

Less than once a month

One to three times a month

About once per week

More than once a week

Q16. Are there any aspects of the (Sunnyside/Brooklyn) neighborhood that encourage you to use alternative transportation (i.e., walking, biking, bus, etc.)? [Select all that apply]

Nearby transit stops

Neighborhood Greenways (Bicycle Boulevards) 
Low levels of vehicle traffic

Nearby destinations

Seeing other people in the neighborhood biking, walking, or taking public

transportation

Other (please specify):

No, Nothing

Q17. Is there any aspects of the (Sunnyside/Brooklyn) neighborhood that discourage you to use alternative transportation (i.e., walking, biking, bus, etc.)? [Select all that apply]

No access to transit stops

Streets are not safe to bike on

I don't feel safe walking in my neighborhood

I have no destinations to walk to in my neighborhood

I have a disability that limits my ability to get around

Other (Please specify):

No, Nothing

[Attitudes / Beliefs / Time effects / Neighborhood features section] 
Q18. Please indicate how strongly you agree or disagree with each of the following statements using a scale of 1 to 5 , where $\mathbf{1}$ means you strongly disagree and $\mathbf{5}$ means you strongly agree. [ROTATE statements]

Q18a. I really don’t care much about natural resources use and see little reason to conserve.

Q18b. There's not very much an individual can do to conserve natural resources that will have an impact in the long run.

Q18c. We could all use less natural resources than we do and if many people conserved, we could make a difference.

Q18d. Regardless of whether it makes a difference, everyone has a moral obligation to do the best they can to conserve natural resources.

Q18e. I would rather just pay more for natural resources rather than be asked to conserve them.

Q19. Approximately how long have you lived in the (Sunnyside/Brooklyn) neighborhood?

Enter___ Years

Less than a year

Don't know

Refused

Q20. Please briefly explain why you chose to live in the (Sunnyside/Brooklyn) neighborhood? 


\section{Open end}

Not applicable - I've lived here my whole life

\section{Don’t know}

\section{Refused}

Q21. Would you say that since living in the (Sunnyside/Brooklyn) neighborhood your household has become more or less sustainable?

\section{More sustainable}

\section{Less sustainable}

\section{Stayed about the same}

Q19. Sustainable features in a neighborhood can include many things, such as water catchment barrels, community art projects, solar panels, gardening, or composting bins.

How much does seeing sustainable features in the (Sunnyside/Brooklyn) neighborhood encourage you to do similar things? Please answer on a scale from 1 to 5 , with 1 being "not at all influential” to 5 being "very influential".

\section{$1,2,3,4,5$}

\section{Don't know}

I don't see these types of features in my neighborhood 
Q20. In general, how much does living in the (Sunnyside/Brooklyn) neighborhood influence how sustainable you are? Please answer on a scale from 1 to 5 , with 1 being "not at all influential" to 5 being "very influential."

$1,2,3,4,5$

Don't know

[Demographics section]

The next few questions are for statistical purposes only.

Q23. Do you own or rent your home?

Own / Rent/Other:

[IF Rent] Q24a. Do you live in...

A split or shared house with multiple units

A multi-unit apartment complex

A Single-family house

Q24. What is your gender?

Male

Female

Other

Q25. Which of the following age groups are you in?

18-24

25-34

$35-44$ 
55-64

65-75

76 or over

Q26. Which of the following best describes your working status?

[Select all that apply]

Full time for an employer

Part time for an employer

Self-employed or home-based business

Unemployed

Retired

Student

Other (please specify):

Q27. What is the last year of education you had the opportunity to complete?

Less than 12th grade (not a high school graduate)

High school graduate

Some college or other post-secondary education

College graduate

Some post-graduate

Master's degree or higher

Q28. Which of the following groups best identifies you? 
White or Caucasian

Black or African-American

Asian or Asian-American

American-Indian or Alaskan Native

Native Hawaiian or other Pacific Islander

Spanish, Hispanic, or Latino

Other (please specify):

Q29. Which of the following best describes your household's total annual income for 2011?

Less than $\$ 10,000$

$\$ 10,000$ - \$14,999

$\$ 15,000$ - $\$ 24,999$

$\$ 25,000$ - \$34,999

$\$ 35,000$ - \$49,999

$\$ 50,000$ - $\$ 74,999$

$\$ 75,000$ - $\$ 99,999$

$\$ 100,000$ or more

END. Do you have any final comments?

DRAWING: To be entered into the drawing to win a \$100 Visa gift card please provide your preferred email address or phone number below.

Enter email or phone:

No thanks (opt-out) 